Adolescent Sexual Decision Making:

At the Intersection of Health Beliefs and Gender Ideals

Erika Laine Austin

Herndon, Virginia

B.A., James Madison University, 1997

M.A., University of Michigan, 1999

A Dissertation presented to the Graduate Faculty of the University of Virginia in Candidacy for the Degree of Doctor of Philosophy

Department of Sociology

University of Virginia

January, 2004

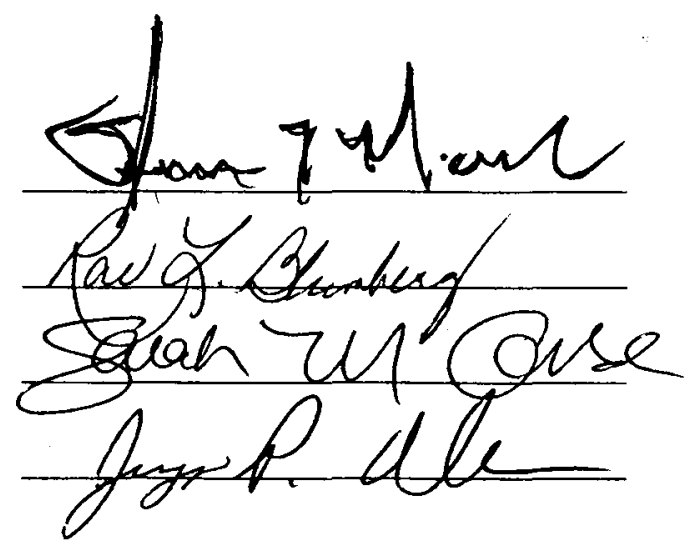




\section{Abstract \\ Adolescent Sexual Decision Making: At the Intersection of Health Beliefs and Gender Ideals}

This work offers an examination of the sexual decision making of adolescents. Specifically, this research seeks to understand the factors that prevent adolescents from consistently acting to protect themselves from unwanted pregnancy and sexuallytransmitted diseases. Borrowing the Health Belief Model from the public health literature, I consider the role of health beliefs (e.g., feeling susceptible to pregnancy or STDs) in predicting preventive health behaviors, such as the use of birth control. The social performance of gender is also highly salient in the decisions adolescents make regarding sex. I argue that the desire to conform to traditional ideals of femininity and masculinity often results in sexual decision making that puts adolescent health at risk. Health beliefs and gender ideals thus represent two competing forces that adolescents must balance in making decisions about their sexual behavior. To understand the balance of health beliefs and gender ideals in adolescent sexual decision making, I first conducted interviews with a sample of 25 adolescents. I explored adolescents' experiences with school-based sex education, discussions with parents about sex, views of sexuality in the media, and the influence of peers in sexual decision making. I then undertook a statistical analysis of the National Longitudinal Study of Adolescent Health to determine how the Health Belief Model is modified by the inclusion of gender, cues to action (representing sources of gender socialization), and gender ideals. I used this modified Health Belief Model to examine sexual abstinence, the timing of the transition to sexual 
intercourse, having engaged in non-romantic sexual intercourse, and the use of birth control at first and most recent intercourse. My statistical results confirm that the Health Belief Model is modified by gender, as different health beliefs are significant predictors for females' and males' behavior. In addition, many of the cues to action operate differently by gender; for example, exposure to media increases the sexual risk behavior of young men, while school-based sex education generally reduces young women's sexual risk behavior. Adherence to gender ideals is also strongly associated with sexual risk behavior, confirming the hypothesis that both health beliefs and gender ideals shape adolescent sexual decision making. 


\section{Adolescent Sexual Decision Making: At the Intersection of Health Beliefs and Gender Ideals}

Chapter One: Introduction.....................................................

Chapter Two: Gender and Sexuality in Adolescence..................................8

Chapter Three: Potential of the Health Belief Model..............................25

Chapter Four: Qualitative Findings on Adolescent Sexual Decision Making.............36

Chapter Five: Quantitative Data and Methods....................................59

Chapter Six: Sexual Abstinence as a Preventive Health Behavior......................72

Chapter Seven: Influences on the Transition to First Intercourse.....................92

Chapter Eight: Avoidance of Non-Romantic Sexual Relationships..................106

Chapter Nine: Use of Birth Control.........................................118

Chapter Ten: A Brief Exploration of Race/Ethnicity in Adolescent Sexual

Decision Making...................................................137

Chapter Eleven: Conclusions and Future Directions..............................151

References................................................................ 166

Appendix 1: Institutional Review Board Protocol..................................176

Appendix 2: In-Depth Interview Schedule.....................................182

Appendix 3: Tables of Regression Coefficients and Standard Errors...................186 
With love and gratitude to Robert N. Bozick, Marybeth J. Mattingly, Steven L. Nock, and my sister, Jillian G. Austin 


\section{CHAPTER ONE: Introduction to the Project}

There is immense public concern regarding the consequences of adolescent sexual behavior, and research indicates that this concern may be warranted. Recent estimates indicate that while teen pregnancy rates have been declining since reaching a peak in the late 1980s, the United States continues to have the highest rate of teen pregnancy, abortion, and parenthood in the developed world - this is a direct result of lower levels of contraceptive use among adolescents in the United States (Panchaud et al., 2000). Adolescents are also emerging as a key population at risk for STDs such as chlamydia and HIV, relative to their counterparts in other developed countries and as compared with American adults (Panchaud et al., 2000). In addition to the physical risks adolescents face as a result of sexual activity, there is consistent evidence that early initiation into sex is correlated with reduced educational and occupational attainment, especially for minority adolescents (Crockett et al., 1996; Genuis and Genuis, 1995; Kirby et al., 1994). More intangible but equally important is the potential for sexual exploitation and violence faced by sexually active adolescents (Fine, 1988; Lear, 1997).

Humans are sexual beings throughout the life course, and the development of one's sexual self is a key marker of the transition from childhood to full participation in adult life (Miller and Simon 1980). Ideally, then, adolescent sexuality should be seen as a "central and positive part of the total well-being of young people" (Chilman, 1990). There remains little emphasis, however, on the development of a comprehensive, positive perspective on adolescent sexuality; indeed, the suggestion that healthy adolescent 
sexuality should be encouraged is often met with intense public outrage (Levine, 2002). Rather, the focus of public health research, education efforts, and public discourse continues to be on the risks associated with adolescent sexual behavior.

Specifically, the majority of social responses to adolescent sexuality—both liberal and conservative - focus on the potential impact of sexuality on adolescent health. ${ }^{1}$ For example, the Sexuality Information and Education Council of the United States (SIECUS) was founded in 1964 with the goal of promoting sexual health throughout the life course. According to their web site, SIECUS serves as a key source of positive information on sexuality for policy makers, schools, the media, religious organizations, parents, and teens, affirming that sexuality is a "natural and healthy part of living." Even proponents of abstinence-only educational programs for adolescents couch their concerns in terms of health. The Personal Responsibility and Work Opportunity Reconciliation Act (Public Law 104-193), the welfare reform act signed into law in 1996 by the $104^{\text {th }}$ Congress, included over $\$ 250$ million for abstinence-only education (Heins, 2001). This law includes language stating that "abstinence from sexual activity is the only certain way to avoid out-of-wedlock pregnancy, sexually ransmitted diseases and other associated health problems."

Adolescents also appear to make the connection between sexual behavior and health risks, and yet many continue to put themselves and their well-being in jeopardy by failing to consistently employ safer-sex practices (Lear, 1997). This willingness to engage in behavior that places health at risk is surprising, given that the responsibility to

\footnotetext{
${ }^{1}$ In this work, "sexual risk behavior" is broadly defined as those actions that increase the potential for negative health outcomes, including early sexual debut, failure to use condoms, and casual sexual encounters. Sexual intercourse itself can also be viewed as a risk behavior in that it is often accompanied by the aforementioned behaviors.
} 
remain healthy is a powerful motivating force in Western society. Individuals experience various forms of stigmatization for failing to maintain the ideal state of health, making those decisions that relate to the maintenance of health a central concern of individuals as social actors (Goffman, 1963; Mechanic, 1994). The drive to maintain good health (through the prevention of STDs and unplanned pregnancy) should thus be a compelling factor in adolescent sexual decision making.

The desire to eliminate the health risks associated with adolescent sexual behavior is thus purported to be the primary motivation for both liberal and conservative responses to adolescent sexuality. I would argue, however, that this emphasis on health obscures another important reason for the immense degree of public concern with adolescent sexuality; namely, adolescent sexuality serves as a key site at which the traditional system of gender (and heterosexuality by extension) is played out in the lives of adolescents, and thus also negotiated within society. As with many politically-charged issues, the public debate over the health risks associated with adolescent sexuality may in fact be a more fundamental debate about society itself-in this case, the changing nature of gender in our society.

My dissertation is therefore an examination of the role of health concerns and the traditional system of gender in adolescent sexual decision making. Public discourse has chosen to put health considerations at the forefront of discussions of adolescent sexuality, but it is unclear the extent to which the desire to protect one's health enters into the decisions adolescents themselves make. My overarching goal in this work is thus to consider both the role of health and the role of gender as motivations for adolescent 
sexual decision making, to provide a clearer understanding of how adolescents balance these two forces.

There are significant limitations in the ways that the traditional health perspective has been applied to the study of adolescent sexuality; these difficulties arise primarily from the lack of consideration of the sociocultural context in which decisions about sex are made. Most commonly, health is conceptualized solely as an individual-level characteristic. While this may be appropriate for those behaviors that individuals undertake solely for the protection of their own health (such as the use of seat belts or regular cancer screenings), this approach is problematic when the health behavior of interest is interactive by definition. Sexuality is essentially a social phenomenon, and its salience derives from its intimate connection with the sociocultural phenomenon of gender. The regulation of both gender and sexuality is highly ideological and supported through the forces of law, stigmatization, and even violence, as well as individual internalization. The decisions that adolescents make about their sexual health are thus motivated by the discourses of both health and gendered sexuality; in short, these decisions occur at the intersection of health beliefs and society's ideals of gender and sexuality.

\section{Theoretical Contributions}

The primary goal of this study is to consider the application of an individual-level, health-based approach to the understanding of adolescent sexual decision making. Specifically, I examine the applicability of the Health Belief Model to adolescents' decisions regarding a number of behaviors known to increase the physical health risks 
associated with sexual activity. Briefly, proponents of the Health Belief Model argue that the decision to undertake the steps necessary to protect one's health is motivated by a set of health beliefs; these beliefs deal with an individual's evaluation of their risk and the barriers they perceive will prevent them 'from taking steps to avoid a given health risk. My work expands the traditional Health Belief Model by more fully incorporating gender into the model through a consideration of the ideology of gendered sexuality. This is accomplished through an examination of the four primary information sources - schoolbased sex education, parents, peers, and the media - through which social norms pertaining to femininity and masculinity are transmitted to adolescents. By considering both the content of gendered information and the ways in which individuals act out femininity and masculinity, I address the ways that individual action reproduces gender at the societal level. This moves beyond the simple inclusion of gender as a variable; rather, this work seeks to demonstrate the specific ways in which the social phenomenon of gender matters in individuals' lives.

\section{Methodological Contributions}

In addition to the theoretical contributions to the study of adolescent sexual decision making noted above, the design of this study also offers a number of methodological contributions. First, this study combines in-depth qualitative interviews of a sample of adolescents with quantitative analysis of a nationally-representative data set. While both quantitative and qualitative methods have been used separately to study adolescent sexual decision making, I consciously designed this study to take full advantage of the strengths of each methodological approach. More importantly, I view 
these two approaches as reciprocally related. Both the design and interpretation of the statistical models were highly informed by the qualitative findings, while the generalizability of the in-depth interviews was assessed through examination of the nationally-representative data set. Either approach could have stood alone, but the combination of both produces an understanding of adolescent sexual decision making that moves beyond what has been offered previously.

Due to the use of in-depth interviews with adolescents, this project contributes substantially to the understanding of adolescent culture. Numerous studies have examined the statistical correlates and outcomes of adolescent sexual behavior, but there has been little research that asks adolescents themselves to explain their decision making processes (for two notable exceptions see Thompson, 1995 or Fine, 1988). This research thus seeks to give voice to adolescents, attempting to understand the daily pressures they face and the conflicts they must resolve as they move into adulthood.

Finally, this work offers a much-needed link between the disciplines of sociology and public health. Many researchers have lamented the limited theoretical grounding of much public health research on adolescent sexual behavior (Herold, 1983). Additionally, this work points to the immense potential of sociological research to inform public health policy. By examining the specific pathways through which gender ideology shapes the health behavior of both women and men, I move beyond a mere critique of the injustice of gender inequality. Rather, this work illustrates how the social construction of gender constrains us all as individuals. 


\section{Overview of the Dissertation Chapters}

In Chapter Two I review the relevant literature on adolescent sexual decision making, establishing the assumptions on which my work is based. This chapter argues for the inclusion of gender in the study of adolescent sexuality, and explicates the cultural interaction of gender and sexuality. Chapter Three provides a detailed discussion of the conceptual model which informs this work, the Health Belief Model.

Beginning in Chapter Four I report the results of my empirical analyses. I discuss my analysis of the in-depth interviews with adolescents in Chapter Four, with specific attention to the question of whether a health belief perspective can reasonably be expected to predict adolescents' sexual risk behavior. Chapter Five introduces the National Longitudinal Study of Adolescent Health and describes my operationalization of the key constructs of the Health Belief Model. Chapters Six through Nine use nested logistic regression models and Cox proportional hazards models to compare different specifications of the Health Belief Model, in an effort to determine whether my inclusion of indicators of gendered sexuality significantly improves the explanatory power of the model. Chapter Ten explores the intersection of race/ethnicity and gender in the transition to sexual intercourse. Finally, Chapter Eleven offers conclusions and recommendations for policy. 


\section{CHAPTER TWO: Gender and Sexuality in Adolescence}

In this chapter I explore the relationship between gender and sexuality, providing the conceptual background on which this study is based. First, I examine the literature on adolescent sexual decision making, to assess the extent to which it differs from that of adults. I then turn to a discussion of the connection between gender and sexuality, considering both the content of this connection and its implications for adolescents' sexual decisions. I conclude the chapter with an exploration of the mechanisms through which the gendered ideals related to sexuality are transmitted to adolescents.

\section{Adolescent Sexual Decision Making}

This study explores how adolescents negotiate their early years of sexual involvement, focusing on the processes through which adolescents make decisions about their sexual lives. Sexual decision making holds special salience during adolescence, as individuals must decide at what age, where, and with whom to engage in various sexual activities. These decisions are a function of a crucial developmental goal during adolescence: the transition to the adult system of sexuality, characterized by the rigid, oppositional characterizations of femininity and masculinity, as well as what Adrienne Rich (1980) has termed "compulsory heterosexuality." The study of adolescent sexual decision making is thus complicated by the transitional nature of adolescence, and it is unclear the extent to which adolescent decision making differs from that of adults. 
The period of adolescence has been variously defined as ranging from 10 to 19 years or even 15 to 24 years of age (Gage, 1998). The lack of agreement as to the parameters of adolescence stems from the fact that traditional end of adolescence, the age at the first major life transition-into the work force, the completion of education, or marriage - has been moving steadily back in recent decades (D'Emilio and Freedman, 1988). There has not generally been a corresponding change in attitudes toward adolescent sexuality, however; as a result, adolescents are placed in the precarious position of having matured physically but not being allowed to enter into mature social roles (Luker, 1996). Society disdains casual sexual encounters, and yet adolescents are continually told that they are not yet mature enough to enter into mature, committed relationships (Rhode, 1993).

This lack of a definite, independent social role is especially problematic for adolescents, given that the years following puberty are also fraught with rapid physiological and emotional changes (Gage, 1998). Moreover, adolescents are legally subject to the authority of adults until the age of 18 , and many remain dependent on their parents for financial support into their early twenties. This close linkage to parents undoubtedly influences the adolescent sexual decision making process, and while most studies cite the protective benefits of strong parent-child ties in promoting safer sexual behavior, it could also be argued that this continued social dependence limits adolescents' decision making autonomy. What is clear is that as they age, the sexual decision making of adolescents comes to more closely approximate the rational cost-benefit analysis ascribed to adults (Gage, 1998). 


\section{Gender and Sexuality}

This work seeks to move beyond traditional conceptualizations of the role of gender in sexual decision making (and health behavior generally) by focusing explicitly on the social performance of gender. Articulated most adeptly by Candace West and Don Zimmerman (1987, p. 126), the social performance of gender implies:

"an ethnomethodologically, and therefore distinctly sociological, understanding of
gender as a routine, methodical, and recurring accomplishment...the 'doing' of
gender is undertaken by women and men whose competence as members of
society is hostage to its production. Doing gender involves a complex of socially
guided perceptual, interactional, and micropolitical activities that cast particular
pursuits as expressions of masculine and feminine "natures." This ethnomethodological approach to gender calls into question a number of common usages of the term. First, modern society often uses sex, gender, and sexuality interchangeably, confounding the biological and the social. Sex is a biological classification based on the examination of the external genitalia at birth, or through chromosomal testing when the genitals appear ambiguous (Fausto-Sterling, 2000). Gender, however, refers to the "psychological, social, and cultural aspects of maleness and femaleness" (Ǩessler and McǨenna, 1985). Sexuality, though commonly used to denote an individuals' preferred sexual partners, refers in this work more broadly to both behaviors and desires, the "appropriate" objects of which are culturally defined by an individual's gender (Schwartz and Rutter, 1998).

Following Kessler and McKenna (1985), I use the term gender exclusively in this work, as my interest lies in the cultural (rather than biological) differences in the feminine and masculine performances of sexuality. My intention is the conscious rejection of an essentialized view of the differing natures of women and men; rather, $\bar{I}$ 
seek to highlight the role of culture in the social construction of both gender and sexuality. As Judith Lorber (1994, p.79) notes:

"Western society's values legitimate gendering by claiming that it all comes from physiology - female and male procreative differences. But gender and sex are not equivalent, and gender as a social construction does not flow automatically from genitalia and reproductive organs...social statuses are carefully constructed through prescribed processes of teaching, leaming, emulation, and enforcement."

The confusion of sex and gender may thus be more purposive than accidental, as the maintenance of patriarchal society relies on the supposed indisputability of sex-based differences (Connell, 1987). In reality, however, it is the social meanings that we assign to femininity and masculinity that make gender salient, and the ranking of feminine and masculine traits that perpetuates gender inequality.

Even once sex and gender have been distinguished conceptually, there remains a tendency to view gender as a relatively immutable characteristic (developed through gender socialization and fixed around age three), much as biological sex is viewed to be fixed (West and Zimmerman, 1987) The identification of certain institutions and structural arrangements (e.g., the division of labor, the family) as "gendered" serves to reinforce the notion that gender acts primarily as a top-down phenomenon, such that individual experiences are a result of macrolevel forces (West and Zimmerman, 1987). Conversely, the ethnomethodological approach locates the production of gender within the social interactions undertaken by individuals. Though not suggesting that gender emerges spontaneously from social interaction, free from any social or cultural constraints, this approach does afford individuals significantly more agency than the traditional gender role approach. The social performance of gender can thus be viewed as the specific location of the reproduction of gender, acting as the link between gender at 
the micro- and macrolevels. I believe that this perspective is uniquely well-suited to the discussion of adolescent sexual decision making; while such decisions obviously take place at the microlevel, they are intimately shaped by the larger sociocultural - and thus gendered--context in which they occur.

Sexuality, and decisions about sexual behavior in particular, also falls at the complicated intersection of biology and culture. It is impossible to ignore the intimate connection of sexuality to reproduction and thus to the (sexed) physical body, but it is equally impossible to dismiss the role that culture plays in shaping the experience and meaning of sexuality. Much previous work on sexuality and sexual decision making has focused on the biological and psychological aspects of sexual desire, and this limited view of sexuality is also reflected in our common understanding of how sexuality operates in our lives. I contend, however, that this biopsychological approach obscures the reality that sexuality (and the decisions we make regarding sex) are a direct product of social construction, and thus of culture. There are of course biological aspects of desire and arousal, but the meanings we give sexuality are the result of continual cultural negotiation.

As gender and sexuality are highly interrelated, a large portion of the messages individuals receive regarding sexuality reflect normative views of gender. This link between gender and sexuality becomes particularly salient at adolescence, as conformity to traditional gender ideals becomes more rigorously enforced following puberty (DeGaston, Weed, and Jensen, 1996). Attitudes toward and experiences of sexuality thus become "gendered" in that the culturally-sanctioned expression of sexuality is intimately tied to the appropriate performance of gender. Ideals of gender and sexuality reflect 
mutually reinforcing cultural messages that merge together to produce what may be termed "gendered sexuality."

Content and Context of Gendered Sexuality. The performance of gendered sexuality conforms to many of the traditional dichotomies through which women and men as social groups are understood in this society. The doctrine of separate spheres has long been employed (both explicitly and implicitly) to assign responsibility for care of children and the home to women, while men are expected to be economic providers. Evidence suggests that these traditional roles continue to be enacted even at the microlevel of intimate relationships. Men are often called to play the instrumental role, planning and paying for dates and initiating sexual contact (Rose and Frieze, 1989). Historically, women's expressive role in relationships and their presumed desire for marriage and children has been thought to work against the consistent use of contraceptives; though the reality of this connection may be changing, the traditional norms linking women with the private sphere of the family remains a powerful influence on individuals' actions (MacCorquodale, 1984).

The patriarchal construction of gender relations by definition places men in a position of dominance over women, and this dominant/subordinate relationship informs normative views regarding the appropriate negotiation of heterosexual relationships. The normative performance of femininity requires women's submissiveness. This has obvious implications for decision making in heterosexual relationships, as women are often unable to express fully their concerns and desires (Fine, 1988). Moreover, the traditional performance of gender exercises considerable social power even outside of 
dyadic relationships. For example, the emphasis placed on male sexual conquest may encourage men to make unhealthy decisions by encouraging sexual promiscuity (Pleck, Sonenstein, and $\mathrm{Ku}, 1993)$.

Scripting the Performances of Gendered Sexuality. Gendered sexuality, the contours of which are transmitted along with factual information about sex, can be examined from the perspective of scripting theory. Developed as a rejection of the Freudian emphasis on biological determinants of behavior, the idea that individuals order their lives through the use of scripts was applied to sexuality in the early 1970s by William Simon and John Gagnon (Gagnon and Simon, 1973). Simon and Gagnon define three interrelated levels at which sexual scripts operate: cultural scenarios, which serve as overarching guides to the proper performance of sexual roles; interpersonal scripts, actively created by individuals as they incorporate specific components of cultural scenarios into their everyday interactions; and intrapsychic scripts, through which individuals understand themselves as sexual actors (Simon and Gagnon, 1986). Seeking to clarify the original concept of scripting, Judith Laws and Pepper Schwartz (1977) characterized sexual scripts as "a repertoire of acts and statuses that are recognized by a social group, together with the rules, expectations, and sanctions governing these acts and statuses." Given the prevalence of messages about gender in the culture, scripting theory offers a tool for understanding the mechanisms through which messages about gender are enacted in individuals' sexual lives through incorporation at the psychological level; hence, the performance of gendered sexuality (İrvine, 1994). 
Shared knowledge of the appropriate performance of gendered sexual scripts also serves as a powerful form of social control. Though gendered sexual scripts are actively used by social actors, they reflect traditional ideals of gender and sexuality over which individuals hold relatively little sway. Not surprisingly, the required degree of compliance to gendered sexual scripts differs by gender. The primary socially-acceptable sexual script available to adolescent women is that of sexual gatekeeper, whose goal is to delay sexual intercourse until a love-based commitment has been established (Kane and Schippers, 1996; Reed and Weinberg, 1984; Van Roosmalen, 2000). Women's adherence to this sexual script is ensured by the intensely negative social stigma assigned to those women who fail to limit their sexuality in this way (Tanenbaum, 2000). Men, on the other hand, have a number of acceptable masculine sexual scripts available to them, including the "casual sex" script. The performance and evaluation of this script is geared primarily toward other men, representing a form of homosocial behavior that moves the performance of gendered sexuality outside of the heterosexual dyad and into the public sphere (Reed and Weinberg, 1984).

The idea that the performance of gendered sexual scripts is evaluated by social actors implies an audience for their performance, and while it is clear that peers are the primary audience for adolescents' displays of sexuality, this misses the intimate connection between the performance of gendered sexuality and social power. As noted earlier, men perform masculine sexuality for the benefit of other men, both as a means of social bonding and to reinforce the subordination of women and non-heterosexuals. What is crucial to recognize is that women also perform their sexuality for men-the audience for gendered sexual performances is always male. Janet Holland and her 
colleagues (1996) capture this phenomenon with the term "male in the head," illustrating the fact that normative gendered scripts for sexuality come to act as a powerful form of internalized social control. Drawing on Foucault's discussion of surveillance and discipline, Sandra Bartky (1990) suggests that, "In contemporary patriarchal culture, a panoptical male connoisseur resides within the consciousness of most women. They stand perpetually before his gaze and under his judgment." While this "male in the head" is undoubtedly a powerful constraint on women's sexuality (given men's greater social power), the "male in the head" also constructs a specific form of hegemonic masculinity which most men as individuals are unable to achieve (Connell, 1987).

Many have noted that feminine and masculine performances of sexuality are not mirror opposites, as they do not represent equivalent access to social power; certainly there is no "female in the head" that constrains men's sexuality. Indeed, even when women perform feminine sexuality according to prevailing norms, they remain in a subordinate position in which their control over their bodies is limited (Holland et al., 1996). While much attention has been paid to the ways in which feminine sexuality puts women's health at risk (see Fine, 1988 for example), I will argue throughout this work that the gender ideals which inform both feminine and masculine sexual scripts work against preventive sexual health behavior.

Gendered Sexuality and Health. As I will detail below, adolescents draw on numerous sources of information when making decisions about sex, not all of which are explicitly related to health. It is possible to sort the sexual information that adolescents receive into two broad categories: factual, health-based information about reproduction, 
contraception, and disease prevention, and normative information about appropriate sexual attitudes and behaviors. These two categories are analogous to what the education literature terms the "formal" and "hidden" curricula (McKay, 1998; Szirom, 1988). In this case, the formal curriculum provides health information, while the hidden curriculum presents countless messages regarding what society views as normal and acceptable expressions of sexuality (Szirom, 1988).

Adolescents' decisions about sex, while certainly influenced by health concerns, are thus also deeply embedded in the cultural context in which they take place. While adolescents do appear to recognize the risks of sexual behavior, cultural prescriptions regarding the appropriate performance of gendered sexuality are also highly salient in the sexual decisions adolescents make. The tendency of adolescents to place social concerns above health considerations makes sense from a developmental perspective: adolescents must become integrated into social networks of their peers as they mature into independent adults (Christopher, 2001). At the same time, health concerns seem distant to young people convinced of their invincibility (Fisher, Misovich, and Fisher, 1992). Expanding the traditional perspective on health decisions (which posits that preventive health beliefs directly predict positive health behaviors) to include the influence of the cultural messages provided by school-based sex education, parents, peers, and the media offers a more comprehensive model of adolescent sexual decision making. This model may help to explain how adolescents balance formal health information with the "hidden" cultural messages concerning gendered sexuality to which they are continually exposed. 


\section{Sources of Information}

The overarching goal of this work is the recognition of the cultural context in which adolescents make decisions about sex; specifically, I examine how gendered sexual scripts shape adolescents' sexual behavior. Using the perspective of scripting explicitly links cultural ideals regarding the normative performance of femininity and masculinity with individual action, clarifying the mechanisms through which the social performance of gender impacts individuals' lives. It is not enough to simply say, however, that normative views on gender are constant across the population, that all individuals are equally beholden to cultural norms regarding gendered sexuality. Rather, incorporation of cultural norms is variable, dependent on exposure to various sources of information. The literature on adolescent sexual decision making identifies four prominent sources of information on which adolescents rely for both factual and normative information, and exposure to these sources can serve as a rough proxy for exposure to the formal and hidden curricula of sexual information available to adolescents.

School-based Sex Education. Nearly all adolescents are provided with factual information on the health risks associated with sexual behavior through school-based sex education; well over 90 percent of adolescents report exposure to school-based sex education as of 1998 (Lindberg, $\mathrm{Ku}$, and Sonenstein, 2000). ${ }^{2}$ Indeed, adolescents themselves point to sex education as a valuable source of information about the health

\footnotetext{
${ }^{2}$ Two-thirds of public school districts include sex education in their middle school or high school curricula; the remaining school districts leave decisions regarding sex education up to individual schools and teachers (Dailard, 2001).
} 
risks associated with sex. Based on their analysis of the 1997 Commonwealth Fund Survey of the Health of Adolescents, Sutton et al. (2002) found that school-based sex education has become the top-ranked information source for adolescents across all categories of gender, race, and socioeconomic status, moving ahead of both family and friends. Studies also indicate that information on health risks is a common component in sex education curricula. Fully 92 percent of male adolescents and 93.5 percent of female adolescents report having received information on how to prevent the spread of HIV/AIDS through safer sex practices (Lindberg, Ku, and Sonenstein, 2000).

Though the appropriate content of sex education curricula continues to be widely contested in the political arena, most agree that the primary function of school-based sex education is the provision of factual information about the health risks associated with sexual behavior. What is often overlooked is the fact that this information is firmly embedded in the dominant cultural discourse regarding gendered sexuality. Michelle Fine (1988) notes that sex education's focus on the risks of sexual behavior usually serves to constrain young women's sexual subjectivity. By emphasizing the potential for female sexual victimization, sex education limits young women's ability to desire and enjoy sexual relationships. This has direct implications for women's health, as this sexual fear often results in a "sex happens" orientation that reduces women's ability to protect themselves from pregnancy and STDs (Thompson, 1995). Moreover, schoolbased sex education presents marriage (or committed, long-term, heterosexual relationships at the very least) as the sole place in which women can safely express their sexuality, further reinforcing traditional heterosexual relations. In terms of both the 
formal and hidden curricula, then, schools contribute greatly to adolescents' knowledge of both gender and sexuality.

Parents. Though there has been increasing emphasis on the role of schools and other community organizations in the sexual health education of adolescents, there remains an abiding belief that information about sexuality ought to be provided first in the home (Moore, Peterson, and Furstenberg, 1986). Research on parent-child communication about sexuality, however, points to inconsistent findings on the outcomes of such communication. Parents and adolescents often disagree on the degree and content of past parent-child discussions about sex (Fisher, 1989; Newcomer and Udry, 1985; Rogers, 1999). While parents report general satisfaction with their discussions of sexuality with their adolescent children, adolescents themselves often report that their parents have failed to address adequately their concerns (Clark et al., 1997). Moreover, parents tend to focus exclusively on information about the risks of sex, but fail to provide specific directions on how to avoid those risks (Miller et al., 1998; Newcomer and Udry, 1985). This emphasis on risks is especially prevalent in parents' reactions to their daughters' emerging sexuality; parents frequently employ the language of "dire consequences" when discussing sex with daughters, though not with sons (Tolman, 1994). Gendered sexuality, and the constraints on women's sexuality it entails, is thus evident in the messages parents convey to their children.

Parents also attempt to exert direct control over their adolescent children's sexuality through discipline and monitoring of activities. . Miller and colleagues (1986) find a curvilinear relationship between parental control and sexual activity, however, 
suggesting that a moderate degree of parental control is most likely to reduce adolescent sexual behavior. Rodgers (1999) reports similar findings on the importance of parental monitoring in reducing adolescent sexual risk behavior. Interestingly, young women whose parents employ psychological control (primarily guilt) are more likely to engage in risky sexual behavior, confirming Miller et al.'s findings that excessive parental control may backfire. Through both their discussions with adolescents and more active attempts at controlling adolescent sexuality, parents work (perhaps unconsciously) to enforce traditional norms of gendered sexuality.

Peers. While parents can serve as an important source of sexual health information, adolescents often find it difficult to engage their parents in detailed discussions of their sexual lives (Clark et al., 1997). Developmentally, however, the weakening of parentchild ties during late adolescence is a natural and necessary step in the transition to adulthood. As adolescents leave the safety of the family to become independent adults, they are also coming into their own as social actors; as such, the opinions of their social network of peers take precedence over the wishes of parents (Christopher, 2001). Peers are thus a key source of sexual health information for adolescents. While aware of the potential for misinformation from peers, adolescents consistently report turning to close friends for help in making decisions about sex (Clark et al., 1997).

Though peers may serve as a source of information about sex, they also act as mediators of culture; indeed, it is primarily through peers that social norms are transmitted and enforced (Murphy, Rotheram-Borus, and Reid, 1998). Throughout early adolescence, peer groups are so differentiated by gender as to form what has been termed 
"separate worlds" in which girls and boys as social groups operate according to two separate, gendered cultures (Maccoby, 1998; Thorne and Luria, 1986). ${ }^{3}$ Within these separate groups, individuals experience various forms of social control designed to ensure adherence to the groups' norms, including peer pressure (both toward deviance and conformity), assignment of reputations, and gossip (Holland et al., 1996; Simon, Eder, and Evans 1992; Tolman, 1994). The decisions adolescents make regarding their sexual lives can thus be seen as group decisions in a sense, in that the group's reactions to individual decisions are used to maintain the boundaries of that peer group.

Media. The media —including television programming, movies, music, magazines, and Internet sites—play an enormous role in most adolescents' lives; indeed, adolescents spend between six and seven hours a day with some form of media (Brown and Keller, 2000). Sexual content is especially prevalent in media directed at adolescents, and research indicates that adolescents often seek out media with sexual content specifically because it offers an easy and unembarrassing way to learn about romantic and sexual relationships (Huston, Wartella, and Donnerstein, 1998). Recognizing this, many outlets have begun to create media with the explicit intent of increasing adolescents' knowledge of safer sexual practices-what is commonly termed "edutainment." ${ }^{\text {"4 }}$ For the most part, however, the media do not act as responsible sexual health educators, given that profit (rather than conscience) tends to be the primary determinant of content (Brown and

\footnotetext{
${ }^{3}$ Though this "separate worlds" hypothesis has been challenged by recent findings of significant behavioral differences within gender groups (Thome, 1993), most children and young adolescents participate in singlegender groups (Zarbatany et al., 2000).

For instance, the writers of the hit medical drama $E R$ included information on emergency contraceptives at the urging of the Kaiser Family Foundation (Folb, 2000).
} 
Keller, 2000). Interestingly, though fully 72 percent of adolescent respondents to a 1998 Kaiser Family Foundation survey reported that their peers' sexual behavior is influenced by television programming, only 22 percent conceded that their own behavior is similarly shaped. Exposure to media is thus a key component in the cultivation of the socially normative attitudes toward gender and sexuality that shape the decisions adolescents make regarding their own sexual behavior (Signorielli, 1993).

Access to information is not the only reason adolescents turn to various forms of media; obviously, media is a significant source of entertainment for adolescents and also serves as a means of escape from everyday life. More importantly, however, adolescents' media choices play an important role in the transition to adulthood. Jeanne Steele's (1999) model of adolescent media use highlights the importance of media in the development of identity in adolescence. She suggests a circular Media Practice Model in which individuals actively select and incorporate specific media messages into their lived experiences. In so doing, individuals shape the identity they wish to display, which thus informs their future media choices. This circular model differs from traditional theories of media use, which often paint individuals as passive recipients of media messages. Rather, Steele's model suggests that adolescents' media choices are an integral part of who they are and who they hope to become in the future; in regards to sexuality, adolescents' media choices help to shape their performance of gender roles and thus their sexual behavior. 


\section{Conclusions}

This chapter provides the groundwork for the analyses to come, by clarifying my perspective on gender and its relation to sexuality. I have argued for an ethnomethodological approach which views gender as a social relation accomplished through individuals' actions. I employ the perspective of scripting theory to illustrate how the active performance of gender at the microlevel is constrained by the patriarchal structure of gender at the macrolevel. I have also identified the four most common sources on which adolescents rely for information about sexuality; these sources act as the mechanisms through which gender ideals are transmitted to adolescents. In the next chapter I introduce the Health Belief Model in greater detail, with specific attention to how the performance of gendered sexuality interacts with health beliefs in adolescent sexual decision making. 


\section{CHAPTER THREE: Potential of the Health Belief Model}

As noted in the introductory chapter, a health risk perspective is commonly applied to the study of adolescent sexual decision making. My primary reason for adopting the health risk approach to adolescent sexual decision making is a practical one: school-based sex education offers a specific site to address the health risk behavior of adolescents. Though the appropriate content of sex education curricula continues to be widely contested in the political arena, research indicates that certain sex education programs are effective at decreasing sexual risk behavior. ${ }^{5}$ Douglas Kirby (1992), evaluating findings on the efficacy of numerous sex education curricula, found several programs that effectively delayed first heterosexual intercourse, promoted greater use of condoms for pregnancy and STD prevention, and reduced the number of sexual partners. Many of these positive results were based on studies employing experimental designs and included both abstinence-only and comprehensive sexuality education curricula (Kirby, 1992; Kirby et al., 1994). In short, empirical evidence supports the contention that school-based sex education has the potential to encourage health risk prevention among adolescents.

The logic underlying most school-based sex education curricula closely parallels the most prominent theoretical model of health behavior developed in the public health

\footnotetext{
${ }^{5}$ A 1999 survey conducted by The Alan Guttmacher Institute found that 86 percent of school districts with established sex education policies required discussion of abstinence, while 51 percent encouraged abstinence as an effective means of pregnancy/STD prevention. Only 14 percent of schools surveyed provided comprehensive sexuality education that addressed risk prevention in the context of overall sexual health (Landry et al., 1999).
} 
literature; this congruence is no accident. ${ }^{6}$ Since its development in the 1950 s the Health Belief Model has become the most widely used theoretical model in public health research (Janz and Becker, 1984). The relationship suggested by the model is exceedingly straightforward: individuals with strong preventive health beliefs (subjective evaluations of an individual's health risks) are more likely to undertake preventive health behaviors (Rosenstock, 1974). Given the simplicity of the model, its applications to studies of health beliefs have been varied and wide-reaching. Indeed, Clarke (2000) and colleagues' search of the Medline data base found that over 64 percent of health behavior studies between 1974 and 1994 employed the Health Belief Model. Recently health behavior research in the developing world has begun to utilize the Health Belief Model as well (Agha, 2002). Because the Health Belief Model is relatively broad in its definition of preventive health behaviors, beliefs, and outcomes, it has been used to examine a wide range of health issues (Janz and Becker, 1984).

\section{Historical Development of the Health Belief Model}

The Health Belief Model has been action-oriented since its creation, hence its common application to health education curricula. Seeking to address high rates of noncompliance with simple preventive health behaviors, public health researchers sought to build a theoretically coherent model to explain the relationship between health beliefs and behaviors (Rosenstock, 1974). Drawing on existing work in cognitive-behavioral

\footnotetext{
${ }^{6}$ Douglas Kirby (1992) notes that the content and strategies used by many school-based sex education programs derive from established theoretical approaches including the Health Belief Model and Bandura's social learning theory.
} 
psychology, the researchers identified four basic health beliefs that predict the likelihood of undertaking preventive health behaviors:

Perceived Susceptibility: an individual's subjective perception of their risk of a given negative health outcome

Perceived Severity: an individual's assessment of the seriousness of a given negative health outcome

Perceived Benefits: an individual's view of the effectiveness of preventive health measures to reduce the risk of a negative health outcome

Perceived Barriers: an individual's analysis of the benefits and costs of undertaking the preventive health measure

The model suggests that individuals engage in a form of cost-benefit analysis when making decisions about their health, such that individuals who appreciate the risks associated with a given negative health outcome (such as disease or injury) will be more likely to undertake actions to avoid such an outcome (Rosenstock, 1974). This model moves beyond a limited focus on the role of objective factors (such as knowledge or intelligence) in health decision making to consider the ways that individuals make use of the health information they receive.

Studies using the Health Belief Model find consistent support for the hypothesized relationship between health beliefs and preventive health behaviors. Reviewing over 25 studies employing the Health Belief Model, Janz and Becker created a "significance ratio" to determine the percentage of statistically significant results found using the various constructs that comprise the Health Belief Model (Janz and Becker, 1984). They found "perceived barriers" to be the construct most consistently predictive of health behaviors, with 91 percent of the total studies finding barriers to be statistically 
significant. Even the weakest predictor, "perceived severity," was found to be significant in 59 percent of the studies, suggesting that the four core health belief constructs of the Health Belief Model are indeed highly correlated with health behaviors. Additionally, psychometric testing of over 30 questionnaires derived from the Health Belief Model found factor loading that was consistent with the theoretical model, and the reliability of the model appeared to be similar across race/ethnicity, age, and gender (Weissfeld et al., 1987).

\section{Applications of the Health Belief Model to Sexual Health Decisions}

The Health Belief Model was originally designed to address simple preventive health behaviors, such as vaccination against Swine Flu and genetic screening for TaySachs disease. The model has also been applied to sick-role behaviors such as compliance with anti-hypertensive regimes and utilization of clinics for health care (Condelli, 1986; Herold, 1983; Hiltabiddle, 1996; Janz and Becker, 1984). These studies represent a clear-cut application of the model, with straightforward compliance/noncompliance outcomes resulting from a simple set of preventive health beliefs.

Recently, the Health Belief Model has been applied to considerably more complex health beliefs and behaviors, including prevention of the negative health outcomes associated with various sexual risk behaviors (Condelli, 1986; Eisen, Zellman, and McAlister, 1992; Herold, 1983; Hiltabiddle, 1996). In particular, the model has been used to examine the prevalence of condom use to prevent the spread of HIV/AIDS (DiFranceiso et al., 1998; Laraque et al., 1997; Montgomery et al., 1989). For example, Laraque and colleagues (1997) employ the Health Belief Model to assess various 
predictors of condom use among adolescents in Harlem. Using blocks of variables to capture individual perceptions of the risks of unprotected sexual behavior, the authors find specific motivating factors (such as the desire to delay parenthood) to be most predictive of consistent condom use (Laraque et al., 1997). Other studies have examined outcome variables such as the number of sexual partners, using the number of partners as a proxy for exposure to STDs (Levinson, Jaccard, and Beamer, 1995). In short, studies of sexual health behavior using the Health Belief Model have focused on the risk of contracting STDs and, for women, the risk of experiencing an unplanned pregnancy.

\section{Critiques and Modifications of the Health Belief Model}

Though most studies of health behavior using the Health Belief Model find each of the core constructs to be statistically significant, the overall explanatory power of the model (as measured by the explained variance of the model) continues to be limited in most studies (Rosenstock, Strecher, and Becker, 1988). Levinson and colleagues (1995) note that proponents of the Health Belief Model tend to blame poor study design for the limited efficacy of the model, while critics of the model point to more fundamental theoretical problems. I concur that traditional uses of the model suffer from both theoretical and operational weaknesses, though I argue that inattention to the social implications of gender differences may account for many of the problems inherent in the model.

First, the Health Belief Model is explicitly individualistic in its focus; the model posits a direct relationship between an individual's health beliefs and the behaviors they undertake to protect their health. Health, however, can be considered to operate both at 
the individual level and as a more general, public concern. If the responsibility to maintain good health is viewed as an exclusively individual concern, the Health Belief Model is likely to explain health behaviors adequately. It has been suggested, however, that two distinct orientations toward health exist-individualistic and collective. Steers and colleagues (1996) offer these orientations as an explanation for their empirical findings on racial/ethnic differences in the utility of the Health Belief Model. They contend that while European Americans tend to hold individualistic views about health, Hispanic, African, and Asian Americans are more likely to be collectively-oriented. As a result, the individual-focused variables of the Health Belief Model (especially perceived susceptibility) are more likely to predict the health behavior of European Americans.

In a similar manner, I believe that the orientation toward health (and thus the applicability of the Health Belief Model) is also likely to differ by gender. Research indicates significant gender differences in the perception and evaluation of health conditions; this is especially pronounced in the case of mild or prolonged illnesses (Verbrugge, 1985). Women, given their historical connection to care for the home and children, also tend to be much more conscious of health than men. More to the point, I . suggest that health decision making varies by gender in a manner similar to the variation by race/ethnicity noted by Steers et al. Following Gilligan's (1982) findings on the role of gender in moral reasoning, I hypothesize that the orientation to health is shaped by gender socialization. Women are socialized to be primarily relational (often to the point of placing the needs of others before their own), while men's focus is largely individualistic. If this orientation holds for health decision making, we would expect the 
individualistic Health Belief Model to be more predictive of men's behavior than of women's.

Another critique of the Health Belief Model is its lack of sociocultural context; this critique is especially salient when using the model to examine decisions regarding sexual behavior. As noted earlier, the Health Belief Model is predicated upon the view of individuals as fully rational actors who undertake preventive health behaviors in accordance with their health beliefs. I argue, however, that this view ignores the ways that individuals' actions are shaped by social context in which they occur. Specifically, I contend that the structure of gendered relationships and the normative performance of gendered sexuality must be incorporated into the Health Belief Model when it is used to predict sexual risk behavior. ${ }^{7}$

Many decisions regarding sexual behavior are dyadic in nature, such as the selection and use of contraceptive methods or whether to be monogamous (Manning, Longmore, and Giordano, 2000). In the case of heterosexual relationships, this dyad includes one woman and one man (Gutierrez, Oh, and Gilmore, 2000). Given the current structure of gender relations, men often exercise considerably greater power than women in sexual relationships; historically this imbalance has been a result of women's economic dependence on their male partners. ${ }^{8}$ As women often perceive their options outside of heterosexual relationships to be limited, their desire to please their male

\footnotetext{
${ }^{7}$ Of course, this sociocultural context also includes race/ethnicity, class, nationality, and many other characteristics on which individuals are currently stratified in this society. This research, being primarily exploratory in nature, addresses only gender.

${ }^{8}$ Interestingly, one study found that women and men appear to disagree regarding the balance of power in sexual relationships. Though women believe men's greater overall social power gives them more power in heterosexual relationships, men view women's roles as sexual gatekeepers as giving them greater power (Kane and Schippers, 1996).
} 
partner may come into conflict with their ability to make decisions to protect their own health (Abel, Marion, and Seraphine, 1998). In a more general sense, the experience of women as an oppressed class in society also has direct implications for health, as individuals who experience the silencing effects of oppression often find themselves unable to make self-affirming choices (Amaro and Raj, 2000).

The appropriate performance of gendered sexuality may also influence sexual health decisions, as the dominant sexual scripts for both women and men may encourage individuals to act in ways that are contrary to their health. Traditionally feminine sexuality is based on passivity and innocence; the ideal woman is not expected to voice her sexual concerns and desires, not even those directly related to her health (Fine, 1988). The masculine sexual script entails a lack of emotional concern or attachment; "real men" seek out sex with as many partners as possible with little consideration of the risks (Pleck et al., 1993). Even within relationships, the dominant sexual script precludes honest, open discussion of sexual health issues, as such discussions are seen as offending the sensibilities of both women and men alike.

\section{Proposed Use of the Health Belief Model}

This study represents a more systematic consideration of the applicability of the Health Belief Model to adolescent sexual decision making than has been offered in previous studies; specifically, this study considers how adolescents themselves understand their sexuality, in order to determine if the Health Belief Model can reasonably be expected to explain adolescent sexual risk behavior. In the qualitative analysis presented in Chapter Four, I seek to develop an understanding of the subculture 
of adolescent sexuality. Focusing on preventive health beliefs, sexual risk taking, and views on the normative performance of gendered sexuality, I address the question of whether adolescents apply a health perspective when thinking about their sexual behavior. This analysis lays the groundwork for the operationalization of the statistical models presented in Chapters Six through Ten.

The statistical models I present expand the Health Belief Model by fully incorporating gender into the model. ${ }^{9}$ Existing studies consider gender differences, but I contend that simply including gender in the Health Belief Model represents little more than an acknowledgement of sex-based differences in sexual behavior. As noted in the above critiques, there has been little critical investigation into how the social performance of gendered sexuality modifies the Health Belief Model. The consideration of both gender (as a variable) and gender ideals moves beyond a mere biological understanding of sex-based differences, more fully incorporating the health implications of the social performance of gender into the model.

Additionally, this project examines the relative influence of various sources of sexual health beliefs (e.g., sex education, media, parents, peers). These sources represent what Rosenstock refers to as "cues to action" (Rosenstock, 1974). A clearer understanding of these cues will aid in understanding how adolescents acquire sexual health beliefs and norms of gendered sexuality, providing necessary background to the question of how these influences are balanced in the belief-behavior relationship.

\footnotetext{
${ }^{9}$ Though extant research includes gender as a demographic control variable, this research interacts gender with all other predictor variables to address gender differences suggested by the literature and the qualitative component of this research.
} 
In summary, I argue that individuals translate the information they receive (both formal and hidden, from a variety of sources) into subjective evaluations of the risk for a given negative health outcome. If this translation of subjective beliefs into behavior took place in a vacuum, it might be reasonable to assume that strong preventive health beliefs would necessarily result in preventive health behaviors. Individuals are, however, much more complex than this simple equation implies; indeed, the decisions of social actors are fully enmeshed in the cultural context in which they take place. In the case of sexual decision making, I argue that the subjective evaluations individuals make are highly shaped by the connection between gender and sexuality. The information provided by the various cues to action, both objective (e.g., factual health information) and subjective (e.g., media depictions of gendered sexuality), is interpreted and incorporated into individuals' decision making processes in a purely subjective manner. This study therefore seeks to explicate, through both qualitative and quantitative analyses, the subjective dimensions of this decision making process. 


\section{CHAPTER FOUR: Qualitative Findings on Adolescent Sexual Decision Making}

In the previous chapter I offered a detailed explanation of the development and application of the Health Belief Model, as well as a discussion of the common critiques of the individual-level health belief perspective. Though the Health Belief Model has been widely used in research on adolescent sexual behavior, there is little work that addresses an important background question on which these empirical studies are based; in short, is the Health Belief Model a useful tool with which to understand adolescent sexual decision making? Do adolescents perceive their decisions about their sexual behavior to be a function of their health beliefs?

This chapter addresses this question by asking adolescents themselves to describe their sexual decision making processes; I believe this exploration represents a necessary step that must be undertaken before statistical modeling can begin. Moreover, the qualitative investigation offered in this chapter will aid in the evaluation of the major critiques of the Health Belief Model and assist me in modifying the model to represent adolescents' decisions regarding sexual risk behavior more accurately. Additionally, the analysis presented in this chapter provides evidence for my contention that the role of gender norms in adolescent sexuality must be considered, in addition to and in interaction with health beliefs. 


\section{Qualitative Study Design}

The qualitative portion of this study is based on in-depth, semi-structured interviews I conducted with female and male adolescents during the summer of $2002 .^{10}$ The adolescent respondents were recruited using a modified snowball sampling method in which several primary adolescent contacts (individuals known to me who were not included in the sample) provided acquaintances with a contact letter in which I explained my research and requested their participation. If the adolescent was willing to be interviewed, a meeting was scheduled at which a detailed consent form ensuring confidentiality was signed. Each interview was audiotaped and transcribed.

The respondents were adolescents ages 18-19 who had not yet left their parents' home. The total sample consists of 25 adolescents, 13 female and 12 male. Two of the subjects were of Asian descent, while the remainder were European American. All respondents came from upper-middle class families and all were college-bound. Twenty of the respondents attended public high schools, four attended Catholic high schools, and one attended a private evangelical Christian school. It must be noted that the snowball sampling method I employed produced an extremely homogeneous sample. The goal of the qualitative component of this research is to illustrate broad psychosocial and cultural processes (in terms of health beliefs and gendered sexuality, respectively), and I believe my sample is adequate to describe adolescent sexual decision making broadly defined. The quantitative portion of this research, on the other hand, will address the generalizability of these processes.

\footnotetext{
${ }^{10}$ This research was approved by the University of Virginia's Institutional Review Board for the Social and Behavioral Sciences (see Appendix 1).
} 
I designed the interview schedule with several related goals in mind. As my intent in conducting interviews with adolescents was to ascertain the applicability of the Health Belief Model, I designed several questions to assess the four key health beliefs included in the model (susceptibility, severity, benefits, and barriers). Another key area of interest was the sources of information on which adolescents rely when making decisions about sexual behavior; these sources of information may serve as "cues to action" that should be included in the Health Belief Model (Rosenstock, 1974). Based on previous findings on common information sources (Sutton et al., 2001), I included detailed questions on the content and timing of school-based sex education, discussions with parents, interactions with peers, and media use. I also developed a number of questions directly addressing the relationship between gender and sexual decision making (see Appendix 2 for complete interview schedule). Minor modifications were made to the interview schedule following the third interview in order to explore the role of peers (and peer pressure in particular) in greater detail.

My analytic strategy was based on a systematic review of the interview transcripts. During the transcription process, I created a memo for each interview in which I recorded initial impressions, emerging themes, and notable deviations. As the qualitative component of this study was designed specifically to provide context for the statistical analysis to come, my analysis of the interview transcripts focused on three broad categories. I first explored the respondents' views on gender, examining descriptions of women's and men's expected behavior in sexual situations and considering the explanations respondents offer for gender differences in sexual behavior. 
I next sought to establish the applicability of a health perspective to adolescent sexual decision making; specifically, I searched for evidence of the four major constructs of the Health Belief Model. I focused this search on adolescents' discussions of schoolbased sex education, as this is the information source most explicitly linked with factual health risk information. Additionally, I explored the relationship between gender and sexual health beliefs, seeking to answer the following questions:

- Do adolescents associate decisions about sexual behavior with health risks; that is, do they employ a health risk perspective in their sexual decision making?

- Do adolescents possess the preventive sexual health beliefs associated with preventive sexual health behavior?

- Do social norms defining the appropriate performance of gender interact with preventive sexual health beliefs, as suggested by the "gendered sexuality" perspective?

Last, I examined the respondents' reports of the sources on which they rely for information about sex. Though the literature on adolescent sexual decision making points to several common sources, I wanted to understand how adolescents evaluate these sources in terms of their content and usefulness, and the extent to which they consciously incorporate information from these sources into the sexual decision making. 


\section{Perceptions of Gender and Sexuality}

Because my research is predicated on the belief that normative views of gender influence sexual decision making, my first step in the qualitative research was to examine adolescents' reports of typical gender stereotypes. I chose to focus my questions on stereotypes (rather than individual views on gender), as the goal of this research is to offer a general description of the process of adolescent sexual decision making. I sought simply to establish that this sample of adolescents has been exposed to mainstream norms regarding gender and its relations to sexuality.

At the beginning of each interview I asked the respondents to complete a brainstorming activity in which they listed descriptive words and phrases that described how women and men are "expected" to act in sexual situations. As would be expected, my respondents all noted the traditional dominant-subordinate relationship between men and women. Women were often referred to as passive and obedient, ready to respond to men and to go along with their wishes. Men were described as aggressive leaders who were expected to make the first move in sexual situations. Women were perceived to attach intense emotional meaning to sexual relationships, while it was suggested that men engage in sex solely for the sake of having sex. The respondents also reported that women are supposed to act innocent and unknowledgeable, as if they are unaware of men's sexual intentions, though surprisingly no corollary assumption was made about men's sexual knowledge. No respondent offered any description of gender roles that differed from the norm, indicating that these perspectives on women and men are indeed widely known. 
I fully expected that adolescents would describe traditional gender stereotypes. I was therefore more interested in the explanations they offered for why these stereotypes exist and how they influence women's and men's experiences with sex. As I anticipated, many young men pointed to physical explanations for men's interest in sex, suggesting that the immense hormonal surge during adolescence was responsible for men's aggressive pursuit of sex with any available partner. Both young women and men acknowledged the historical double standard by which society judges sexuality differently for women and men. Interestingly, the interaction of biology and the double standard is offered as an explanation for why women's sexual behavior is judged so much more harshly than men's. Because men are thought to be driven by their hormones (while women are not), women who are unwilling or unable to control their sexual behavior are judged to be weak in character or psychologically disturbed; men, on the other hand, are excused and even applauded for the same behavior.

Throughout my interviews my respondents made numerous references to society's construction of gendered sexuality. Though many expressed a general sense of injustice, only one respondent (a self-described feminist) offered any direct resistance to traditional gender norms. No other respondents suggested that gender roles should be changing faster than they are. It is unclear whether this comfort with the status quo is a function of my respondents' developmental stage or a reflection of their gender attitudes, but the fact remains that my sample appears both aware and relatively accepting of traditional gender norms. 


\section{Applicability of a Health Perspective}

One reason for continued high rates of adolescent sexual risk behavior in the face of near-universal exposure to school-based sex education may be that adolescents do not approach their decisions about sexual behavior from a health risk perspective. Perhaps adolescents do not place much stock in school-based sex education, failing either to remember or to incorporate messages about health risks into their behavior. A goal of this research is thus to determine whether the health risk perspective can reasonably be expected to influence adolescent sexual behavior.

School-Based Sex Education. Given that each of my respondents had been exposed to at least one school quarter of sex education, I sought to understand what adolescents had taken from their sex education experiences. Obviously sex education can only work to develop health beliefs when adolescents are paying attention, and my respondents indicate that this is not always the case. The majority of the respondents noted that males in particular did not appear to take sex education seriously. Many of the male respondents claimed that sex education, especially during middle school, was merely a joke and that they spent a considerable amount of class time giggling and chatting. Some suggested that the fact that sex education is commonly taught by physical education teachers reinforces the idea that sex education class need not be taken seriously. More alarming was the report of one male respondent, who claimed that male students were actively prevented from trying to learn:

What could have been included in your sex ed classes-what kind of stuff do you wish they'd talked about? 
I don't know. I think it's better on a personal basis, like if an adult is talking to you one on one, rather than in a group environment. Because in a group environment you're not totally focused. You're with your friends and everything. You're not trying to be like "Oh yeah," and then they'll call you a fag. I would have preferred it if it was one on one. (Brad, sexually active male)

This quote vividly illustrates the linkage between the appropriate performance of gender and sexuality. As the respondent makes clear, young men may be actively prevented from trying to learn the information necessary for the development of health beliefs associated with safer sexual behavior by their peers' use of a common yet powerful adolescent strategy, the accusation of homosexuality.

Another pervasive finding was the placement of healthy sexual decision making solely in the hands of women. Though this assignment of responsibility may relate to the greater physical risks women face due to pregnancy, respondents' recollections of the responsibility message suggest that it extends to all sexual decision making, not simply pregnancy prevention:

So in general, do you think that the sex ed you got in school was useful and realistic, based on what you know about how adolescents think about sex?

Not really. It's useful for the facts, but not for any decisions...you know what you said about it being equal? It was always presented as being more the girl's responsibility for getting pregnant and avoiding STDs and stuff. Even though it would be the guy that would wear the condom, it's the girl's responsibility to make sure he does. It was always presented that way. (Cara, sexually abstinent female)

The most startling theme that emerged through my interviews was adolescents' conceptualization of health. Put bluntly, health is fear; protecting one's health means being sufficiently afraid of negative health outcomes. This association emerged repeatedly, in adolescents' general definitions of sexual health and in their reports of what they learned in school based sex education. As one sexually abstinent male 
respondent stated, "I think they tried to scare the shit out of you so you didn't do it [have sex]."

Susceptibility and Severity. The Health Belief Model posits that an individual's behaviors result from their evaluation of health risks. The two health beliefs most closely aligned with perceptions of risk are susceptibility and severity, and these health beliefs play a significant role in sex education curricula. Indeed, many respondents reported that sex education focused almost entirely on facts about the risks associated with sexual behavior, to the exclusion of discussions of the social and emotional aspects of sexual decision making. All respondents agreed, however, that sex education seemed intent on developing these two risk-related health beliefs.

As might be expected, many adolescents ascribe to the "it can't happen to me" viewpoint on the potential outcomes of high risk behavior; this sense of invulnerability is consistent with adolescents' stage of emotional development (Crosby, 1996). Interestingly, adolescents acknowledge the implications of this attitude and seem to struggle to balance it with their perceptions of risk:

How susceptible, how at risk, do you think most adolescents feel to the risks of sex?

That's a tough question, because I think there's...it's kind of a double sided blade, because kids are aware that there's a lot of STDs out there and I know kids that have had STDs, I know kids that do have them. But at the same time a lot of kids think that it just won't happen to me. And I still kind of have that idea in my head too, but like I said I've had friends who have had them. I try to be as careful as possible, but I still kind of believe it's not going to happen to me. (Robbie, sexually active male) 
Regardless of how their sense of susceptibility enters into individuals' decision making processes, adolescents do acknowledge that as a group they are at significant risk for negative health outcomes, and that their risk is increasing as more of their peers are becoming sexually active:

How susceptible do you think that most adolescents feel to the risks of sex?

I think it's really grown in the last year with the surfacing of all these different diseases, just because they want to make sure that they're using the protection and everything. So I'd say that it's really gone up recently. I know that with my friends, the ones that are sexually active, they're always making sure that they have condoms on hand. I think they're really a lot more aware to what's going on and everything that could happen if they made a mistake. (Adam, sexually active male)

As noted earlier, responsibility for sexual decision making and the sense of susceptibility to negative health outcomes are highly related; as such, views about susceptibility tend to be linked to views on the role of women in sexual decision making. While adolescents may be technically correct in their belief that unplanned pregnancy is a negative health outcome to which only women are susceptible, this fails to explain why males are not believed to be susceptible to STDs:

I think that the girls value safe sex a lot more than guys do, 'cause obviously a guy can't get pregnant. Of course, the guy might have to pay for an abortion or pay child support if they have the kid, but he's not going to be the one sitting in the hospital bed, and guys don't think about that. I think for some reason guys think a lot less about getting STDs. I don't know why. But definitely the whole pregnancy thing...I've know guys who have gotten girls pregnant and they're like, "Yeah, I paid for an abortion, big deal." So I think that that's the main reason right there-girls don't want to get pregnant and guys don't care. (Micah, sexually active male)

If I was a girl I would be afraid about a baby. I don't think STDs are a huge factor right now, just because I personally haven't been exposed to anybody that has AIDS. (Dan, sexually active male) 
One potential explanation for high rates of sexual risk behavior among adolescents may derive from their beliefs on the severity of negative health outcomes. Much like susceptibility, severity seems to enter into decision making in a genderspecific way:

I think girls have to take into account that getting pregnant is their problem completely. It affects them a lot more than the man. So every time they do something they have to really take into account that if something goes wrong this is their kid and they don't know if the guy's going to be around or not. So that might be a reason for them to be more hesitant. But I think that also shapes guys' decisions because they don't have all that baggage and it's easier for them to get out of situations. The risk is not as much theirs as it is the girl's. (Doug, sexually active male)

\section{What are women's biggest concerns related to sex?}

I think I'm a lot more cautious [than men], just because I know, even though in terms of diseases men have risks too, but the fact about getting pregnant and especially at this time in my life, I'm going to college. That would put a big damper on my future if the baby were to come right now, so I think it's made me more cautious and more aware of the realities of it. (Nell, sexually active female)

Getting pregnant, 'cause at this age at least, girls don't want to get pregnant and ruin their lives. (Shannon, sexually active female)

Clearly, women's direct anatomical connection to pregnancy increases their perceptions of both their susceptibility to and the severity of unplanned pregnancy. As the respondent quoted above makes clear, men can quite literally escape the potentially severe consequences of an unplanned pregnancy The fact that women alone appear to incorporate the risk of pregnancy into their sexual decision making, however, may derive from gendered norms of sexuality. The traditional identification of women with the private sphere of home and family has come into conflict with women's increased 
educational and career aspirations, creating a sense of conflict within women that heightens their perceptions of severity.

Benefits and Barriers. A case can be made that the apparent relationship between health beliefs and gender is, in reality, a mere reflection of very real differences in reproductive biology; practically speaking, women are at sole risk for pregnancy and possibly at greater risk for STDs. When examining health beliefs related to the benefits of and barriers to preventive health behavior, however, it becomes clear that genderbased differences in these health beliefs derive from the social meanings attached to gender in our society.

It is also important to note that benefits and barriers often act in a reciprocal fashion, as a health belief associated with the benefits of risk prevention may also be viewed as an absence of barriers to preventive action. The relationship between benefits and barriers is further complicated by norms related to gendered sexuality; often, what is beneficial for women acts as a barrier for men and vice versa. It is thus in relation to benefits and barriers that the power of gender norms appears to have the greatest potential to modify the relationship between preventive sexual health beliefs and behaviors.

Throughout my interviews with adolescents, concerns about sexual reputation emerged repeatedly as a primary consideration in decisions about sexual behavior. All respondents, regardless of gender, sexual status, or religiosity, reported an intense concern with maintaining a positive reputation, though the definition of a positive sexual reputation is highly dependent on gender. For young women, a positive sexual reputation is based upon sexual relationships with a limited number of partners, always within the 
context of a committed, long term relationship. Young men, however, are actively encouraged by their peers to seek out sexual relations with numerous attractive women. Adolescents' evaluations of reputation thus serves as a powerful motivating force in their sexual decision making, with females seeking to limit their number of sexual partners (or at least to minimize public knowledge of their sexual relations). Males, on the other hand, strive to be known as highly sexually active. The concern for reputation is clear in a statement of one male respondent:

I think women are much more concerned about reputation, and with good reason. It's much more socially acceptable for guys to have more sexual partners and be more active than women. Everybody always says if guys have sex with five women, the guy is cool. But if women have sex with five guys, the woman is a whore. I think reputation is one of the biggest factors in sex, in the way you act. (Brad, sexually active male)

Though this statement underscores the power of normative views of gendered sexuality, this is not to suggest that adolescents blindly accept society's evaluations of women's and men's sexuality. When adolescents were asked to list the words they use to describe women and men who are sexually active, many expressed discomfort and a sense of injustice at their inability to identify a single negative term commonly applied to sexually active males. While all respondents noted "whore," "slut," and "easy" as terms used to describe sexually active women, "player" was the only term most had heard applied to males. More to the point, respondents agreed that "player" was most often used to praise a young man's sexual prowess, and also emphasized that "player" was never applied to women.

These divergent views on sexual reputations clearly indicate the modifying effect of gender in the relationship between the preventive health beliefs and behaviors of 
adolescents. For women, concerns about reputation act as a constraint on the number of sexual partners (a known risk factor), indicating that the desire to maintain a positive reputation operates as a benefit-related sexual health belief. Men's reputations, conversely, are enhanced by having numerous sexual partners, thus the quest for a positive reputation acts as a barrier to preventive health behavior.

Health beliefs associated with barriers also appear to be modified by adolescents' gendered experiences with peer pressure. Again, the traditional emphasis on high levels of male sexual activity seems to encourage young men to act in ways that put their health at risk, as my male respondents reported intense pressure to gain extensive sexual experience and a sense of personal failure when they fail to conform to this expectation:

If I don't have a girlfriend, or if I'm not with anyone, it bothers me because...the only reason it would bother me is because my friends would be like, if it's been a long time, people would say, "He has no game." But, I think it's mostly personal. (Dan, sexually active male)

Young men also reported exerting peer pressure on others, actively seeking to undermine the decisions made by friends:

Just for example, I have a friend who's real intact morally and he doesn't want to have sex. He's waiting for the right girl. And everyone just eggs him on, 'cause there's other girls that are around! And we're just like, "Get it out of the way, just do it! Who gives a shit?" So I guess like that, that's peer pressure. (Mark, sexually active male)

My respondents, both male and female, all suggested that men's decisions are more likely than women's to be shaped by gendered expectations. Young men's desire to perform sexuality in a gender-appropriate manner and thus to be viewed as "more manly" appears to be a crucial aspect in their sexual decision making. 
Finally, in order to assess directly the role of gender in sexual decision making, I presented my respondents with a scenario in which they were asked for their reaction to discovering a female friend was carrying condoms. Though the respondents consistently noted throughout the interviews that condoms are an effective means of reducing exposure to STDs and the potential for pregnancy, their responses to this hypothetical scenario point to very different social judgments passed on women and men who exhibit behavior acknowledged to be consistent with preventive health beliefs:

What if your female friend was carrying condoms?

Probably would be mixed thoughts of whether or not she's prepared or whether or not she's a slut and she's going to be having lots of sex so she always has to have condoms with her. I mean, you kind of have to evaluate the person's personality and know them well to know whether or not she's a smart person or whether she's a person who's wanting sex all the time. (Luke, sexually active male)

\section{What if it were a guy friend that had condoms?}

If it was a guy it would just be "just in case." He's probably just prepared, he's ready to go. Most guys, they're seen as ready and willing, so most guys put themselves in that place. (Luke, sexually active male)

\section{What if a female friend was carrying condoms?}

I wouldn't think any less of her. I mean, I guess depending on if she was in a serious relationship, then I wouldn't think anything of it. If she was a virgin who was a Christian who told me she wanted to wait to have sex until marriage and she was carrying around condoms then I might be a little puzzled and ask her about it. But I wouldn't really think that much of it. (Nell, sexually active female)

What if it was a guy friend who you saw had a bunch of condoms?

I wouldn't think anything of it. (Nell, sexually active female) 
What if your female friend had condoms? What would your reaction be?

Where the hell has she been-I wonder why she has all these condoms? (Mark, sexually active male)

What would your reaction be if a guy friend was carrying condoms?

That a boy! (Mark, sexually active male)

While the reactions to my hypothetical situations may have been somewhat facetious, I believe these reactions are telling. Throughout the interviews my respondents expressed their intense desire to "fit in" with their peers by not calling undue attention to themselves through atypical behavior, especially behavior atypical for their gender. The adolescents repeatedly stressed the importance of acceptance by their peers in their decision making. While not directly assessable through these data, this concern suggests that young women might be less likely to carry condoms, even if they possess the preventive health beliefs that lead them to believe the use of condoms would help them to avoid health risks. In short, though adolescents (in this case female adolescents) may have preventive health beliefs, society's expectations regarding appropriate gender behavior may reduce the likelihood that they will undertake preventive health behaviors. In this sense, gendered sexuality operates as a mediating factor between health beliefs and behaviors.

\section{Sources of Information about Sex}

I began each interview by asking the respondents to make a list of all of the sources on which they rely for information about sex. As might be expected, 22 of the 25 respondents reported that they rely on friends for information about sex, followed by 20 
respondents who mentioned television programs and movies as important sources. School-based sex education and family (including parents and siblings) tied with 19 mentions each. This is somewhat surprising, given that all respondents reported having experienced school-based sex education while fewer than half reported that they had discussed sexual issues with their parents. The fact that friends and the media are the top sources of information is revealing, however, lending support to the contention that cultural messages about sexuality are highly influential in the decisions adolescents make about sex.

Discussion with Parents. My findings on discussions with parents are somewhat counter-intuitive. Considerably more young men reported having discussed sex with their parents; ten had spoken with their father about sex, and nine had discussed sex with their mother. Only seven young women reported having spoken with their mother, and only one had talked with her father. Moreover, young women were much more likely to not have discussed sex at all with their parents; five young women reported no discussions while only two young men had not discussed sex with a parent. There were no apparent gender differences in whether discussing sex with a parent was considered uncomfortable, as about half of my respondents reported that it was.

I was surprised to find that the content of parent/child discussions about sex were not as dependent on gender as I had expected. Though several of the young men reported that their parents had purchased condoms for them and many of the young women noted that their parents encouraged them to abstain from sex, the only real difference noted by my respondents was the seriousness with which parents discussed sex. Most young men 
reported that parents had joked with them, while none of my female respondents recalled joking with parents about sex. This suggests that although the content of discussions may be the same for young women and men, the nature of parent/child discussions reinforces traditionally gendered sexuality. The seriousness, and thus the responsibility, for sex is placed in the hands of young women, while young men are allowed and even encouraged to treat sexual relationships lightly. As one male respondent noted, his mother's favorite statement regarding his sexual behavior is, "Dammit, Corey, all I want is no grandchildren before you get out of college. That's all I want!" (Corey, sexually active male)

Media Messages. Research indicates that adolescents spend approximately half of their waking hours using some form of media (television, video games, music, etc.); the reports of my respondents are consistent with these findings. Regardless of their media exposure, the adolescents in my study believe themselves to be critical media users. Many suggested that although the media had shaped their initial views on gender and sexuality when they were younger, their ability to differentiate between media representations and reality had increased as they grew older. My respondents noted the tendency of television programming and movies to exaggerate romantic and sexual relationships for dramatic effect, and they also recognized the use of sex as a marketing device. In general, most seemed resigned to the role of media in their lives, as one respondent's statement on media influences illustrates:

I think whether or not anyone likes it your views on sex are going to definitely be shaped by the media. You watch TV and movies and listen to the radio every day, so I think it's almost like that's...not idolized, but your picture of the way 
other peoples' lives revolve around sex and stuff. Even though you know it's not reality, sometimes you wish it would be reality. It definitely molds your views on sex...it definitely has an impact. (Kelly, sexually active female)

Many of my respondents also reported having seen programming specifically developed to inform adolescents of the risks of sexual behavior. Many referred to “MTV's First National Sex Quiz" as a particularly informative source, noting that the program reminded them of many of the specific facts regarding sexually transmitted infections that they had forgotten since their last school-based sex education class. They also noted many programs that depict the risks of adolescent sexual behavior in a manner they felt was unrealistic and even comical. Describing how peer pressure really works, one respondent noted that the reality is nothing like the after-school specials in which a group of peers at a party states, "Have sex or we'll kill you!" Though obviously said in jest, this recollection indicates that adolescents' experiences with sex are often quite different from the depictions seen on television.

\section{Conclusions}

The results presented in this chapter are not generalizable to any population of adolescents; indeed, the conclusions I draw are not even applicable to every respondent in my sample. Though the adolescents I interviewed share many demographic commonalities, there is certainly variation in their health beliefs and behaviors, in their degree of acceptance of traditional norms of gendered sexuality, and in the very processes through which they make decisions about sexual risk behavior. The goal of this qualitative component of my research was not to offer a single vision of adolescent 
sexual decision making, but rather to expand the discussion of sexual risk behavior by examining the three general topics noted above. From this examination I have developed a number of hypotheses that will be addressed in the statistical analysis presented in subsequent chapters.

The first goal of my qualitative analysis sought to establish a general sense of adolescents' knowledge and acceptance of traditional gender norms, and my analysis of the interviews reveals that the adolescents in my sample are aware of traditional norms regarding gender. Moreover, my adolescent respondents appear to link experiences with sexuality with the appropriate performance of gender, confirming my belief that gender norms should be included in models used to study adolescent sexual decision making.

The second portion of my qualitative analysis focused on a series of questions concerning health, gender, and the Health Belief Model. First, adolescents are aware that decisions about sexual behavior have direct implications for their health. Though their recollection of the specifics of their school-based sex education was limited, my respondents have clearly incorporated the general risks of STDs and unplanned pregnancy into their knowledge of sexual health. The fact that adolescents associated the health information they received in sex education primarily with fear of negative health outcomes may be cause for concern, as there may be a point at which this fear overwhelms the ability of preventive sexual health beliefs to shape behavior. Additional examination of the role of fear in decision making is thus necessary to find the balance between an appreciation of risks and the paralysis that may result when fear predominates. 
The second and third questions related to adolescents' possession of the sexual health beliefs associated with safer sex practices. The results here are somewhat mixed, as adolescents' perceptions of the appropriate performance of gender seems to heavily influence health beliefs. Though all adolescents appreciate their susceptibility to negative health outcomes in theory, this does not always translate into individual action. Young men in particular seem to have difficulty transforming belief into action; this may be a result of men's limited social responsibility for negative sexual health outcomes and their lack of connection to the severity of unplanned pregnancies.

The social considerations related to reputation and peer pressure represent the more troubling aspects of the interaction of gendered sexuality with preventive health beliefs. Although the desire to maintain a positive sexual reputation acts to reduce young women's exposure to health risks, it does so by limiting their ability to experience their sexuality free from social constraints. In a similar way, pressure from peers pushes young men to seek out sexual experiences that may be emotionally and psychologically unsatisfying, in addition to presenting an increased risk of negative health outcomes. Both reputation and peer pressure work to undermine adolescents' sense of empowerment and control over their sexuality. It may therefore be that what is commonly viewed as negative health decisions are in reality not decisions at all, but unconscious adherence to society's expectations regarding adolescent sexual behavior.

Last, I examined the four sources of information on sex that will be treated as "cues to action" in my statistical model. The purpose of these questions was to determine which sources adolescents draw on most, and also to consider the content of these sources. As noted earlier, information regarding sex and sexual decision making can be 
divided into two broad categories akin to the formal and hidden curricula in education. It seems clear that school-based sex education is the most common source of factual, formal information, though specific television programs also provide such information from time to time. Peers and other media sources serve as informal sources, providing adolescents with subtle, even hidden, messages about what is appropriate behavior for women and men in sexual situations. My analysis suggests that although adolescents are aware that these sources contain messages regarding gender and sex, there have been only limited attempts to challenge these norms. I therefore believe my contention that norms of gender shape adolescents' sexual decisions to be supported by my data and should be included in my statistical models. 


\section{CHAPTER FIVE: Quantitative Data and Methods}

The qualitative analysis reported in the previous chapter suggests that both health beliefs and gender ideals shape the decisions of adolescents regarding their sexual behavior. It is not possible to determine, however, the relative influence or possible interactions of health beliefs and gender ideals based on the qualitative analysis alone. This chapter introduces the statistical analyses that will provide a clearer picture of adolescent sexual decision making, describes the measures to be used, the conceptual model, and the hypotheses I will test empirically in subsequent chapters.

\section{Background on the National Longitudinal Study of Adolescent Health}

The National Longitudinal Study of Adolescent Health (commonly known as the AddHealth Study) is the most comprehensive nationally-representative study of adolescent health to date. Data collection began in September of the 1994-5 school year, at which time the sampled adolescents were enrolled in grades 7 through 12 . The adolescents were re-interviewed in 1996, and in 2000 the respondents were followed as they entered young adulthood. Because data collection for the study is on-going, access to the data is highly regulated. Permission was obtained from the Carolina Population Center (CPC) to analyze the complete data set, which includes all adolescent respondents as well as numerous contextual variables created by researchers at the $\mathrm{CPC}$ (Bearman, Jones, and Udry, 1997). 
There are a number of reasons I chose to use the AddHealth Study for my examination of adolescent sexual decision making. First, the complex sampling design employed in the AddHealth Study results in a sample that is truly representative of the United States' population of adolescents who were enrolled in school during the 1994-5 school year. A stratified, random sample of 80 high schools and 52 middle schools was sorted into clusters based on region, urbanicity, size, type (public or private), racial composition, and grade span. All adolescents who were in attendance on the day of the survey (and who were not opted out of survey participation by their parent/guardian) completed the In-School Questionnaire (Bearman, Jones, and Udry, 1997).

The AddHealth Study is innovative in terms of the breadth of topics covered. Recognizing the embeddedness of adolescent health, the study gathers extensive information on the contexts in which adolescents live, including the family, peer groups, dyadic relationships, schools, and neighborhoods. Moreover, the study includes measures of countless health-related attitudes and behaviors, ranging from crime, violence, sexual relationships, depression, and nutrition. Such varied measures allow for multiple levels of analysis and the use of sophisticated statistical methods. The AddHealth Study is one of the most highly-regarded data collection efforts in recent years, representing the cutting edge of public health research.

Another strength of the AddHealth Study is the numerous sources from which it collects data about the schools and adolescents included in the sample. In addition to the In-School Questionnaire completed by the sampled adolescents, a subsample of approximately 22,000 adolescents was selected to complete an In-Home Questionnaire in Wave 1. Many sections of this questionnaire were administered using laptop computers 
equipped with audio computer-assisted self-interviewing software; the use of selfadministered questionnaires is believed to reduce the impact of social desirability bias in the reporting of sensitive information (Tourangeau and Smith, 1996). A follow-up InHome Questionnaire (Wave 2) was administered to the same subsample of adolescents one year after the original data collection. Administrators from the sampled schools also completed questionnaires providing detailed information about the sampled schools. Lastly, each subsampled adolescent's primary female care-giver (usually the mother or step-mother) completed a Parent Questionnaire to provide information about the adolescent's home life and health status. My analyses employ Wave 1 of the In-Home questionnaire, which is comprised of data collected directly from adolescents during 1995. The final sample includes the 18,924 adolescents who responded to the In-Home Questionnaire. $^{11}$

\section{Measures}

Following is a brief description of the coding of all variables included in my statistical models. Because the Health Belief Model predicts that preventive health beliefs will have a positive effect on health behaviors, I have coded each variable to reflect this directional relationship. For continuous variables, higher values indicate greater support for preventive health beliefs. In the case of dummy variables, the category included in the model represents the category associated with preventive health beliefs. This coding scheme aids in the interpretation of coefficients and odds-ratios, as

\footnotetext{
${ }^{11}$ Many respondents drop out of the logistic regression analyses due to missing data; specifically, many of the measures included in the models were only asked of adolescents aged 15 or older.
} 
positive signs and odds-ratios greater than one are associated with a reduced likelihood of engaging in sexual risk behaviors.

Demographic Characteristics. Several demographic controls are entered into the models to examine differences in social location. These background variables are included in recognition of consistent demographic differences in sexual health behavior, though the focus of this work will be solely on gender-based differences. Mother's education is used as a proxy for socioeconomic status; high school graduation (including GED) or less is the omitted category while individuals with at least some education beyond high school (either vocational training or college) are combined into a single category which is included in the model. ${ }^{12}$ Race/ethnicity is recoded so that each respondent is assigned to only one category: African American, Asian, European American, Hispanic, or Other Race/Ethnicity. Dummy variables are created for each of these categories, with European American serving as the reference category in the model. Age at the time of the in-home interview is collapsed into five discrete categories raging from 15 years 11 months or less to 19 years or more.

Health Belief Model. This block includes the seven variables which operationalize the four theoretical constructs on which the model is based; Table 5.1 provides the exact question wording for each variable. Susceptibility is measured by the respondent's belief that they are at risk for pregnancy (or for impregnating their parmer for male

\footnotetext{
${ }^{12}$ The decision to split educational attainment in this manner was based on the results of the crosstabulation of education with receipt of public assistance, another common indicator of socioeconomic status.
} 
respondents) or at risk for $\mathrm{HIV}$ infection. The severity of unplanned pregnancy is captured by agreement with the statement that now would be the worst time for an unplanned pregnancy, while views on the severity of HIV infection are measured with the statement that AIDS causes great suffering. The benefits scale is comprised of five variables, all of which relate to reasons why the respondent might seek to avoid an unplanned pregnancy (i.e., pregnancy would embarrass the family). Each of the original variables is measured on a 5-point scale ranging from strongly agree to strongly disagree, resulting in a scale with a potential range of 5 to $25 .^{13}$ Finally, two self-efficacy barriers are included, representing the respondent's evaluation of the difficulty of using birth control and their belief that they would be able to demand the use birth control once they had become sexually aroused.

Cues to Action. The literature on adolescent sexual decision making notes four key sources on which adolescents rely for information about sex; these sources are included in this block of variables. School-based sex education includes whether the respondent recalls being taught about pregnancy and HIV/AIDS. The number of hours spent watching television in the past week is an indicator of media exposure. Separate measures are used for quality of communication with parent(s), while another variable captures adolescents' evaluation of how their parents feel about their sexual activity. Lastly, the influence of peers is captured by adolescents' reports that they recently discussed personal problems with their closest female and male friend.

\footnotetext{
${ }^{13}$ The Cronbach's alpha coefficient (a measure of internal reliability) for this scale is .73 , indicating a moderately strong correlation between the variables included in the scale.
} 
Gender Ideals. There are few variables that directly address the dimensions of gendered sexuality that emerged through my interviews with adolescents. One variable which captures a gendered-based difference in orientation toward sexual activity asks respondents to report whether members of the opposite sex would find the respondent more attractive if they were known to be sexually active. This variable taps into concerns about peers and reputation, both of which my qualitative research showed to be highly linked to gender. The other variable used to represent gender ideals is a measure of whether the respondent reports that their peers will respect them more if they are known to be sexually active. Both of these variables act as indicators of gender ideals in that they are likely to operate differently for female and male respondents due to the normative performance of gendered sexuality. Young men may be rewarded for their public displays of sexuality, though young women are likely to perceive that public knowledge of their sexual behavior will be harshly judged. Bivariate analysis of each variable by gender bears this assumption out. While 62 percent of females disagree that they would be more respected by peers if known to be sexually active, only 38 percent of males rejected this statement. Similarly, 60 percent of females rejected the statement that being sexually active would make them more attractive to boys, while 60 percent of males agreed with the statement, reporting that being sexually active would make them more appealing to girls. 
Table 5.1 Question Wording for All Measures Included in the Analysis

\begin{tabular}{|c|c|}
\hline Predictor & AddHealth Question Wording \\
\hline Risk of Pregnancy & $\begin{array}{l}\text { Imagine that sometime soon you were to have sexual } \\
\text { intercourse with someone just once, but were unable } \\
\text { to use any method of birth control for some reason. } \\
\text { What is the chance that you/your partner would get } \\
\text { pregnant? }\end{array}$ \\
\hline Risk of AIDS & $\begin{array}{l}\text { Suppose that sometime soon you had sexual } \\
\text { intercourse for a whole month, as often as you wanted } \\
\text { to, without using any protection. What are the } \\
\text { chances that you would get the AIDS virus? }\end{array}$ \\
\hline Now Worst Time for Pregnancy & $\begin{array}{l}\text { Getting (someone) pregnant at this time in your life is } \\
\text { one of the worst things that could happen to you. }\end{array}$ \\
\hline AIDS Causes Suffering & $\begin{array}{l}\text { If you got the AIDS virus you would suffer a great } \\
\text { deal. }\end{array}$ \\
\hline $\begin{array}{l}\text { Benefits of Avoiding Pregnancy } \\
\text { (scale) }\end{array}$ & $\begin{array}{l}\text { If you got (somebody) pregnant, it would be } \\
\text { embarrassing for your family. } \\
\text { If you got (somebody) pregnant, it would be } \\
\text { embarrassing for you. } \\
\text { If you got (someone) pregnant, you would have to quit } \\
\text { school. } \\
\text { If you got (someone) pregnant, you might marry the } \\
\text { wrong person, just to get married. } \\
\text { If you got (someone) pregnant, you would be forced to } \\
\text { grow up too fast. }\end{array}$ \\
\hline $\begin{array}{l}\text { Birth Control Is Not Too } \\
\text { Difficult to Use }\end{array}$ & $\begin{array}{l}\text { In general, birth control is too much of a hassle to } \\
\text { use. }\end{array}$ \\
\hline $\begin{array}{l}\text { Able to Refuse Sex if No Birth } \\
\text { Control }\end{array}$ & $\begin{array}{l}\text { If you wanted to use birth control, how sure are you } \\
\text { that you could stop yourself and use birth control } \\
\text { once you were highly aroused or turned on? }\end{array}$ \\
\hline $\begin{array}{l}\text { Learned about Pregnancy in } \\
\text { School }\end{array}$ & $\begin{array}{l}\text { Have you learned about this in a class at school: } \\
\text { pregnancy? }\end{array}$ \\
\hline Learned about AIDS in School & $\begin{array}{l}\text { Have you learned about this in a class at school: } \\
\text { AIDS? }\end{array}$ \\
\hline Hours of TV Watched per Week & How many hours a week do you watch television? \\
\hline
\end{tabular}




\begin{tabular}{l|l}
\hline $\begin{array}{l}\text { Discussed Problems with Female } \\
\text { Friend }\end{array}$ & $\begin{array}{l}\text { Did you talk to \{closest female friend\} about a } \\
\text { problem during the past seven days? }\end{array}$ \\
$\begin{array}{l}\text { Discussed Problems with Male } \\
\text { Friend }\end{array}$ & $\begin{array}{l}\text { Did you talk to \{closest male friend\} about a problem } \\
\text { during the past seven days? }\end{array}$ \\
$\begin{array}{l}\text { Good Communication with } \\
\text { Parent }\end{array}$ & $\begin{array}{l}\text { You are satisfied with the way you and your } \\
\text { mother/father communicate. }\end{array}$ \\
$\begin{array}{l}\text { Parent Disapproves of } \\
\text { Adolescent Sex }\end{array}$ & $\begin{array}{l}\text { How would \{your parent\} feel about your having sex } \\
\text { at this time in your life? }\end{array}$ \\
$\begin{array}{l}\text { More Attractive to Opposite Sex } \\
\text { if Known to be Sexually Active }\end{array}$ & $\begin{array}{l}\text { If you had sexual intercourse, it would make you more } \\
\text { attractive to women/men. }\end{array}$ \\
$\begin{array}{l}\text { More Respected by Opposite } \\
\text { Active }\end{array}$ & $\begin{array}{l}\text { If you had sexual intercourse, your friends would } \\
\text { respect you more. }\end{array}$ \\
\hline
\end{tabular}

\begin{tabular}{l|l}
\hline Outcomes & AddHealth Question Wording \\
\hline $\begin{array}{l}\text { Ever Had Heterosexual } \\
\text { Intercourse }\end{array}$ & $\begin{array}{l}\text { Have you ever had sexual intercourse? When we say } \\
\text { sexual intercourse, we mean when a male inserts his } \\
\text { penis into a female's vagina. }\end{array}$ \\
$\begin{array}{l}\text { Used Birth Control at First } \\
\text { Intercourse }\end{array}$ & $\begin{array}{l}\text { Did you or your partner use any method of birth } \\
\text { control the first time you had sexual intercourse? }\end{array}$ \\
$\begin{array}{l}\text { Used Birth Control at Most } \\
\text { Recent Intercourse }\end{array}$ & $\begin{array}{l}\text { Did you or your partner use any method of birth } \\
\text { control when you had sexual intercourse most } \\
\text { recently? }\end{array}$ \\
Intercourse & $\begin{array}{l}\text { Not counting the people you have described as } \\
\text { romantic relationships, have you ever had a sexual } \\
\text { relationship with anyone? }\end{array}$ \\
\hline
\end{tabular}




\section{Descriptive Statistics}

Before moving to a discussion of the full multiple regression models in the following chapters, it is useful to consider the univariate and bivariate relationships between gender and each of the predictor variables. In order to reflect the United States' population of adolescents enrolled in school during the 1994-5 school year, all results are weighted using the weight variable constructed by the AddHealth team at the Carolina Population Center. This weight variable is designed to adjust for the oversampling of certain subpopulations, the inclusion of genetic pairs (including twins and siblings), and the saturation sampling of several high schools. Cases with missing weights are eliminated from the analysis, resulting in a total sample of 18,924 adolescent respondents. $^{14}$

\begin{tabular}{lcc} 
Table 5.1 Descriptive Statistics, AddHealth Study Complete Contractual Data* \\
\hline \multicolumn{1}{c}{ N } & $\%$ \\
\hline Sex & 9287 & 49.1 \\
Female & 9637 & 50.9 \\
Male & & \\
& & \\
Mother's Education & 9151 & 54.5 \\
High School or Less & 7624 & 45.5 \\
More than High School & 2149 & $\mathrm{NA}$ \\
(Missing cases) & \\
& & \\
Race/Ethnicity & 2832 & 15.0 \\
African American & 629 & 3.3 \\
Asian & 12221 & 64.6 \\
European American & 1017 & 5.4 \\
Hispanic & 2225 & 11.7 \\
Other Race/Ethnicity & \\
& 18924 & 100.0 \\
Total Sample & \\
\hline Results are weighted to reflect the US population of adolescents in $1994-5$. & \\
\hline
\end{tabular}

\footnotetext{
${ }^{14}$ I normalized the sample weights so that the sample sizes reported in my results would equal the actual sample size of 18,924 .
} 
Table 5.1 presents the distribution of the sample by basic demographic characteristics. The table reveals that the proportion of females and males in the sample is virtually equal. A small majority of adolescents report that their mother's education is high school or less, resulting in a sample that is slightly skewed toward adolescents of lower socioeconomic status. It is important to note that just over 11 percent of adolescents failed to report their mother's educational attainment; these adolescents are excluded from all further analyses. ${ }^{15}$ Almost two-thirds of adolescents report being of European (e.g., white or Caucasian) descent, followed by 15 percent who claim African American as their primary race. Hispanics and Asians both represent only small portions of the sample, though their numbers are sufficient for inclusion in the analyses. Finally, 11.7 percent of respondents could not be classified into the four preceding categories, resulting in their being assigned to the "Other" race/ethnicity group. As this group is a residual category comprised of individuals from a variety of backgrounds, I omit them in the following statistical analyses.

\section{Multivariate Model}

The purpose of the statistical analyses in the following three chapters is to apply the Health Belief Model to the sexual decision making of adolescents. Based on an extensive review of the literature and the results of my qualitative interviews, however, I argue that the Health Belief Model may need to be modified in order to more accurately reflect the cultural context in which decisions about sexuality occur. I therefore develop

\footnotetext{
${ }^{15}$ The missing values for father's education was even higher, approximately one third of the total sample. My decision to use only mother's education reflects my concern regarding the potential bias introduced by including only those cases with valid responses for both mother's and father's education, which would effectively eliminate adolescents not living in two-parent households.
} 
a series of nested models to compare the explanatory power of the simple Health Belief Model with several more complex operationalizations of the relationship between gender, health beliefs, cues to action, and gender ideals in predicting various preventive health behaviors. Figure 5.1 depicts the complete theoretical model, portions of which are operationalized by the addition of each block of variables in the nested models:

Figure 5.1—Modified Health Belief Model

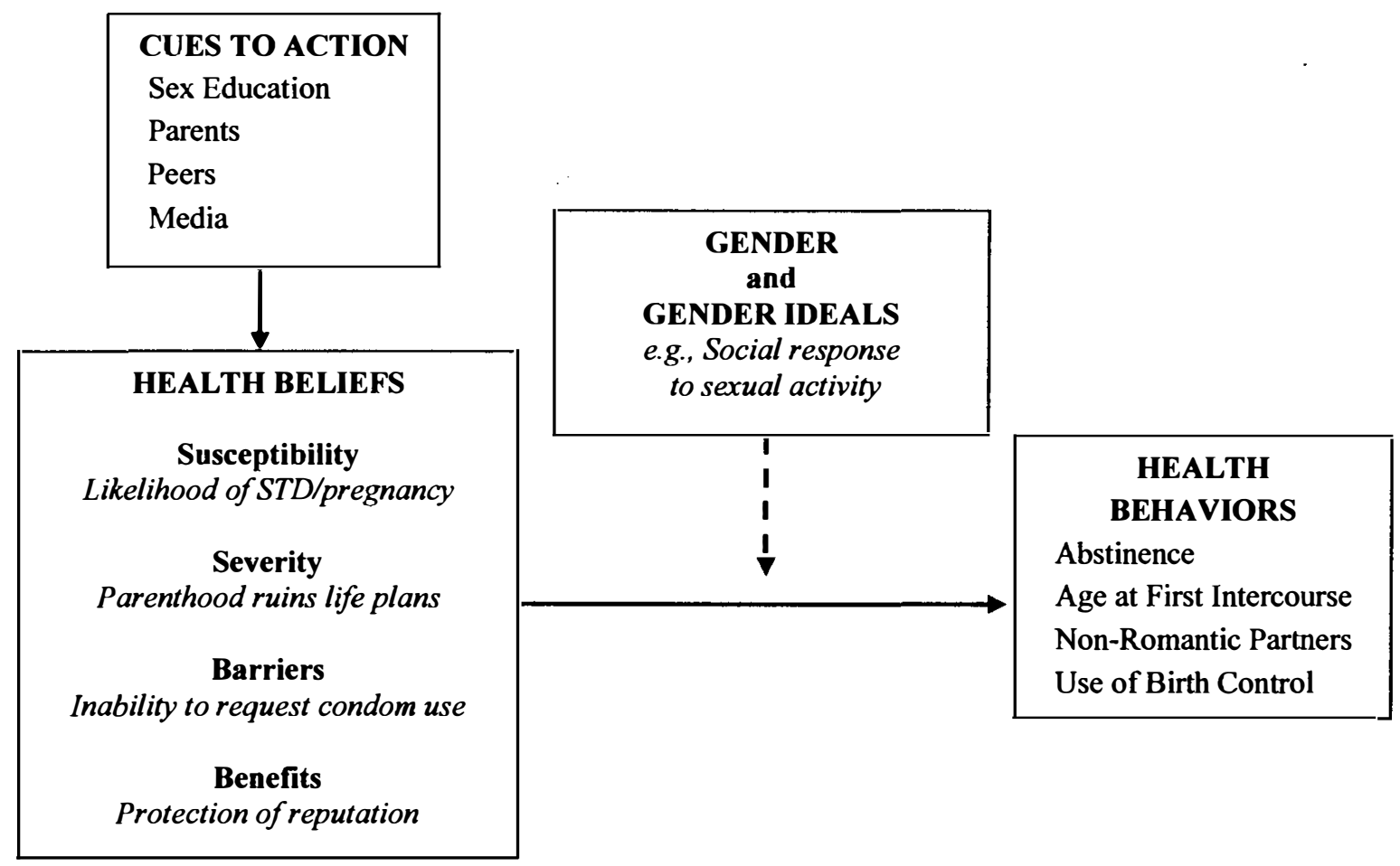

Following is a brief discussion of the development of the models, as well as the general hypotheses I will test at each stage. Given the potential for gender differences in each of the predictor variables, I interact gender with all variables in the models. Though this results in large and somewhat unwieldy models, it allows for a direct comparison of 
the magnitude of the coefficients for females and males while also providing a measure of the statistical significance of gender differences. Demographic characteristics are included in each nested model to control for known demographic differences in the average values of the outcome variables.

The first reduced model represents the traditional Health Belief Model and includes only the seven variables used to operationalize the four health belief constructs-susceptibility, severity, barriers, and benefits-hypothesized to influence preventive health behaviors. The purpose of this first model is to establish the applicability of a health belief approach to adolescent sexual decision making, testing the general hypothesis that the variables included in the Health Belief Model will be significant predictors of the adolescent sexual behaviors of interest; namely, the probability of being sexually abstinent, the probability of not engaging in non-romantic (casual) sexual relationships, and the probability of using birth control.

The second reduced model adds all demographic characteristics (gender, race/ethnicity, socioeconomic status, and age) as well as interaction terms created by multiplying the gender variable by each of the health beliefs. These interaction terms represent the unique effect of the health belief variables for females, while the main effect health belief variables represent the effects for males (given that males are coded as zero and females coded as one). My interviews with adolescents point to significant gender variations in these health beliefs, suggesting that susceptibility, severity, and benefits will be strong predictors of young women's behaviors, while barriers will be the strongest influence on young men's sexual health behaviors. Finding significant interaction terms in this model would provide evidence for my contention that the Health 
Belief Model is modified in important ways by gender, requiring that gender interactions be included in all subsequent models.

In Models 3 through 6 I sequentially add the cues to action (parents, peers, sex education, and exposure to media) to the health beliefs and demographic characteristics already in the model. These cues to action act as mechanisms through which norms of gendered sexuality are transmitted to adolescents; as such, I expect that they will operate differently for young women and men. Based on the findings from my qualitative analysis, I hypothesize that discussions with parents and exposure to school-based sex education will be most predictive of young women's preventive health behaviors, while interaction with peers and exposure to media will be most predictive of young men's preventive health behaviors. Model 7 enters all of the cues to action at once, allowing an examination of the relative influence of each block of variables.

Finally, Model 8 introduces the two measures representing gender ideals. This model will allow a comparison of the magnitude of the effects for health beliefs and gender ideals. Conceiving of health beliefs and gender ideals as competing forces suggests that these two influences must be "balanced" by adolescents as they make decisions about their sexual behavior. I predict that both health beliefs and gender ideals will be significant predictors of young women's preventive health behaviors, while health beliefs will not be significant predictors of young men's preventive health behaviors once gender ideals are entered into the model.

There are a number of outcome variables in the AddHealth Study that are appropriate for analysis using the model specified above. Because these variables are dichotomous (representing either occurrence or non-occurrence of a given event), the 
most appropriate inferential technique for this study is logistic regression analysis. Based on the logit transformation (an S-shaped distribution), logistic regression employs maximum likelihood estimation to produce the set of parameter estimates which best fit the sample data (Pampel, 2000). I interpret the logit coefficients, which represent the direction and magnitude of the change in the logged odds of the outcome variable for every one unit change of the indicator variable. In the case of dummy indicator variables, the logit coefficients simply represent the difference in the logged odds of the outcome variable for each category of the dummy variable included in the model, compared against the omitted reference category.

The fit of a logistic regression model is commonly assessed by comparing the -2 log likelihood (a logged ransformation of the likelihood that the sample data would be observed given the parameter estimates) of the baseline model (in which all parameters are set equal to zero) to that of the model under consideration; this is analogous to the $F$ statistic comparing the full and reduced models in OLS regression. There are a number of ratios of the baseline and model $-2 \log$ likelihood that can be interpreted in a manner similar to $\mathrm{R}^{2}$ in OLS regression; though dichotomous dependent variables do not have "variance" in the same way as continuous variables in OLS regression, the pseudo- $\mathrm{R}^{2}$ values calculated using the $-2 \log$ likelihood in logistic regression speak to the reduction in prediction error in a similar way.

I have chosen the outcome variables representing the preventive health behaviors which occur most frequently in the literature. These outcomes, or sexual decisions, are roughly analogous to the considerations adolescents reported making in the qualitative interviews, namely: when to have sex, with whom, and how (safe or unprotected). 
Chapter Six addresses the question of when to have sex, using logistic regression to predict the probability of never having engaged in voluntary heterosexual intercourse. ${ }^{16}$ Remaining sexually abstinent is universally acknowledged to be the single most effective way to prevent pregnancy and the transmission of sexually transmitted infections; as such, abstinence can be considered a preventive health behavior. ${ }^{17}$ In Chapter Seven I employ Kaplan-Meier analysis to examine respondents' average age (in months) at first voluntary heterosexual intercourse and Cox proportional hazards models to examine the age at transition to sexual intercourse. Previous research indicates that younger adolescents are at significantly greater risk from sexual behavior than their older counterparts, due to their limited use of condoms or other contraceptives (O'Donnell, O'Donnell, and Stueve, 2001).

Chapter Eight examines the question of with whom adolescents have sex, using logistic regression to predict the probability that a respondent reports having engaged in "non-romantic" sexual intercourse; that is, intercourse with someone who is not acknowledged to be a steady or committed partner. Although romantic involvement with a partner does not guarantee safer sex practices, adolescents are much more likely to take risks in non-committed sexual relationships (Levinson, Jaccard, and Beamer 1995). Finally, in Chapter Nine I address the use of birth control, both at first sexual intercourse and at the most recent sexual intercourse.

\footnotetext{
${ }^{16}$ As with the indicator variables, all outcomes are coded so that the positive (or healthy) sexual behavior is modeled.

${ }^{17}$ Though it is not possible to determine whether the decision to remain sexually abstinent derives directly from a desire to avoid negative health outcomes, the end result is the same.
} 


\section{CHAPTER SIX: Sexual Abstinence as a Preventive Health Behavior}

From a health perspective, the benefits of abstinence from heterosexual vaginal intercourse are clear. Sexually active adolescents are at risk for a variety of potentially serious sexually transmitted diseases, including HIV. Indeed, recent estimates reveal that adolescents and young adults continue to be at an especially high risk for STDs, including chlamydia and gonorrhea. More alarmingly, though HIV infection among adults has been declining, young people's rates of HIV infection have remained constant in recent years (CDC 2002). In addition, adolescent girls face the possibility of unintended pregnancy as a result of heterosexual intercourse. Given that the forms of contraception/disease prevention most commonly employed by adolescents (i.e., the birth control pill and condoms) are far from fool-proof, abstinence truly is, as advocates of abstinence-only sex education would attest, the only 100 percent effective means of avoiding STDs and unintended pregnancy (Santelli et al., 1997). ${ }^{18}$ This is especially true given that adolescents often fail to use birth control pills and condoms properly and consistently; the user-failure rates for adolescents are consistently higher compared to other populations (Fu et al., 1999).

Of course, all individuals face some risk of STDs or unintended pregnancy as a result of heterosexual intercourse. In some ways, adolescents may actually be at decreased risk, given that many adolescents first enter into sexual relationships with

\footnotetext{
${ }^{18}$ Although there are scattered reports of women becoming pregnant through an exchange of body fluids without vaginal penetration, this is exceedingly rare. Of greater concern is the potential for STD transmission through skin-to-skin contact; it is widely acknowledged that HPV, for instance, can be spread without virginal penetration.
} 
partners who are also virgins (reducing potential exposure to STDs) and the fact that younger female adolescents may not have reached menarche or may ovulate irregularly (reducing the probability of pregnancy). Regardless of the actual health risks adolescents face as a result of sexual activity, however, the public perception of adolescent sexuality focuses almost exclusively on the negative consequences of adolescent sexuality.

\section{History of Adolescent Sex and Abstinence}

Though the visibility of adolescent sexuality reached new heights in the last decades of the $20^{\text {th }}$ century, there is no denying that adolescents have been sexually active throughout history. In truth, it is only society's willingness to openly acknowledge adolescent sexuality that has changed over time. Numerous examples exist which point to the intricate balance between grudging acceptance of adolescent sexuality and the need to control the possible outcomes of early sexual activity, namely pregnancy outside of marriage. $^{19}$

Perhaps the most fascinating historical example of culturally-sanctioned adolescent sexual exploration was the practice of "bundling," in which a young woman and a young man spent the evening together in bed (sometimes separated by a board between them and fully clothed, but often not). This practice of bundling, brought to the United States by German immigrants, was common and accepted throughout American history from colonial times through the introduction of the automobile, which provided adolescents with greater privacy for intimate activities (Hine, 1999). Bundling was

\footnotetext{
${ }^{19}$ Though teenage parenthood has declined in recent decades (due to increased availability of hormonal contraceptives, condoms, and legal abortion), the United States continues to have one of the highest rates of teen pregnancy in the developed world (Singh and Darroch, 2000).
} 
viewed as a legitimate outlet for young people's curiosity and a necessary precursor for those adolescent couples seriously considering marriage, though pregnancies resulting from bundling were considered scandalous and often resulted in excommunication from the church and community.

Throughout the $20^{\text {th }}$ century, pregnancies resulting from premarital adolescent sexuality were actively disguised, at least among middle- and upper-class adolescent girls of European descent (Solinger, 2000). Adolescent girls who "got themselves in trouble" were often sent away to homes for unwed mothers before their pregnancy began to show and returned after placing the baby up for adoption, often with the excuse of having been studying abroad or visiting distant relatives. It must be noted that this face-saving option was usually not available to poor and minority adolescents, contributing to the popular perception that these young women were significantly more sexually active than their more affluent European-American counterparts. This exaggerated fear of young minority and poor women's sexuality contributed to on-going efforts to regulate childbearing by these women, resulting in numerous instances of forced sterilization and compulsory contraceptive use throughout the $20^{\text {th }}$ century (Roberts, 1997).

The 1960s and 1970s saw a number of dramatic policy changes aimed ostensibly at providing women greater control over their own fertility (though many programs continued to focus on reducing the fertility of specific groups). In 1964, the Supreme Court ruled that married adolescents could legally obtain contraceptives in the case of Griswold v. Connecticut; unmarried adults were extended the same right in the 1972 by Eisenstadt v. Baird. The provision of contraceptives to adolescents continued to be hotly debated, as traditionally it was illegal to provide medical services to children living in 
their parents' homes (Luker, 1996). The 1977 Supreme Court decision in Carey v. Population Services International finally allowed contraceptives to be distributed to minors. In addition, the 1973 decision in Roe v. Wade legalized abortion in the United States, though states began adding restrictions requiring parental consent for adolescents almost immediately.

Thus, following the "sexual liberation" Americans experienced in the 1960s and the liberalization of family planning laws in the 1970s, the public perception of adolescent sexuality shifted significantly in the early 1980s. Reagan's election in 1980 heralded a dramatic shift in political, social, and moral responses to sexuality, and the sexual lives of adolescents became the subject of great public concern. A near-hysteria emerged in response to the supposed explosion in the rates of adolescent pregnancy and childbearing, and though the demographic trends are quite complex, the general consensus among researchers is that the threat of adolescent pregnancy and parenthood was grossly overestimated by the public (Luker, 1996). Congress responded to public concern with the passage of the Adolescent Family Life Act of 1981 (Public Law 97-35, popularly known as the "Chastity Bill"), which sought to reign in adolescent sexual behavior by encouraging greater family involvement in promoting abstinence (Miller et al., 1986). At the same time, HIV/AIDS emerged as a potential outcome of sexual activity that was previously unimaginable, namely, the possibility that sex could kill.

\section{Gendered Sexuality and Abstinence}

Sexual abstinence during adolescence may be advisable from a health perspective, as developmentally many adolescents find the emotional complexities of sexual decision 
making difficult to navigate. Indeed, society has placed age restrictions on a variety of other activities which may place adolescents at risk, including driving motor vehicles, drinking alcoholic beverages, and even attending movies with mature themes. The notion that sexual abstinence is put forth simply because it represents the best possible choice for adolescent health is debatable, however. The intense politicization of abstinence-only education (coupled with visceral reactions to the suggestion that adolescent sexual exploration might in fact be both natural and healthy) suggests that popular discourse surrounding sexual abstinence operates at a cultural level above and beyond mere concerns about the avoidance of negative health outcomes (Levine, 2002).

As demonstrated above, the public's response to adolescent sexuality is exceedingly conflicted, and this confusion is reflected in the highly contradictory messages adolescents receive regarding their appropriate sexual choices. Much of the public discourse surrounding adolescent sexuality is thus characterized by a series of intertwining yet contradictory expectations: adolescents are told not to have sex, at least until they are emotionally ready; but if they do have sex (which they probably will because abstinence is impractical given raging hormones), they should be sure to use an effective form of contraception (Blinn-Pike, 1999).

Of course, there are individuals (often organized along political and religious lines) who tend toward either extreme, believing, on the one hand, that complete abstinence should be upheld as the only acceptable option for unmarried individuals versus those who believe that adolescents' rights to sexual health care and sexual autonomy should be increased (Levine, 2002). Even among adults who believe abstinence to be the preferable choice for adolescents, many believe that those 
adolescents who are sexually active should have access to contraception, while also arguing that parents should be involved in an adolescent girl's decision to seek an abortion (Luker, 1996).

Conflicting views regarding adolescent sexuality are further complicated by the fact that society upholds fundamentally different norms for female and male expressions of sexuality. Though abstinence is held as the ideal for all adolescents (who, due to their emotional and psychological immaturity are considered unable to handle the complexities of sexual relationships), the social repercussions for sexual behavior are markedly different for young women and men. While young men's sexual exploration is tolerated and even encouraged, young women often face social pressure to postpone (or at least conceal) their sexual exploration until marriage (Reed and Weinberg, 1984); the fact that young women's sexuality can be rendered visible through pregnancy only adds to the social power of this double-standard.

\section{ANALYSIS}

The decision to become sexually active represents one of the key ransitions from childhood to adult status, both in the eyes of society and for individual adolescents themselves. Just as there are numerous societal reactions to adolescents' initiation of sexual intercourse, there are multiple factors that enter into the adolescent sexual decision making process. I have argued throughout this work that health concerns and norms of gendered sexuality (as ransmitted through parents, peers, sex education, and the media) influence the decisions adolescents make regarding their sexual health. In this chapter I 
examine nested logistic regression models predicting the probability of not having engaged in heterosexual intercourse, of remaining sexually abstinent.

\section{RESULTS}

\section{Gender and the Health Belief Model}

The fundamental goal of this work is first to determine the suitability of the Health Belief Model for examining adolescent sexual behavior, and then to explore whether the model is modified in important ways by gender. Model 1 (see Table 6.1), which includes only the variables representing health beliefs (susceptibility, severity, benefits, and barriers), addresses the ability of the Health Belief Model to predict adolescent sexual abstinence. In Model 2, gender and other key demographic characteristics are incorporated into the model. Gender is interacted with each of the health beliefs in order to test the hypothesis that the beliefs operate differently for females and males. In order to conclude that the Health Belief Model is meaningfully moderated by gender, one or more of the gender interaction terms must be found to be significant, indicating a gender-based difference in the role of health beliefs.

It is important to reiterate that race/ethnicity, socioeconomic status, and age (in years) are not interacted with other variables in the model. This has the effect of controlling for differences in the mean value of the dependent variable (in this case, the probability of being a virgin) for each group, but does not address how the other predictors may vary by these demographic characteristics. ${ }^{20}$ By way of example, this

\footnotetext{
${ }^{20}$ Though not ideal, this approach is necessary given the complexity of interpreting third-order interaction terms.
} 
approach controls for the fact that African American adolescents as a group are more likely to be sexually active, but does not consider the unique ways that identifying as African American interacts with health beliefs, gender, socioeconomic status, or age. 
Table 6.1 Logistic Regression Analysis Predicting Probability of Being a Virgin: Health Belief Model with Gender Interactions

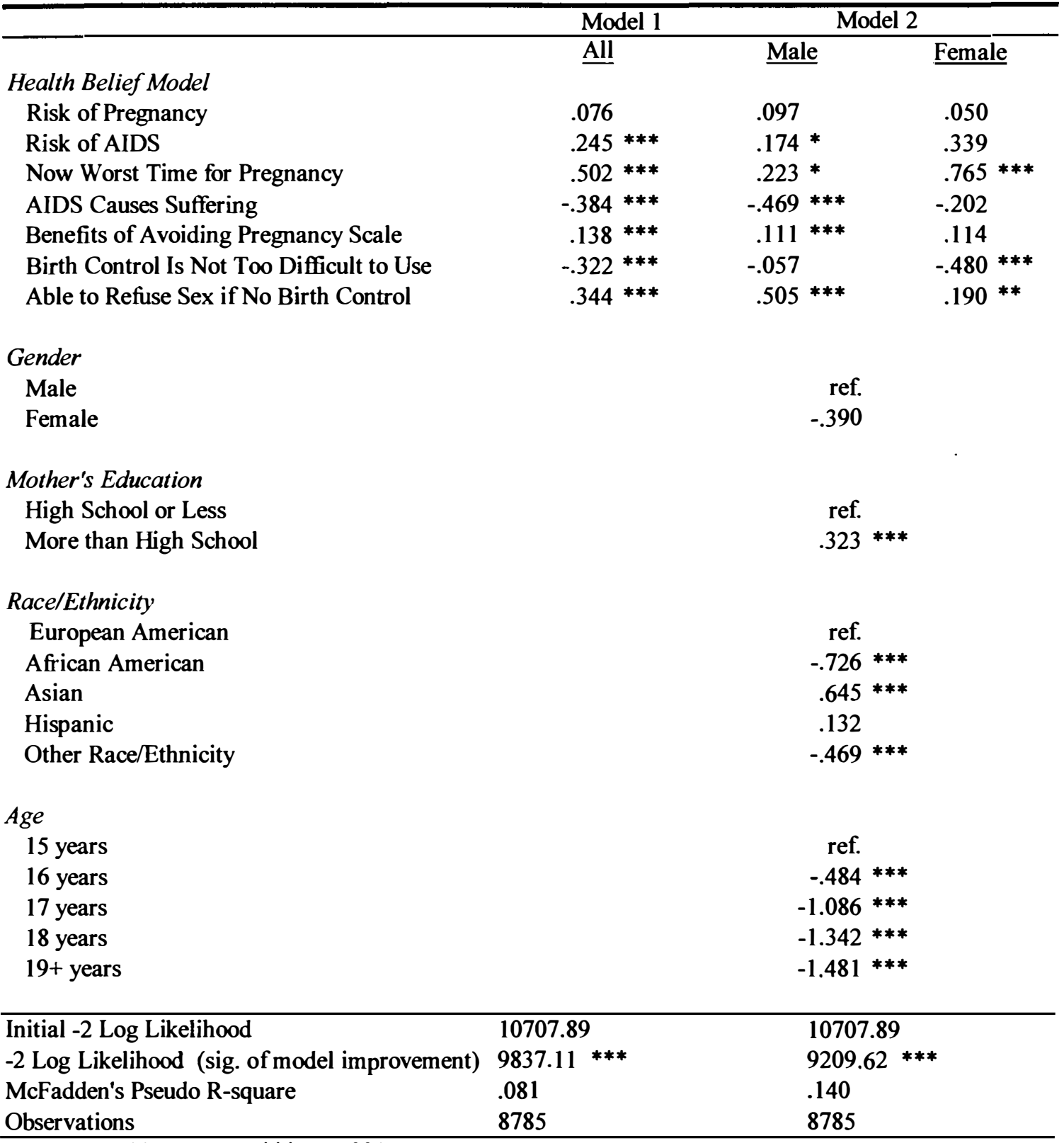

${ }^{*} \mathrm{p}<.05 \quad{ }^{* *} \mathrm{p}<.01 \quad{ }^{* * *} \mathrm{p}<.001$ 
Model 1 reveals that, with the exception of the variable representing the risk of pregnancy, each of the health beliefs are significantly associated with abstinence from heterosexual intercourse. ${ }^{21}$ Believing pregnancy during adolescence to be undesirable has the strongest relationship to sexual abstinence; as my interviews with adolescents suggested, pregnancy (not STDs) is the primary concern of adolescents. Two of the health beliefs, the severity of AIDS and the barrier presented by birth control, operate in the opposite direction than predicted. That is to say, adolescents who believe AIDS would cause a great deal of suffering are more likely to be sexually active. Likewise, those adolescents who believe that birth control is not too difficult to use are less likely to be sexually abstinent. Put another way, those adolescents who feel that birth control is difficult to use are also those who are sexually active. The problem of causal ordering is pronounced here, however, as it is possible that sexually active adolescents have found it difficult to use birth control. The paradoxical finding relating to the severity of suffering caused by AIDS is less easily explained, though it is possible that the typical adolescent sense of invincibility could contribute to the sense that AIDS could never happen to them.

Model 2 reveals several significant demographic differences in adolescents' decisions to remain sexually abstinent. African American adolescents are less likely on average than European American adolescents to be virgins, while adolescents of Asian descent are significantly more likely on average to be sexually abstinent. Adolescents whose mothers attained education beyond high school (roughly analogous to middle class

\footnotetext{
${ }^{21}$ It is important to note that the cross-sectional nature of the data cannot assure proper casual ordering; in short, it is not possible to conclude that health beliefs cause health behaviors. Rather, these results speak only to the strength and direction of the association of health beliefs and health behaviors.
} 
status) are less likely to be sexually active. As expected, with each additional year of age adolescents are less likely to be sexually abstinent. Each of these differences in sexual abstinence is consistent with the findings of other researchers (Forste and Haas, 2002; Upchurch et al., 1988).

Model 2 also introduces interaction terms between gender and each of the health beliefs; these terms reveal whether specific health beliefs operate differently for young women and men. ${ }^{22}$ Fear of AIDS and a positive evaluation of the benefits of avoiding unplanned pregnancy are significantly associated with abstinence for both females and males; no significant gender difference in the magnitude of these effects exists. The paradoxical finding regarding suffering due to AIDS appears significant again, also with no difference by gender. Several important gender differences do emerge, however. Viewing adolescence as the worst time for pregnancy is associated with abstinence for females but not for males. Females who report that birth control is difficult to use are less likely to be abstinent, though this factor is not significant for males. Both males and females who report being able to resist sex if birth control were not available are more likely to be sexually abstinent, and the effect is more than twice as strong for males than females.

Given the gender differences that emerge in Model 2, I believe that adequate evidence exists to conclude that the Health Belief Model is modified in important ways by the inclusion of gender. Though the original Health Belief Model appears well-suited

\footnotetext{
${ }^{22}$ In each case, the coefficients for males are treated as the main effect against which the coefficients for females are compared. The coefficient for males indicates whether the slope for a given health belief differs significantly from zero, while the coefficient for females addresses whether the difference between the slope for males and females is significantly different from zero.
} 
to the examination of adolescent sexual decision making, adding gender to the model reveals differences in magnitude of several of the health beliefs for males and females.

\section{Cues to Action}

The findings from Model 2 support my contention that gender influences the ways that adolescents incorporate health beliefs into their sexual decision making. The next step is to consider where these gender differences may come from and how they might enter into the sexual decision making process. The literature on adolescent sexuality points to a number of information sources on which adolescents draw when making decisions about their sexual behaviors; these sources are termed "cues to action" in the health behavior literature. Variables representing each of these cues to action (parents, peers, sex education, and the media) are entered separately in Models 3 through 6 (see Table 6.2$).{ }^{23}$ I hypothesize that these cues to action are the conduits through which adolescents are socialized into the norms of gendered sexuality. Specifically, my interviews with adolescents suggest that parental disapproval of adolescent sexual behavior and school-based sex education will be stronger predictors for females, while discussions with peers and exposure to media will play a greater role in males' behavior.

\footnotetext{
${ }^{23}$ Though the demographic variables entered in Model 2 are also included in the remainder of the models, I do not present or interpret these coefficients in subsequent tables.
} 
Table 6.2 Logistic Regression Analysis Predicting Probability of Being a Virgin: Cues to Action

\begin{tabular}{|c|c|c|c|c|c|c|c|c|c|}
\hline & \multicolumn{3}{|c|}{ Model 3} & \multicolumn{2}{|c|}{ Model 4} & \multicolumn{2}{|c|}{ Model 5} & \multicolumn{2}{|c|}{ Model 6} \\
\hline Health Beliefs & $\mathrm{Ma}$ & & Female & Male & Female & Male & Female & Male & Female \\
\hline Risk of Pregnancy & .073 & & .076 & .102 & .041 & .096 & .047 & .101 & .059 \\
\hline Risk of AIDS & .206 & * & .307 & $.172 *$ & .340 & $.191^{* *}$ & 337 & .107 & 209 \\
\hline Now Worst Time for Pregnancy & .131 & & $.662 * * *$ & .222 & $.759 * *$ & .206 & $.770 * * *$ & .180 & $.7333^{* *}$ \\
\hline AIDS Causes Suffering & -.482 & $* * *$ &. .189 & $-.469 * * *$ & -.202 & $-.457^{* * *}$ & -.200 & $-.455 * * *$ & -.187 \\
\hline Benefits of Avoiding Pregnancy Scale & .091 & $* * *$ & 097 & $.111^{* * *}$ & .113 & $.109 * * *$ & .115 & $.106^{* * *}$ & .107 \\
\hline Birth Control Is Not Too Difficult to Use & -.062 & & $-.505 * * *$ & -.059 & $-.482 * * *$ & -.067 & $-.476 * * *$ & -.019 & $-.407 * * *$ \\
\hline Able to Refuse Sex if No Birth Control & .447 & $* * *$ & $.136^{* *}$ & $.513^{* * *}$ & $.188 * *$ & $.501^{* * *}$ & $.192 * *$ & $.501^{* * *}$ & $.258^{*}$ \\
\hline Cues to Action & . & & & & & & & & \\
\hline Good Communication with Parent & .376 & $* *$ & $.744 * *$ & & & & & & \\
\hline Parent Disapproves of Sex & 1.024 & *** & $1.336^{*}$ & & & & & & \\
\hline Learned about Pregnancy in School & & & & -.218 & 086 & & & & \\
\hline Learned about AIDS in School & & & & .269 & .114 & & & & \\
\hline Hours of TV per Week & & & & & & $-.007^{* *}$ & $.005 * *$ & & \\
\hline Talked to Female Friend about Problems & & & & & & & & $-.523 * * *$ & $-.098 * * *$ \\
\hline Talked to Male Friend about Problems & & & & & & & & $-.206 * * *$ & $-1.031 * * *$ \\
\hline Attended Youth Group & & & & & & & & $.298 * * *$ & $.669^{* * *}$ \\
\hline Initial -2 Log Likelihood & \multicolumn{3}{|c|}{10707.89} & \multicolumn{2}{|c|}{10707.89} & \multicolumn{2}{|c|}{10707.89} & \multicolumn{2}{|c|}{10707.89} \\
\hline -2 Log Likelihood (sig. of model improvem & & & $43 * * *$ & \multirow{2}{*}{\multicolumn{2}{|c|}{$\begin{array}{l}9204.02 \\
.140\end{array}$}} & \multicolumn{2}{|c|}{$9199.16^{* *}$} & \multirow{2}{*}{\multicolumn{2}{|c|}{$\begin{array}{l}8870.05 \\
.172\end{array}$}} \\
\hline McFadden's Pseudo R-square & \multicolumn{3}{|c|}{.172} & & & .141 & & & \\
\hline Observations & \multicolumn{3}{|c|}{8785} & \multicolumn{2}{|c|}{8785} & \multicolumn{2}{|c|}{8785} & \multicolumn{2}{|c|}{8785} \\
\hline
\end{tabular}


In Model 3 the variables representing the influence of parents are entered into the model. Both good general communication with a parent and believing that the parent would disapprove of the adolescent being sexually active are significantly associated with the decision to remain sexually abstinent. The parent effect is significantly stronger for females; this is especially true for discussions with parents, the coefficient for which is twice as strong for young women than for young men. This finding supports my hypothesis that parents are a more influential factor for girls.

Surprisingly, school-based sex education about pregnancy and AIDS does not appear to be related to adolescents' decisions to remain abstinent. Adding these to variables to the model does not significantly improve the fit, resulting in a rejection of my hypothesis that sex education influences females more than males. My hypothesis that media exposure would influence young women and men differently does appear to be supported by the results in Model 5, however. While greater exposure to media (namely, hours of television watched per week) is associated with a greater probability of being abstinent for females, greater media exposure reduces the likelihood of being abstinent for males.

Some of the most striking gender differences emerge in regard to the influence of peers. Talking to male and female friends is significantly associated with a reduced probability of sexual abstinence for both young women and men, but the real story is in the magnitude of the differences. Young men who report talking to a close female friend are almost five times as likely to be sexually active (compared with those young men who do not talk to a female friend), and young women who talk to a close male friend are also approximately five times more likely to have sex. However, the coefficient for 
young women talking to a male friend is twice as strong as a young man talking to a female friend, suggesting that peers matter much more for adolescent girls. ${ }^{24}$ The effect of attending a youth group also supports this contention, as the coefficient is more than twice as large for females. These findings stand in contrast to my hypothesis that peers would matter more in the sexual decision making of young men.

Model 7 (see Table 6.3) includes all of the cues to action together in a single model, as well as all health beliefs. Each of the cues to action reaches significance when all are included simultaneously in the model. This represents a change from the previous models, as sex education now appears to be significantly associated with sexual abstinence for both young women and men. Interestingly, having learned about pregnancy in school decreases the probability of being sexually abstinent; this is especially true for young men (the coefficient for females is actually positive, though it is not significantly different from the coefficient for males and thus cannot be interpreted). In addition, the inclusion of all cues to action reduces the influence of gender on one of the health beliefs which had been significant in previous models, the sense of being able to refuse sexual intercourse if no birth control is available. The coefficients for this variable do not differ significantly by gender in Model 7 , suggesting that the cues to action do indeed capture in some sense the cultural difference between females and males.

\footnotetext{
${ }^{24}$ Given the wording of the AddHealth questionnaire, it is impossible to determine if the "close friend" is a romantic partner or a peer in the more traditional sense.
} 


\section{Gender Ideals}

In the full model (Model 8), two measures of gender ideals are entered into the model. These measures assess adolescents' perceptions of how their sexual activity may be viewed by others; specifically, each variable represents disagreement with statements that being known to be sexually active would make an individual more respected or more attractive. These variables work differently for young women and men (in that young women are much more likely to reject both statements) and I hypothesize that those adolescents who accept these statements will be more likely to take sexual risks. The results in Model 8 suggest that a small but significant difference does exist between females and males for the respect variable, as the coefficient for females is only about two-thirds the size of that for males. As hypothesized, adolescents who reject the statement that being sexually active makes one more respected were less likely to be sexually active themselves. This suggests that those adolescents who agree with this statement are more likely to have sex, and the results imply that it is actually young men who are more likely to embrace this statement. 
Table 6.3 Logistic Regression Analysis Predicting Probability of Being a Virgin: Cues to Action and Gender Ideals

\begin{tabular}{|c|c|c|c|c|}
\hline & \multicolumn{2}{|c|}{ Model 7} & \multicolumn{2}{|c|}{ Model 8} \\
\hline & $\underline{\text { Male }}$ & $\underline{\text { Female }}$ & Male & $\underline{\text { Female }}$ \\
\hline \multicolumn{5}{|l|}{ Health Beliefs } \\
\hline Risk of Pregnancy & .077 & .083 & .065 & .074 \\
\hline Risk of AIDS & .162 & 180 & 135 & 159 \\
\hline Now Worst Time for Pregnancy & .075 & $.652^{* * *}$ & .039 & $.633^{* * *}$ \\
\hline AIDS Causes Suffering & $-.449 * * *$ & -.186 & $-.467 * * *$ & -.197 \\
\hline Benefits of Avoiding Pregnancy Scale & $.086^{* * *}$ & .092 & $.091^{* * *}$ & .092 \\
\hline Birth Control Is Not Too Difficult to Use & -.041 & $-.435 * * *$ & -.094 & $-.468 * * *$ \\
\hline Able to Refuse Sex if No Birth Control & $.454^{* * *}$ & .215 & $.403^{* * *}$ & .195 \\
\hline \multicolumn{5}{|l|}{ Cues to Action } \\
\hline Good Communication with Parent & $.325 * *$ & $.630^{*}$ & $.299 * *$ & $.603 *$ \\
\hline Parent Disapproves of Sex & $1.015^{* * *}$ & 1.282 & $.981^{* * *}$ & 1.235 \\
\hline Learned about Pregnancy in School & $-.246 *$ & .011 & -.183 & .005 \\
\hline Learned about AIDS in School & $.347^{*}$ & .120 & .304 & .110 \\
\hline Hours of TV per Week & $-.008 * *$ & $.001^{* *}$ & $-.008 * *$ & $.001^{*}$ \\
\hline Talked to Female Friend about Problems & $-.547 * * *$ & $-.094 * * *$ & $-.562 * * *$ & $-.113 * * *$ \\
\hline Talked to Male Friend about Problems & $-.212 * * *$ & $-.996 * * *$ & $-.219 * *$ & $-.996 * * *$ \\
\hline Attended Youth Group & $.241 * *$ & $.571^{* *}$ & $.202 * *$ & $.575^{* * *}$ \\
\hline \multicolumn{5}{|l|}{ Gender Ideals } \\
\hline More Respected if Sexually Active (disagree) & & & $.687^{* * *}$ & $.414^{*}$ \\
\hline More Attractive is Sexually Active (disagree) & & & .009 & .047 \\
\hline Initial -2 Log Likelihood & \multicolumn{2}{|c|}{10707.89} & \multicolumn{2}{|c|}{10707.89} \\
\hline -2 Log Likelihood (sig. of model improvement) & \multirow{2}{*}{\multicolumn{2}{|c|}{$\begin{array}{l}8563.94^{* * *} \\
.200\end{array}$}} & \multirow{2}{*}{\multicolumn{2}{|c|}{$\begin{array}{l}8458.51 * * * \\
.210\end{array}$}} \\
\hline McFadden's Pseudo R-square & & & & \\
\hline Observations & \multicolumn{2}{|l|}{8785} & \multicolumn{2}{|c|}{8785} \\
\hline
\end{tabular}

${ }^{*} \mathrm{p}<.05 \quad{ }^{* *} \mathrm{p}<.01 \quad{ }^{* * *} \mathrm{p}<.001$ 


\section{DISCUSSION}

In this chapter I have examined what adolescents themselves point to as the key sexual health decision of their lives, namely, the decision of whether or not to become sexually active during adolescence. Based on my interviews with adolescents and my theorizing on the influence of gender in sexual health decisions, I have suggested a modification of the traditional Health Belief Model which incorporates gender, four potential mechanisms of gender socialization (i.e.,, cues to action), and gender ideals.

My results in this chapter point to several important findings. First, the Health Belief Model in its traditional form (unmodified by gender) works well to predict adolescent sexual abstinence. All but one of the health belief variables is significant, and the model correctly predicts an adolescent's decision in approximately 64.2 percent of cases (representing a 14.2 percent improvement over simply guessing that half of adolescents will be sexually active and half will not). Adding gender to the model (by interacting gender with each of the health beliefs) significantly improves the model, with the pseudo $\mathrm{R}^{2}$ value increasing from .081 for the traditional Health Belief Model to .140 for the gender-modified Health Belief Model. Though none of the health belief coefficients change directions for females or males in the gender-modified models, three coefficients (believing that pregnancy during adolescence would be bad, feeling birth control is hard to use, and being able to use birth control when aroused) are consistently of different magnitudes for females and males. Gender differences in health beliefs clearly play a role in adolescents' decisions to remain sexually abstinent.

The addition of the cues to action in Models 3 through 6 further suggests that gender influences the decision to remain sexually abstinent. With the exception of 
school-based sex education, each of the cues to action appears to influence the sexual decision making of females and males in significantly different ways. As with the gender differences in health beliefs, the majority of gender differences in the cues to action are a matter of magnitude rather than direction. Talking with parents, talking to a male friend, and attending youth group are all stronger cues for young women, while talking to a female friend is stronger for young men. Interestingly, exposure to media is associated with a lower probability of abstinence for males and a higher probability for females; though small, the gender difference is significant. Table 6.4 depicts the direction of all health beliefs, cues to action, and gender ideals separately for females and males and notes for which group the effect is statistically larger.

In addition to the direct effect of cues to action on the probability of abstinence, the introduction of cues to action also influences the role of health beliefs. While feeling susceptible to AIDS increases the probability of abstinence for both females and males in the gender-modified Health Belief Model, it fails to maintain significance in the full model. Looking at the separate models representing the addition of each cue to action, it appears that the influence of peers is the cue which eliminates the effect of susceptibility to AIDS. It may be that adolescents' discussions with their friends serve as a source of information about the perceived realities of HIV infection, possibly by sharing correct information on the actual modes of transmission, but more likely by creating the impression that no one the adolescent knows has been directly affected by AIDS. 
Table 6.4 Influences on Adolescents' Decision to Remain Sexually Abstinent

\begin{tabular}{|c|c|c|c|}
\hline Influence & $\begin{array}{l}\text { Direction } \\
\text { for Females }\end{array}$ & $\begin{array}{l}\text { Direction } \\
\text { for Males }\end{array}$ & $\begin{array}{c}\text { Stronger for } \\
\text { Females or Males? }\end{array}$ \\
\hline \multicolumn{4}{|l|}{ Health Beliefs } \\
\hline Risk of Pregnancy & n.s. & n.s. & n.s. \\
\hline Risk of AIDS & n.s. & n.s. & n.s. \\
\hline Now Worst Time for Pregnancy & + & + & Females \\
\hline AIDS Causes Suffering & - & - & n.s. \\
\hline Benefits of Avoiding Pregnancy Scale & + & + & n.s. \\
\hline Birth Control Is Not Too Difficult to Use & - & n.s. & Females \\
\hline Able to Refuse Sex if No Birth Control & + & + & n.s. \\
\hline \multicolumn{4}{|l|}{ Cues to Action } \\
\hline Good Communication with Parent & + & + & Females \\
\hline Parent Disapproves of Sex & + & + & n.s. \\
\hline Learned about Pregnancy in School & n.s. & n.s. & n.s. \\
\hline Learned about AIDS in School & n.s. & n.s. & n.s. \\
\hline Hours of TV per Week & + & - & Males \\
\hline Talked to Female Friend about Problems & - & - & Males \\
\hline Talked to Male Friend about Problems & - & - & Females \\
\hline Attended Youth Group & + & + & Females \\
\hline \multicolumn{4}{|l|}{ Gender Ideals } \\
\hline More Respected if Sexually Active (disagree) & + & + & Males \\
\hline More Attractive is Sexually Active (disagree) & n.s. & n.s. & n.s. \\
\hline
\end{tabular}

Note: Table reports results from the full model (Model 8); non-significant results are noted. 


\section{CONCLUSION}

The results in this chapter confirm my contention that while the Health Belief Model is an appropriate tool for examining adolescent sexual decision making, the model works better to predict adolescent sexual abstinence when gender is incorporated through the inclusion of cues to action and ideals of gendered sexuality, and by specifying all results separately by gender. The full model (Model 8 ) reduces the prediction error by 21 percent, compared with an error reduction of only 8.1 percent for the traditional Health Belief Model (Model 1). Regardless of whether or not adolescents perceive the decision to become sexually active as potentially affecting their health, interventions designed to ensure the sexual health of adolescents would do well to present adolescents both with factual health information and the tools to evaluate the gendered pressures they face in making decisions about their sexual behavior. 


\section{CHAPTER SEVEN: Influences on the Transition to Sexual Intercourse}

In the last chapter I examined the application of the Health Belief Model to the most fundamental sexual health decision adolescents face, the choice to engage in sexual intercourse or to remain sexually abstinent. This chapter offers a more nuanced examination of this crucial sexual health decision by considering the role of health beliefs, cues to action, and gender ideals in the age at transition to sexual intercourse. I use the term transition here to refer to the timing of sexual debut, the age at which adolescents first experience sexual intercourse. This transition has recently become a major focus of researchers and policy makers, as several experimental studies have shown that while school-based sex education curricula have little effect on ensuring complete abstinence throughout adolescence, many programs are effective at delaying sexual intercourse (Kirby et al., 1994).

This is a heartening finding given what is known about early sexual debut among adolescents. Evidence suggests that early sexual debut has serious health implications for adolescents, both because these adolescents have longer exposure to sexual health risks and also because their behavior tends to differ from those adolescents who delay their sexual debut. O'Donnell and colleagues (2001), for example, found that adolescents who became sexually active before the age of 15 were significantly more likely than delayers to have more partners and more frequent intercourse, were less likely to use condoms consistently, and experienced more unintended pregnancies. 
In addition to health risks, early sexual debut may also constitute an emotional risk for adolescents. In an examination of the "wantedness" of first sexual intercourse (as measured on a 10-point scale on which female respondents to the 1995 National Survey of Family Growth rated the degree to which they wanted their first experience with sexual intercourse), Abma and her colleagues (1998) found an inverse relationship between age at debut and degree of wantedness - the younger women were when they became sexually active, the more likely they were to report that although the intercourse had been voluntary it had not been wanted. ${ }^{25}$ Other examinations of large age differences between partners (which are common when one partner is young than average) further suggest that young adolescents in relationships with older partners may lack control over their sexual decision making, rendering them unable to refuse sexual intercourse or demand safer sex practices (Kaestle, Morisky, and Wiley, 2002).

The interest among educators, parents, and policy makers in delaying adolescents' transition to first intercourse derives from the potential for negative health outcomes. The idea of delaying, rather than forbidding, adolescent sexual exploration appears to be a "middle of the road" option that appeals to all but the most conservative. This emphasis on delaying transition is especially salient now, given the downward trend in the age at which puberty begins coupled with the increasing average age at marriage. In this chapter I present my analysis with an eye toward how the selected health beliefs and gender ideals operate as risk or protective factors in the effort to delay the transition to first sexual intercourse. I expect those adolescents who ascribe to positive health

\footnotetext{
${ }^{25}$ Comparable studies of young men's wantedness of first intercourse have not been undertaken, so it is unclear whether wantedness of first intercourse varies by gender.
} 
beliefs to be less likely than others to have experienced the transition to sexual intercourse; in particular, I expect that concerns about unplanned pregnancy will work to delay sexual debut for young women. While parents and school-based sex education should serve as protective factors, I suspect that discussions with peers and exposure to the media will increase the risk of transition to sexual intercourse. As I have reversecoded the gender ideals variables (so that each represents the rejection of traditional notions of gendered sexuality), these should also act as protective factors.

\section{ANALYSIS}

While the previous chapter examined the decision of whether or not to become sexually active (a simply dichotomy) using logistic regression, in this chapter I turn to a form of survival analysis that considers the relative probability of becoming sexually active over time. Cox proportional hazards models are a robust statistical technique which employ maximum likelihood techniques to produce the parameter estimates best fitting the sample data. A baseline risk is first estimated, based on a ratio between the number of individuals in the sample for whom the event occurred at a specific point in time (in this case, the proportion of adolescents who had sexual intercourse at a given age in months) over the total sample size. Cox proportional hazards models then examine the influence of each covariate on the probability of the event occurring relative to the baseline risk. For ease of interpretation I present odds ratios, which can be interpreted as either risk factors or protective factors. An odds ratio less than one indicates that the covariate operates as a protective factor-individuals who possess the characteristic are less likely to have made the ransition to sexual intercourse relative to others of the same 
age. Odds greater than one indicate that the covariate increases the probability of the transition to sexual intercourse, thus the covariate acts as a risk factor. Due to the difficulty with interpreting odds ratios for interaction terms, I estimated the models separately for female and male respondents; the logit coefficients and standard errors are reported in Appendix 3.

\section{RESULTS}

Before examining the protective and risk factors in the transition to first sexual intercourse, it is useful to consider the sample distribution of age at transition using Kaplan-Meier survival analysis. Table 7.1 reveals that a greater percentage of males in the sample had become sexually active, as fewer males are "censored" or dropped from the analysis due to non-occurrence of the event. The $25^{\text {th }}$ and $75^{\text {th }}$ percentiles represent the age at which a quarter and three-fourths (respectively) of the sample who became active did so, with the median (or $50^{\text {th }}$ percentile) representing the exact midpoint of the age distribution. The interquartile range is somewhat smaller for young women, perhaps pointing to greater homogeneity among females' experiences with transition relative to that of males. There is no meaningful difference, however, in the average age at transition to sexual intercourse for young women and men. 
Table 7.1 The Transition to First Sexual Intercourse

\begin{tabular}{lcc}
\hline & \multicolumn{1}{c}{ Females } & Males \\
\cline { 2 - 3 } Mean Age at Transition & 17 years, 4 months & 17 years, 3 months \\
25th Percentile & 15 years, 8 months & 15 years, 3 months \\
50th Percentile (median) & 17 years, 1 month & 17 years, 2 months \\
75th Percentile & 19 years, 1 month & 19 years, 8 months \\
Percent Censored (No Transition) & $53.18 \%$ & $51.44 \%$ \\
\hline Observations & 4513 & 3991 \\
\hline
\end{tabular}

Table 7.2 reports the influence of health beliefs and demographic characteristics on the transition to sexual intercourse. Odds ratios are presented separately for females and males to allow a comparison by gender, while the last column represents the statistical significance of the difference between the coefficients for females and males (the direction of this difference can be determined by examining the relative odds for each group). With the exception of susceptibility to pregnancy, all components of the Health Belief Model influence the transition to sexual intercourse, and the effects differ by gender for four of the variables.

For both males and females the probability of transition to sexual intercourse is reduced by an appreciation for the risk of AIDS, and no difference in the magnitude of this effect exists. Young men who believe AIDS causes suffering are at increased risk for transition, as are young women who feel able to use birth control; both effects are in keeping with the counterintuitive results presented in other chapters. Acknowledging the benefits of avoiding pregnancy and feeling able to refuse sex if no birth control is available are significant protective factors for both males and females, though the effect of birth control is stronger for males than for females. 
Table 7.2 Cox Proportional Hazards Model: Health Beliefs in the Transition to Intercourse

\begin{tabular}{|c|c|c|c|}
\hline Predictors & $\begin{array}{c}\text { Males } \\
\text { Relative } \\
\text { Risk }\end{array}$ & $\begin{array}{c}\text { Females } \\
\text { Relative } \\
\text { Risk } \\
\end{array}$ & $\begin{array}{c}\text { Male- } \\
\text { Female } \\
\text { Difference }\end{array}$ \\
\hline \multicolumn{4}{|l|}{ Health Belief Model } \\
\hline Risk of Pregnancy & 0.933 & 0.905 & \\
\hline Risk of AIDS & $0.851 * *$ & $0.801^{* * *}$ & \\
\hline Now Worst Time for Pregnancy & $0.840^{*}$ & $0.673^{* * *}$ & $* *$ \\
\hline AIDS Causes Suffering & $1.348 * * *$ & 1.114 & \\
\hline Benefits of Avoiding Pregnancy Scale & $0.938^{* * *}$ & $0.939^{* * *}$ & $* *$ \\
\hline Birth Control Is Not Too Difficult to Use & 1.067 & $1.274^{* * *}$ & $* *$ \\
\hline Able to Refuse Sex if No Birth Control & $0.724^{* * *}$ & $0.809^{* * *}$ & * \\
\hline \multicolumn{4}{|l|}{ Mother's Education } \\
\hline High School or Less & ref. & ref. & \\
\hline More than High School & $0.878^{* *}$ & 0.971 & \\
\hline \multicolumn{4}{|l|}{ Race/Ethnicity } \\
\hline European American & ref. & ref. & \\
\hline African American & $2.023 * * *$ & $1.248^{* * *}$ & $* * *$ \\
\hline Asian & $0.699 * * *$ & $0.636^{* * *}$ & \\
\hline Hispanic & 1.156 & $0.603^{* * *}$ & $* * *$ \\
\hline Other Race/Ethnicity & $1.277^{*}$ & 1.118 & \\
\hline Observations & 4325 & 4823 & \\
\hline
\end{tabular}


The results in Table 7.2 also reveal a number of significant interactions between gender and the demographic characteristics included in the model. While middle class status (as measured by mother's education) significantly delays the transition to sexual intercourse for young men, there is no social class effect for young women. For males, being African American more than doubles the probability of the transition to sexual intercourse at any given age relative to European American males, while the probability for African American females is almost 25 percent higher than for European American females. In addition, the difference between African American females and males is statistically significant. Asian Americans have a significantly lower probability of transition to intercourse relative to European Americans, regardless of gender. An unusual effect emerges for Hispanic adolescents, as Hispanic females are significantly less likely to become sexually active at any given age relative to European American females. There is no effect for Hispanic males relative to European American males, though Hispanic males have a significantly higher probability of transition compared with Hispanic females. These findings suggest that race/ethnicity and gender interact in important ways, a contention to which I will return in Chapter Ten.

Table 7.3 presents the odds ratios from the full model, including all health beliefs, cues to action, and gender ideals. ${ }^{26}$ It appears that the inclusion of the cues to action and the gender ideals alters young women's views on the threat of unintended pregnancy, though it is impossible to tell how the additional factors produce this finding. In the full

\footnotetext{
${ }^{26}$ I have omitted the intermediate reduced models reported in other chapters as there were no meaningful differences in the protective and risk factors.
} 
Table 7.3 Cox Proportional Hazards Model: Influences on the Transition to Intercourse

\begin{tabular}{|c|c|c|c|}
\hline Predictors & $\begin{array}{c}\text { Males } \\
\text { Relative } \\
\text { Risk }\end{array}$ & $\begin{array}{c}\text { Females } \\
\text { Relative } \\
\text { Risk }\end{array}$ & $\begin{array}{c}\text { Male- } \\
\text { Female } \\
\text { Difference }\end{array}$ \\
\hline \multicolumn{4}{|l|}{ Health Belief Model } \\
\hline Risk of Pregnancy & 0.941 & $0.874 *$ & * \\
\hline Risk of AIDS & $0.888 *$ & $0.862 *$ & \\
\hline Now Worst Time for Pregnancy & $0.874 *$ & $0.769 * * *$ & \\
\hline AIDS Causes Suffering & $1.364 * * *$ & 1.081 & ** \\
\hline Benefits of Avoiding Pregnancy Scale & $0.949 * * *$ & $0.951 * * *$ & * \\
\hline Birth Control Is Not Too Difficult to Use & 1.030 & $1.227 * * *$ & * \\
\hline Able to Refuse Sex if No Birth Control & $0.765 * *$ & $0.838 * * *$ & ** \\
\hline \multicolumn{4}{|l|}{ Cues to Action } \\
\hline Good Communication with Parent & 0.894 & $0.722 * * *$ & ** \\
\hline Parent Disapproves of Sex & $0.674 * * *$ & $0.625^{* * *}$ & \\
\hline Learned about Pregnancy in School & 1.051 & 0.924 & \\
\hline Learned about AIDS in School & 0.844 & 0.932 & \\
\hline Hours of TV per Week & 1.001 & $1.005 * * *$ & \\
\hline Talked to Female Friend about Problems & $1.275^{* * *}$ & 1.098 & \\
\hline Talked to Male Friend about Problems & $1.143 * * *$ & $1.709 * * *$ & *** \\
\hline Attended Youth Group & $0.836 * * *$ & $0.772 * * *$ & * \\
\hline \multicolumn{4}{|l|}{ Gender Ideals } \\
\hline More Respected if Sexually Active (disagree) & $0.703 * * *$ & $0.759 * * *$ & * \\
\hline More Attractive is Sexually Active (disagree) & 1.001 & 0.985 & \\
\hline \multicolumn{4}{|l|}{ Mother's Education } \\
\hline High School or Less & ref. & ref. & \\
\hline More than High School & $0.873 * *$ & 0.984 & \\
\hline \multicolumn{4}{|l|}{ Race/Ethnicity } \\
\hline European American & ref. & ref. & \\
\hline African American & $1.952 * * *$ & $1.293 * * *$ & *** \\
\hline Asian & $0.712 * * *$ & $0.633 * * *$ & \\
\hline Hispanic & 1.068 & $0.611^{* * *}$ & *** \\
\hline Other Race/Ethnicity & $1.283 *$ & 1.084 & \\
\hline Observations & 4325 & 4823 & \\
\hline
\end{tabular}


model, the susceptibility to pregnancy variable acts as a protective factor, reducing the probability of transition for young women but not for young men. This is accompanied by a change in the views on now being the worst time for pregnancy, with the difference between males and females being reduced by half and losing significance (though it remains significant for females and males separately). The paradoxical findings on the AIDS suffering variable increases in size in the full model; the risk of transition is significantly greater for males who think AIDS causes suffering, though there is still no effect for females.

With the exception of school-based sex education, each of the cues to action plays a role in the transition to sexual intercourse. Parental disapproval of adolescent sex operates as a powerful protective factor, reducing the probability of transition for both females and males by over 30 percent. For females, having good communication with parents also reduces the probability of transition by nearly 30 percent; there is no effect for parental communication for males. Youth group attendance also works as a protective factor, and the effect is significantly stronger for young women. Media exposure (as measured by hours of television watched per week) increases the risk of transition for females but not for males. Talking to a male friend is a significant risk factor for both genders, though it too has a greater effect for females. Talking to a female friend, on the other hand, is only a significant risk factor for young men, increasing the probability of transition by 25 percent.

One measure of gender ideals-disagreement with the statement that being known as sexually active leads to increased respectability - is a protective factor, reducing the probability of transition to sexual intercourse for both females and males. Interestingly, 
the effect is significantly stronger for young men, suggesting that all else being equal, young men who reject this gender ideal are approximately five percent less likely to become sexually active relative to the baseline risk compared with young women. Even with the inclusion of all cues to action and gender ideals, the demographic characteristics in the full model retain the same magnitude and direction as in the original model with only health beliefs.

\section{DISCUSSION}

In this chapter I have focused on how health beliefs, cues to actions, and gender ideals operate as risk or protective factors in the transition to first sexual intercourse. To summarize these findings I have created a table which reports the significant risk and protective factors for female and male adolescents.

My fundamental contention throughout this work is that the Health Belief Model can be effectively used to predict adolescent sexual behavior. My results in this chapter confirm that health beliefs do work as protective factors, reducing the probability of sexual risk behavior. At least one measure of each of the four health beliefssusceptibility, severity, benefits, and barriers - is significantly associated with a delayed transition to sexual intercourse. It must be noted, of course, that two health beliefs actually work as risk factors, though the reason for this is unclear.

My second key contention is that the influence of health beliefs in adolescents' decisions about sex is likely to differ for females and males; this contention is also borne out in these results. Specifically, I hypothesized in this chapter that fear of pregnancy would be more salient for young women, and this appears to be true. Though 
Table 7.4 Protective and Risk Factors in the Transition to Sexual Intercourse

\section{Females}

Risk Factors

Talked to Male Friend about Problems

Birth Control Is Not Too Difficult to Use

Hours of TV per Week

\section{Protective Factors}

Parent Disapproves of Sex

Good Communication with Parent

Attended Youth Group

Now Worst Time for Pregnancy

More Respected if Sexually Active (disagree)

Able to Refuse Sex if No Birth Control

Risk of Pregnancy

Risk of AIDS

Benefits of Avoiding Pregnancy Scale

Males

Risk Factors

AIDS Causes Suffering

Talked to Female Friend about Problems

Talked to Male Friend about Problems

Protective Factors

Parent Disapproves of Sex

More Respected if Sexually Active (disagree)

Able to Refuse Sex if No Birth Control

Attended Youth Group

Risk of AIDS

Now Worst Time for Pregnancy

Benefits of Avoiding Pregnancy Scale cue to action (peers)

health belief (barrier)

cue to action (media)

cue to action (parents)

cue to action (parents)

cue to action (peers)

health belief (severity)

gender ideal

health belief (barrier)

health belief (susceptibility)

health belief (susceptibility)

health belief (benefit)

health belief (severity)

cue to action (peers)

cue to action (peers)

cue to action (parents)

gender ideal

health belief (barrier)

cue to action (peers)

health belief (susceptibility)

health belief (severity)

health belief (benefit)

Note: Table reports significant results from the full model. 
susceptibility to AIDS works as a protective factor for both females and males, susceptibility to pregnancy only appears to delay to transition to sexual intercourse for young women. Of course, this finding makes perfect sense, given that only females suffer the negative consequences of an unplanned pregnancy.

An examination of the role of cues to action reveals further differences by gender. As expected, parents are the most important protective factor for both females and males, though it is interesting to note that the discussions with parents variable does not reach significance for young men. This parallels the findings from my interviews with adolescents, as most of the young men with whom I spoke reported never having discussed sex with their parents or only discussing it in a light-hearted, joking manner. Another indication of the power of gendered sexuality gained through my interviews with adolescents was the intense peer pressure faced by young men, and my analysis in this chapter underscores this finding. Though discussions with opposite-sex peers increases the risk of transition to sexual intercourse for both females and males, only in the case of males do same-sex peers operate as a risk factor. This seems to indicate that young women do not exert pressure upon one another to become sexually active in the same way that young men do. Clearly, becoming sexually active operates as an important source of homosocial bonding for young men. Finally, the gender ideals variable also operates in the expected direction, further confirming my hypothesis that gender ideals matter in adolescents' decisions to delay sexual activity.

One notable finding in this chapter which requires additional investigation is the role of race/ethnicity in the transition to first sexual intercourse. Many researchers point to differences in the age at sexual debut as a key reason for persistent racial/ethnic health 
disparities (O'Donnell, O'Donnell, and Stueve, 2001). The results in Tables 7.2 and 7.3 reveal that African American adolescents are significantly more likely to experience the transition to sexual intercourse at any given age relative to European American adolescents. Furthermore, the probability of transition to intercourse differs among African American adolescents, with African American males being significantly more likely than African American females to experience transition at a given age. Asian American adolescents, on the other hand, are significantly less likely on average to transition to sexual intercourse, relative to European American adolescents. Hispanic females are also significantly less likely on average to transition to sexual intercourse, though there is no significant effect for Hispanic males.

These results call into question a common assumption in much of the public health literature, which asserts that minority status operates as a health risk factor (Austin, 2003). While African American adolescents do appear to be at greater risk on average for the transition to sexual intercourse, Hispanic and Asian ethnic identity both work as protective factors, reducing the probability of ransition. Moreover, the race/ethnicity effect differs by gender in many cases. This interaction indicates that a more thorough, nuanced examination of race/ethnicity and gender is required, and I will retum to this issue in Chapter Ten.

Another issue which requires further attention is the role of school-based sex education in delaying the transition to sexual intercourse. Though previous studies have found a variety of sex education curricula to be effective at reducing adolescent sexual risk behavior, neither of my sex education variables (having learned about pregnancy or HIV/AIDS in school) ever reached significance in this model. This is surprising, given 
that the bivariate analysis in Chapter Five revealed that upwards of 90 percent of adolescents in all racial/ethnic groups had exposure to school-based sex education. It is unclear, however, exactly when the adolescents were exposed to school-based sex education. Many sex education reformers argue that a key failure of current programs is that they often come too late--those adolescents most at risk for developing patterns of risky sexual behavior may have already made the transition to sexual intercourse before school-based sex education begins (O'Donnell, O'Donnell, and Stueve, 2001). Of course, the non-significance of the sex education variables should not be taken as conclusive evidence that school-based sex education is meaningless to adolescents; rather, further exploration is needed to determine if the non-significance of sex education is a statistical issue (deriving from problems with the causal ordering or limited variance) or whether these findings point to a more fundamental problem with the design and implementation of sex education curricula. 


\section{CHAPTER EIGHT: Avoidance of Non-Romantic Sexual Relationships}

In the last two chapters I addressed the question of how adolescents decide when to become sexually active, examining first the decision to have sexual intercourse and then the probability of becoming sexually active relative to others of the same age. The majority of constructs included in the Health Belief Model were associated with both decisions, supporting my basic contention that adolescents' sexual health decisions can be considered as a specific case of health behavior. I further asserted that the inclusion of cues to action (through which adolescents are socialized into cultural norms of gendered sexuality) and specific gender ideals would modify the traditional Health Belief Model, and this was also supported by my findings in Chapters Six and Seven.

I now turn to the question of with whom adolescents enter into sexual relationships. In this chapter I use the Health Belief Model to examine adolescents' decisions to enter into non-romantic sexual relationships. ${ }^{27}$ Much like the decision to become sexually active, the decision to engage in non-romantic sexual relationships has major health and social implications for adolescents; as such, I believe the gendermodified Health Belief Model will offer insight into this important decision.

Although commonly considered a health risk behavior, engaging in non-romantic sexual relationships is not in and of itself a risky health practice. True, the risk of contracting a sexually transmitted disease increases with exposure to each new partner;

\footnotetext{
${ }^{27}$ This phenomenon is altermately called casual sex, one-night stands, or having other or secondary partners. I use the term "non-romantic partner" to reflect the wording of the AddHealth survey: "Not counting the people you have described as romantic relationships, have you ever had a sexual relationship with anyone?"
} 
indeed, the risk of STDs increases with every sexual encounter (Lansky, Thomas, and Earp, 1998) In addition, individuals tend to choose partners similar to themselves, suggesting that adolescents who engage in non-romantic sexual relationships are most likely doing so with other adolescents who also seek out non-romantic encounters, further increasing the probability of exposure to STDs (Ford, Sohn, and Lepkowski, 2001). The concern of increased exposure to STDs derives from the assumption that non-romantic sex is unprotected sex, however, and numerous studies challenge this common stereotype of careless "casual" sex.

Evidence suggests that individuals often undertake different sexual health practices in their primary and secondary (i.e., non-romantic) sexual relationships. Lansky et al. (1998) found that the use of protection to reduce exposure to STDs is actually higher in non-romantic sexual relationships, as individuals are more acutely aware of the risk. Indeed, many individuals abandon safer sex practices when involved in romantic relationships, due to the assumption of monogamy and the belief that the use of protection undermines the trust on which romantic relationships are built; this has implications for both the spread of STDs and the risk of unplanned pregnancy.

In addition to the potential for negative health outcomes associated with nonromantic sexual encounters, adolescents face a range of social reactions should their decision to enter into non-romantic sexual relationships become known. According to my adolescent interviewees, such information is likely to become widely known throughout the peer group, with dramatically different implications for the reputations of young women and men. While young men reported being encouraged to enter into sexual relationships whenever possible, the response to young women known to be 
involved in non-romantic sexual encounters was uniformly negative among the adolescents with whom I spoke. This rejection of young women's right to sexual exploration is a common theme in the literature, which points to the lack of recognition of female desire as the primary grounds for condemnation of women who stray beyond the bounds of committed sexual relationships (Fine, 1988; Tanenbaum, 2000). On the other hand, the common depiction of adolescent males as voracious, almost animalistic, in their sexual desire may facilitate and even force young men to seek out non-romantic sexual relationships.

Thus non-romantic sexual relationships have the potential to be risky from both a health and a social perspective, though they are not inherently risky on either dimension. Only when protection against STDs and pregnancy is neglected does non-romantic sex represent a health risk. The social risk of non-romantic sex is more complicated; while such relationships are likely always risky for young women, the risk to the emotional and psychological health of young men is unclear (and beyond the scope of this study). My analyses in this chapter will therefore be primarily exploratory in nature, with an eye toward the influence of birth control attitudes and gender ideals on the probability of never having had a non-romantic sexual relationship.

\section{ANALYSES}

This chapter examines the probability of having entered into a sexual relationship with an individual who is not considered to be a romantic partner. For the sake of consistency with the analyses presented in other chapters, I model the probability of not having had a sexual encounter with a non-romantic partner. After creating a variable to 
represent those individuals who report never having had a non-romantic sexual partner, I use nested logistic regression models to examine the influence of health beliefs, cues to action, and gender ideals on the probability of never having had a non-romantic sexual encounter.

\section{RESULTS}

As seen in Table 8.1, many of the Health Belief Model constructs are not significantly associated with the decision to avoid non-romantic sexual relationships. The risk of pregnancy variable (a measure of susceptibility) and the benefits of avoiding pregnancy scale (representing the benefits of undertaking a health behavior) are both positively associated with avoidance of non-romantic sex. That is to say, those individuals who possess these positive health beliefs are more likely to never have had sex in a non-romantic relationship. Furthermore, the two variables representing the lack of barriers to using birth control are also significant, indicating that those individuals who exhibit greater ability to use birth control are also those who avoid non-romantic sex. The pseudo $\mathrm{R}^{2}$ value for this model is a mere 2.1 percent, however, further underscoring the limited predictive power of the Health Belief Model in this instance. 
Table 8.1 Logistic Regression Analysis Predicting Avoidance of Non-Romantic Sex: Health Belief Model with Gender Interactions

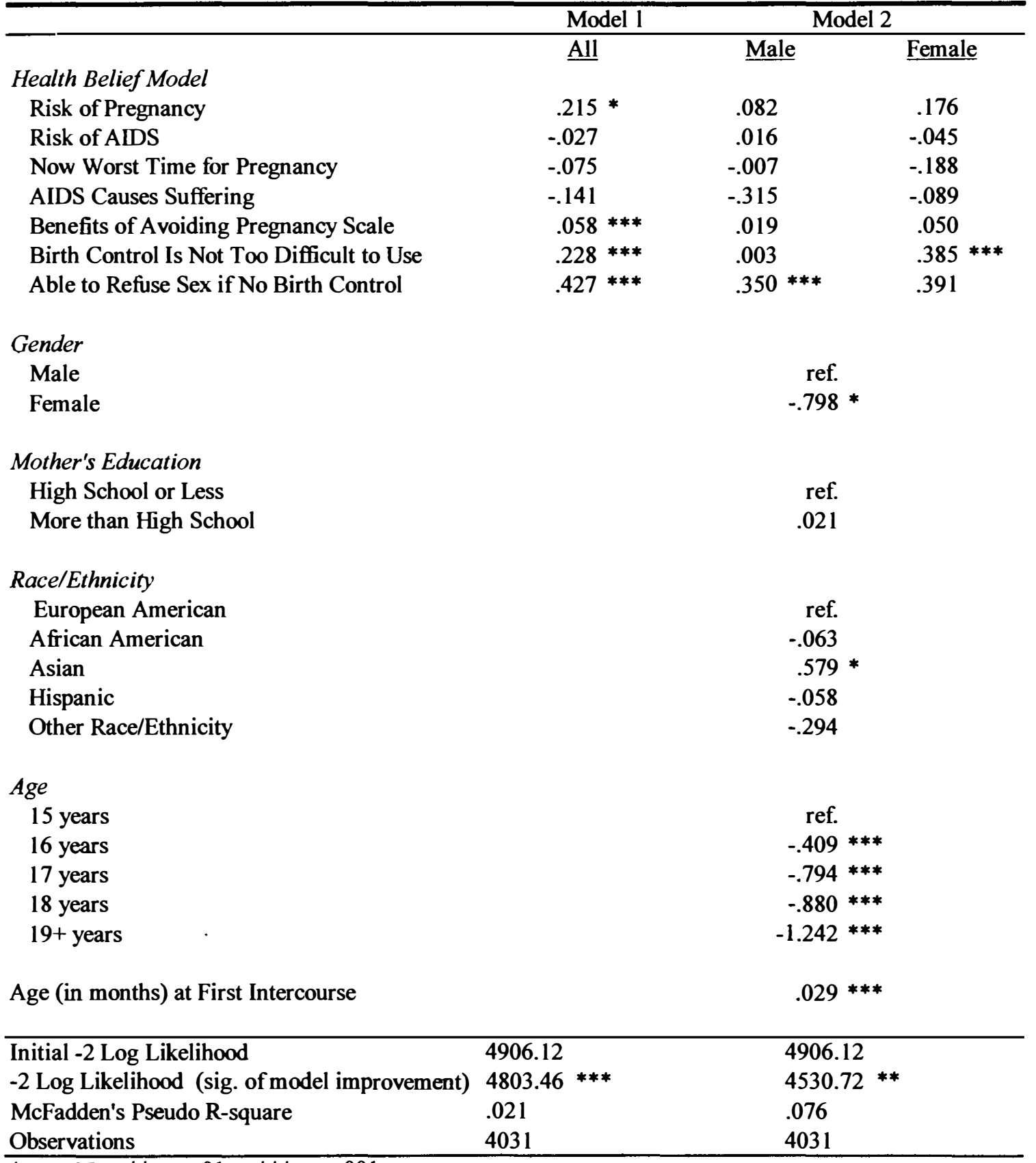

${ }^{*} \mathrm{p}<.05 \quad{ }^{* *} \mathrm{p}<.01 \quad{ }^{* * *} \mathrm{p}<.001$ 
The results in Model 2 reveal some fascinating gender differences, again suggesting that the Health Belief Model is meaningfully modified by the inclusion of gender. First, the risk of pregnancy variable becomes non-significant once demographic variables and gender interactions are included in the model. An interesting gender interaction also emerges in relation to the barriers to birth control use: while the ability to refuse sex if no birth control is available is significant and of a similar magnitude for both females and males, believing that birth control is not too difficult to use is only significant for young women. This finding has both substantive and statistical implications. From a substantive standpoint, this suggests that birth control self-efficacy is not a factor for young men. Statistically, this highlights the importance of estimating the Health Belief Model separately by gender, given that the magnitude of the variable in the original model (without gender interactions) is attributable to females only, not males.

Several of the demographic characteristics introduced in Model 2 are also significant. While no differences in the average probability of non-romantic sex exist among African, European, and Hispanic American adolescents, Asian American adolescents are significantly more likely to avoid non-romantic sex; put more clearly, Asian American adolescents are less likely on average to participate in casual sexual relationships. As expected, the probability of non-romantic sexual relationships increases with each additional year of age. There is no difference by social class, though there does appear to be a significant gender difference such that young women report a greater average probability of having had a non-romantic sexual relationship. This model also includes the age (in months) at first sexual intercourse as a predictor of avoiding nonromantic sexual relationships, as previous research indicates that becoming sexually 
active at an earlier age is associated with greater risk behavior and more sexual partners. This variable is highly significant, with adolescents who experience sexual debut at an earlier age being more likely to report having had a non-romantic sexual relationship. The inclusion of this and other demographic variables pushes the pseudo $\mathrm{R}^{2}$ value up to 7.6 percent, a small but significant increase..

The addition of cues to action in Models 3 through 6 does little to improve the predictive power of the model. Only two of the health beliefs remain significant throughout these models, again exhibiting the differences between females and males noted in the discussion of Model 2. Another situation emerges in which a variable is significant for females but not males, as having learned about pregnancy in school increases the probability that young women will avoid non-romantic sexual encounters. Attending youth group similarly increases the probability of avoiding non-romantic sex for both females and males. Only Model 4 (in which school-based sex education is introduced as a cue to action) is significantly improved by the additional variables, and the pseudo $\mathrm{R}^{2}$ for each of the models is comparable to that of Model 2. 
Table 8.2 Logistic Regression Analysis Predicting Avoidance of Non-Romantic Sex: Cues to Action

\begin{tabular}{|c|c|c|c|c|c|c|c|c|}
\hline & \multicolumn{2}{|c|}{ Model 3} & \multicolumn{2}{|c|}{ Model 4} & \multicolumn{2}{|c|}{ Model 5} & \multicolumn{2}{|c|}{ Model 6} \\
\hline & Male & Female & Male & Female & Male & Female & Male & Female \\
\hline \multicolumn{9}{|l|}{ Health Beliefs } \\
\hline Risk of Pregnancy & .090 & 168 & .087 & 158 & .078 & .176 & .084 & 191 \\
\hline Risk of AIDS & -.004 & -.046 & .018 & -.040 & .035 & -.041 & -.004 & -.049 \\
\hline Now Worst Time for Pregnancy & -.036 & -.196 & -.014 & -.208 & -.019 & -.180 & -.009 & -.195 \\
\hline AIDS Causes Suffering & -.334 & -.069 & -.313 & -.076 & -.311 & -.087 & -.327 & -.082 \\
\hline Benefits of Avoiding Pregnancy Scale & .016 & .048 & .023 & .050 & .018 & .052 & .018 & .050 \\
\hline Birth Control Is Not Too Difficult to Use & -.002 & $.372 *$ & .016 & $.392 *$ & -.010 & $.385^{*}$ & .029 & $.365^{*}$ \\
\hline Able to Refuse Sex if No Birth Control & $.338^{* * *}$ & .378 & $.366 * * *$ & .381 & $.357^{* * *}$ & .392 & $.342 * *$ & .392 \\
\hline \multicolumn{9}{|l|}{ Cues to Action } \\
\hline Good Communication with Parent & .283 & .174 & & & & & & \\
\hline Parent Disapproves of Sex & .145 & .133 & & & & & & \\
\hline Learned about Pregnancy in School & & & -.173 & $.370^{*}$ & & & & \\
\hline Learned about AIDS in School & & & -.424 & .051 & & & & \\
\hline Hours of TV per Week & & & & & -.006 & .003 & & \\
\hline Talked to Female Friend about Problems & & & & & & & -.040 & -.227 \\
\hline Talked to Male Friend about Problems & & & & & & & -.087 & .109 \\
\hline Attended Youth Group & & & & & & & $.256^{*}$ & .098 \\
\hline Initial -2 Log Likelihood & \multicolumn{2}{|c|}{4906.12} & \multicolumn{2}{|c|}{4906.12} & \multicolumn{2}{|c|}{4906.12} & \multicolumn{2}{|c|}{4906.12} \\
\hline-2 Log Likelihood (sig. of model improvement & \multicolumn{2}{|c|}{4521.93} & \multirow{2}{*}{\multicolumn{2}{|c|}{$\begin{array}{l}4518.89 * * \\
.079\end{array}$}} & \multicolumn{2}{|c|}{4527.32} & \multicolumn{2}{|c|}{4520.89} \\
\hline McFadden's Pseudo R-square & \multirow{2}{*}{\multicolumn{2}{|c|}{.078}} & & & \multirow{2}{*}{\multicolumn{2}{|c|}{4031}} & \multirow{2}{*}{\multicolumn{2}{|c|}{$\begin{array}{l}.078 \\
4031\end{array}$}} \\
\hline Observations & & & \multicolumn{2}{|c|}{4031} & & & & \\
\hline
\end{tabular}


Model 7 reveals an unusual set of results, in that several cues to action are now significant which had not reached significance when entered separately into the Models 3 through 6. Adolescents who report being able to discuss issues with a parent are more likely to avoid non-romantic sexual relationships, as are those adolescents who attend youth group meetings. Having learned about pregnancy in school is again a positive factor for young women, though not for young men. Interestingly, media exposure operates quite differently for females and males, as it increases the probability of avoiding non-romantic sex for females but reduces the probability for males (meaning they are more likely to have non-romantic sexual relationships). The gender-specific effects of the two birth control variables hold in these models, as in Models 2 through 6. The final model demonstrates the role of gender ideals in sexual decision making. Adolescents who reject the notion that they will be more respected by peers if they are known to be sexually active are significantly more likely to never have had a nonromantic sexual relationship. This suggests that adolescents who believe they gain prestige through being sexually active are more likely to participate in casual sexual encounters. Interestingly, there is no significant difference between young women and men on this variable. The pseudo $\mathrm{R}^{2}$ for this final model increases to 8.6 percent, a small but significant improvement over the baseline model. 
Table 8.3 Logistic Regression Analysis Predicting Avoidance of Non-Romantic Sex:

Cues to Action and Gender Ideals

\begin{tabular}{|c|c|c|c|c|}
\hline & \multicolumn{2}{|c|}{ Model 7} & \multicolumn{2}{|c|}{ Model 8} \\
\hline & Male & Female & Male & Female \\
\hline \multicolumn{5}{|l|}{ Health Beliefs } \\
\hline Risk of Pregnancy & .093 & .168 & .089 & .157 \\
\hline Risk of AIDS & -.003 & -.041 & -.018 & -.039 \\
\hline Now Worst Time for Pregnancy & -.062 & -.212 & -.087 & -.210 \\
\hline AIDS Causes Suffering & -.339 & -.051 & -.341 & -.048 \\
\hline Benefits of Avoiding Pregnancy Scale & .017 & .048 & .021 & .047 \\
\hline Birth Control Is Not Too Difficult to Use & .020 & $.361 *$ & -.021 & $.342 *$ \\
\hline Able to Refuse Sex if No Birth Control & $.354^{* * *}$ & .373 & $.339 * * *$ & .367 \\
\hline \multicolumn{5}{|l|}{ Cues to Action } \\
\hline Good Communication with Parent & $.303 *$ & .154 & $.292 *$ & .139 \\
\hline Parent Disapproves of Sex & .135 & .136 & .141 & .117 \\
\hline Learned about Pregnancy in School & -.204 & $.371 *$ & -.174 & $.375^{*}$ \\
\hline Learned about AIDS in School & -.392 & .046 & -.403 & .034 \\
\hline Hours of TV per Week & $-.007 *$ & $.003 *$ & $-.008 *$ & $.002 *$ \\
\hline Talked to Female Friend about Problems & -.054 & -.226 & -.058 & -.247 \\
\hline Talked to Male Friend about Problems & -.080 & .128 & -.075 & -.263 \\
\hline Attended Youth Group & $.254 *$ & .072 & $.254 *$ & .082 \\
\hline \multicolumn{5}{|l|}{ Gender Ideals } \\
\hline More Respected if Sexually Active (disagree) & & & $.292 * *$ & .230 \\
\hline More Attractive is Sexually Active (disagree) & & & .086 & .051 \\
\hline Initial -2 Log Likelihood & \multicolumn{2}{|c|}{4906.12} & \multicolumn{2}{|c|}{4906.12} \\
\hline -2 Log Likelihood (sig. of model improvement) & \multicolumn{2}{|c|}{$4496.79 * *$} & \multicolumn{2}{|c|}{$4482.88 * *$} \\
\hline McFadden's Pseudo R-square & \multicolumn{2}{|l|}{.083} & \multicolumn{2}{|c|}{.086} \\
\hline Observations & \multicolumn{2}{|c|}{4031} & \multicolumn{2}{|c|}{4031} \\
\hline
\end{tabular}




\section{DISCUSSION}

This chapter offers an exploration of non-romantic sexual encounters among adolescents. This phenomenon is somewhat different from the health practices examined in other chapters, in that non-romantic sexual relationships are not in and of themselves a health or social risk. It was therefore unclear whether the Health Belief Model would work well to predict the probability of avoiding non-romantic sexual relationships, which is unarguably the only sure way to eliminate whatever health and social risks are associated with non-romantic sex.

Considered without any demographic controls, elements of the Health Belief Model $d o$ work to predict the probability of avoiding non-romantic sexual encounters. Only the measures of severity fail to reach significance, perhaps suggesting that adolescents do not view non-romantic sex as being any riskier than other types of sexual encounters. Once the demographic variables are added, the influence of susceptibility to health risks and the benefits of preventive health behaviors become non-significant, leaving only the potential barriers to preventive health behaviors (or a lack thereof) as significant predictors. As these barriers operate in a positive direction (perceiving no barriers to safer sex practices reduces the probability of non-romantic sex), it may be that adolescents who view themselves as efficacious in their preventive health behavior are more likely to avoid the potential health and social risks associated with non-romantic sexual encounters. On the contrary, those adolescents who feel unable to overcome the barrier of effective birth control use may also be unable to avoid the risks of nonromantic sex. 
The significance of the gender ideal variable in the full model further supports the contention that self-efficacy matters in avoiding non-romantic sexual relationships. It is those adolescents who appear to look outside themselves for affirmation (as captured by this variable, at least) who are more likely to participate in non-romantic sexual relationships. The magnitude of the effect for the gender ideal variable is nearly as large as that for the birth control attitudes, however, making it difficult to conclude whether social or health concerns are more salient in adolescents' decisions about non-romantic sex.

\section{CONCLUSION}

The analysis presented in this chapter is predicated upon an inherently negative view of non-romantic sexual encounters, which is not necessarily the case for all individuals. Aside from concerns about increased exposure to STDs (which evidence suggests may be overstated), the real risk of non-romantic sex may be more psychological than physical. Only when individuals freely choose to engage in sex outside of committed relationships, and when they are fully aware of and prepared to deal with the social consequences, can such encounters be emotionally healthy. Truly free sexual exploration is highly constrained in adolescence, however, given the direct influence of parents and the all-encompassing world of peer relationships. 


\section{CHAPTER NINE: Use of Birth Control}

This chapter explores the use of birth control by adolescents at the time of their first and most recent experiences with heterosexual intercourse. ${ }^{28}$ Birth control decisions are a clear-cut example of a preventive health behavior in the most traditional sense, as the health benefits of birth control are clear: the avoidance of unplanned pregnancy and sexually transmitted diseases. Indeed, pregnancy and STDs represent real risks to adolescent health. Research indicates that adolescent females have a 90 percent probability of becoming pregnant during each year of unprotected sexual intercourse. Additionally, adolescents face significantly higher risks of STDs compared to adults, with approximately one in four adolescents diagnosed with an STD each year (AGI, 1999).

Encouragingly, the sexual risk behavior of American adolescents has decreased markedly in recent years. The 1995 National Survey of Family Growth reveals that fully 75 percent of sexually active adolescents reported using birth control at first intercourses and 83 percent used birth control during their most recent sexual encounter. The use of highly effective hormonal methods of birth control (including the Pill) increased significantly among adolescents in the 1990s, as did the use of condoms (AGI, 2002). These improved sexual health practices look impressive until compared with those of other developed counties. The United States continues to have the highest rate of adolescent pregnancy among developed countries, with over 900,000 girls becoming

\footnotetext{
${ }^{28}$ I use the term "birth control" throughout this chapter owing to the wording of the AddHealth survey questions on which these analyses are based, although my concem is with disease and pregnancy prevention more broadly defined.
} 
pregnant each year (AGI, 2002). Remarkably, American teens are not more sexually active than their counterparts in other developed countries; rather, their lower use of effective contraceptives accounts for the differential rates of pregnancy and STDs (Singh and Darroch, 2000).

The question arises as to what drives the higher risk behavior of American adolescents. Many have speculated that America's traditionally puritanical view of adolescent sexuality contributes to adolescent ignorance of the risks of sexual intercourse and the power they have to prevent them. Abstinence-only education may exacerbate this ignorance, as educators in many localities are barred from even mentioning the AIDS epidemic or the use of condoms (Dailard, 2001). Efforts to distribute condoms or locate sexual health care centers within high schools have also met with outrage in many places. Moreover, given the cost of many forms of birth control, many adolescents cannot obtain them without help from parents, which is not always available given parental disapproval of adolescent sex.

While adolescents face numerous obstacles associated with obtaining and effectively using birth control, their usage rates have increased in recent years. The use of birth control by adolescents arises from a desire to avoid the potentially negative health outcomes of unplanned pregnancy or STDs; in short, adolescents' decisions to practice birth control are motivated by health beliefs. The potential of these health beliefs to produce preventive health behaviors, however, is likely to be modified by the powerful social norms of gendered sexuality; this contention is supported both by the existing literature on this topic and through my interviews with adolescents. Moreover, the decision to use birth control, while primarily an individual-level decision based on the 
desire to avoid unplanned pregnancy or STDs, is also highly dependent on the context of dyadic heterosexual relationships. As such, I expect the desire to undertake birth control in gender-appropriate ways to result in significant gender differences in the Health Belief Model.

My interviews with adolescents revealed a great deal about how adolescents perceive the risks of pregnancy and STDs. Adolescents appear aware of the potential of unplanned pregnancies resulting from unprotected sexual intercourse, which suggests that susceptibility to pregnancy should be a strong predictor of the use of birth control for both young women and men. Many adolescents paint the potentially disastrous experience of an unplanned pregnancy as problematic only for young women, however, as both female and male respondents note that young men can easily walk away from a difficult situation. I therefore hypothesize that the severity of unplanned pregnancy will be associated with birth control use for females only. I further hypothesize that susceptibility to and the severity of infection with an STD will not be significantly associated with use of birth control for either females or males, as neither my female nor male interviewees exhibited any great concern about avoiding STDs.

Regardless of the sense of susceptibility to pregnancy that adolescents may exhibit, there are numerous barriers which may reduce the probability of using birth control. The potential embarrassment associated with obtaining birth control or suggesting its use to a partner may is a well-documented phenomenon among adolescents (Hillier, Harrison, and Warr, 1998). Based on my adolescent interviewees' negative responses to the notion of women carrying condoms, I expect that barriers will negatively affect the probability of using birth control for females more strongly than for males. 
Furthermore, I expect that adherence to gender ideals will also be negatively associated with birth control use, as traditional gender scripts tend to preclude open discussions between partners regarding the use of birth control.

\section{ANALYSIS}

In this chapter I use nested logistic regression models to examine adolescents' reports of the use of birth control during their first experience with heterosexual intercourse. I then develop a second set of nested logistic regression models to examine adolescents' use of birth control during their most recent experience with heterosexual intercourse. This second set of models includes the use of birth control at first intercourse as a predictor of use at most recent intercourse; previous research indicates that the behaviors developed during the early stages of sexual activity often become habitual, underscoring the importance of early intervention to develop healthy sexual practices.

It is important to note that the sample employed in the analyses presented in this chapter includes only those adolescents who report having had heterosexual intercourse; adolescents who have not experienced intercourse are censored from the analysis. Restricting the analysis to include only sexually experienced adolescents eliminates the problem of missing values but also potentially biases the results, as those adolescents who have made the decision to avoid the risks of sex activity through abstinence have been excluded from the analysis. 


\section{RESULTS}

Model 1 (see Table 9.1) indicates that many components of the Health Belief Model are associated with the use of birth control at first intercourse. The notable exceptions are those variables associated with AIDS: neither the risk of AIDS nor the suffering it may cause are significantly associated with use of birth control. All other variables operate in the expected direction. The pseudo $R^{2}$ value for this model is a mere .040 , however, suggesting that the reduction of error over the null model is minimal. Model 2, which includes the gender interaction terms, fares little better. Considering the role of gender and the other demographic characteristics only increases the pseudo $\mathrm{R}^{2}$ value to .048 , an improvement of less than one percent. Two of the variables which had been significant in Model 1 (believing that now would be the worst time for pregnancy and the benefits of avoiding pregnancy scale) fail to maintain significance in the genderinteraction model. Only the risk of pregnancy and the two variables representing views on the use of birth control are significant in Model 2, though no gender differences exists in the magnitude of these effects. Mother's education is positively associated with use of birth control at first intercourse, while Asian and Hispanic adolescents are significantly less likely on average (compared to European Americans) to have used birth control at first intercourse. These findings on the role of demographic characteristics are consistent with other researchers' analyses of the AddHealth data (Ford, Sohn, and Lepkowski, 2001). 
Table 9.1 Logistic Regression Analysis Predicting Use of Birth Control at First Intercourse: Health Belief Model with Gender Interactions

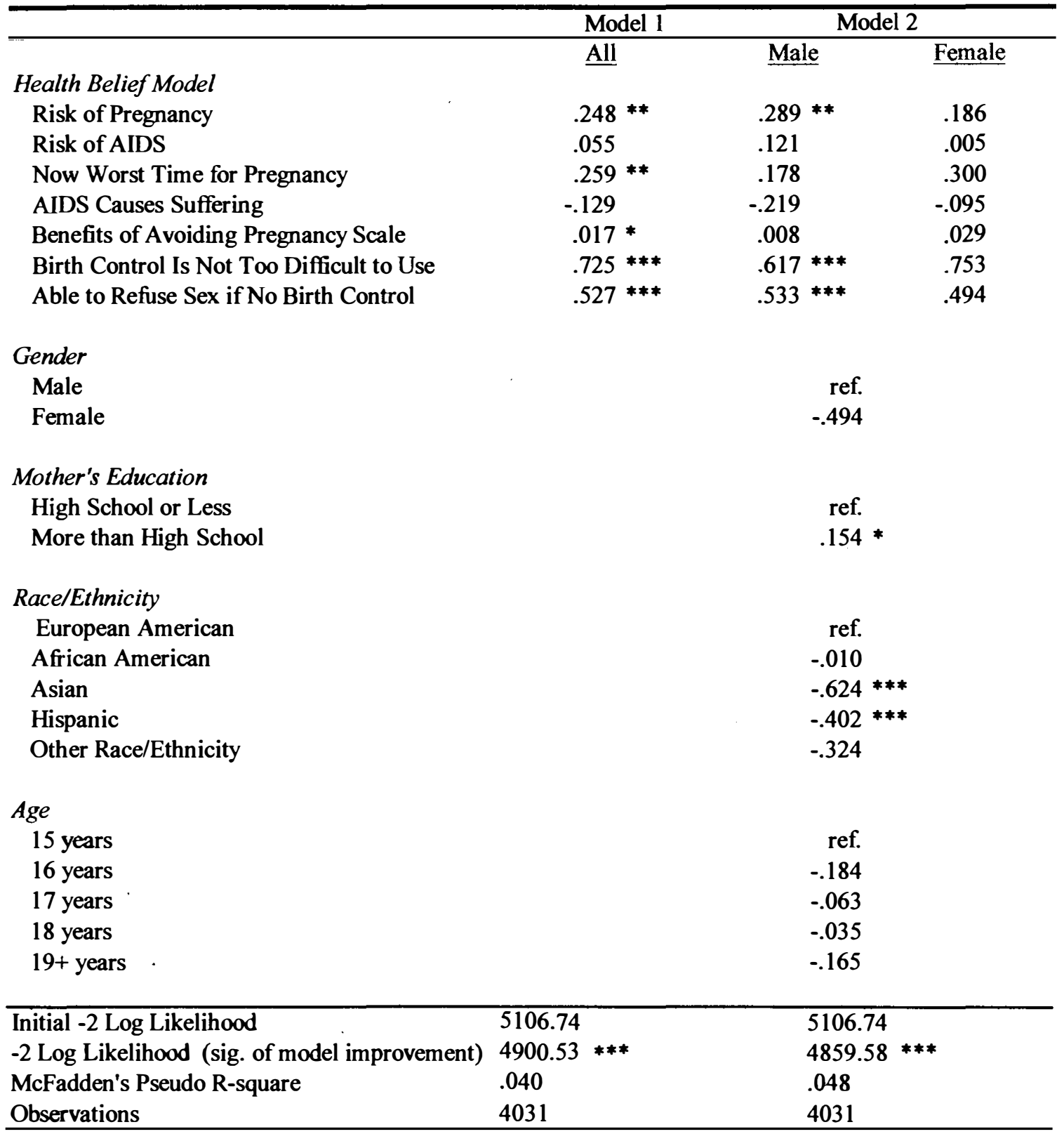


The addition of the cues to action appears to have little impact on the probability of having used birth control at first sexual intercourse, as there is little improvement in the pseudo $\mathrm{R}^{2}$ values. In each of the models (see Table 9.2) the same three health beliefs remain significant (risk of pregnancy and the two birth control attitudes). Several interesting results regarding the role of the cues to action do emerge, however. Parental disapproval of sex appears to be negatively associated with the use of birth control at first intercourse; this makes intuitive sense but is alarming nonetheless. Having leamed about pregnancy through school-based sex education increases the probability of using birth control, which points to the need for early intervention before adolescents become sexually active. Exposure to media decreases the use of birth control to a minimal extent; this is not surprising given the dearth of media depictions in which birth control is discussed. Surprisingly, none of the peer variables is significantly associated with the use of birth control at first intercourse, further suggesting the birth control may simply not be discussed among adolescents. 
Table 9.2 Logistic Regression Analysis Predicting Use of Birth Control at First Intercourse: Cues to Action

\begin{tabular}{|c|c|c|c|c|c|c|c|c|c|}
\hline & \multicolumn{3}{|c|}{ Model 3} & \multicolumn{2}{|c|}{ Model 4} & \multicolumn{2}{|c|}{ Model 5} & \multicolumn{2}{|c|}{ Model 6} \\
\hline & Male & & Female & $\underline{\text { Male }}$ & Female & $\underline{\text { Male }}$ & Female & $\underline{\underline{\text { Male }}}$ & Female \\
\hline \multicolumn{10}{|l|}{ Health Beliefs } \\
\hline Risk of Pregnancy & $.305^{*}$ & & 186 & $.285^{* *}$ & .182 & $.289^{* *}$ & .185 & $.287^{* *}$ & 187 \\
\hline Risk of AIDS & .114 & & .005 & .112 & .011 & .135 & .007 & .107 & .016 \\
\hline Now Worst Time for Pregnancy & .183 & & .301 & .182 & .288 & .160 & .288 & 167 & .311 \\
\hline AIDS Causes Suffering & -.218 & & -.094 & -.208 & -.089 & -.211 & -.099 & -.224 & -.097 \\
\hline Benefits of Avoiding Pregnancy Scale & .013 & & .032 & .007 & .029 & .008 & .029 & .009 & .029 \\
\hline Birth Control IsNot Too Difficult to Use & $.617^{*}$ & **** & .753 & $.617^{* * *}$ & .754 & $.611^{* * *}$ & .753 & $.625^{* * *}$ & .751 \\
\hline Able to Refuse Sex if No Birth Control & $.542 *$ & **** & .484 & $.521^{* * *}$ & .492 & $.537^{* * *}$ & .494 & $.539^{* * *}$ & .491 \\
\hline \multicolumn{10}{|l|}{ Cues to Action } \\
\hline Good Communication with Parent & .114 & & .056 & & & & & & \\
\hline Parent Disapproves of Sex & $-.208 *$ & & -.112 & & & & & & \\
\hline Learned about Pregnancy in School & & & & $.414^{*}$ & .202 & & & & \\
\hline Learned about AIDS in School & & & & -.182 & .132 & & & & \\
\hline Hours of TV per Week & & & & & & $-.006 *$ & -.003 & & \\
\hline Talked to Female Friend about Problems & & & & & & & & -.119 & .106 \\
\hline Talked to Male Friend about Problems & & & & & & & & -.089 & 187 \\
\hline Attended Youth Group & & & & & & & & -.091 & -.141 \\
\hline Initial -2 Log Likelihood & \multicolumn{3}{|c|}{5106.74} & \multicolumn{2}{|c|}{5106.74} & \multicolumn{2}{|c|}{5106.74} & \multicolumn{2}{|c|}{5106.74} \\
\hline-2 Log Likelihood (sig. of model improvemen & \multicolumn{3}{|c|}{4853.88} & \multirow{2}{*}{\multicolumn{2}{|c|}{$\begin{array}{l}4852.15 \\
050\end{array}$}} & \multicolumn{2}{|c|}{4854.68} & \multicolumn{2}{|c|}{4850.35} \\
\hline McFadden's Pseudo R-square & \multirow{2}{*}{\multicolumn{3}{|c|}{$\begin{array}{l}.049 \\
4031\end{array}$}} & & & \multirow{2}{*}{\multicolumn{2}{|c|}{$\begin{array}{l}.049 \\
4031\end{array}$}} & \multirow{2}{*}{\multicolumn{2}{|c|}{$\begin{array}{l}.050 \\
4031\end{array}$}} \\
\hline Observations & & & & \multicolumn{2}{|c|}{$\begin{array}{l}.050 \\
4031\end{array}$} & & & & \\
\hline
\end{tabular}

${ }^{*} \mathrm{p}<.05^{* *} \mathrm{p}<.01^{* * *} \mathrm{p}<.001$ 
In Model 7 (see Table 9.3), all of the cues to action are entered simultaneously. Here the first gender effect emerges, as having discussed a problem with a close male friend is marginally significant (at the $p<.10$ level) for females. Finally, Model 8 depicts the full model predicting the probability of having used birth control at first sexual intercourse. Each of the aforementioned health beliefs and cues to action remain significant and in the same direction. The pseudo $\mathrm{R}^{2}$ for the full model is only .054 , indicating that all of the variables combined improve the prediction of use of birth control at first intercourse by only five percent. This finding confirms that use of birth control at first intercourse is a strong predictor of use in subsequent sexual encounters, highlighting the importance of providing information on birth control to adolescents as early as possible. 
Table 9.3 Logistic Regression Analysis Predicting Use of Birth Control at First Intercourse: Cues to Action and Gender Ideals

\begin{tabular}{|c|c|c|c|c|}
\hline & \multicolumn{2}{|c|}{ Model 7} & \multicolumn{2}{|c|}{ Model 8} \\
\hline & Male & Female & Male & Female \\
\hline \multicolumn{5}{|l|}{ Health Beliefs } \\
\hline Risk of Pregnancy & $.298^{*}$ & 181 & $.297^{* *}$ & 184 \\
\hline Risk of AIDS & .105 & .024 & .105 & .024 \\
\hline Now Worst Time for Pregnancy & .157 & .286 & .156 & .285 \\
\hline AIDS Causes Suffering & -.200 & -.093 & -.201 & -.093 \\
\hline Benefits of Avoiding Pregnancy Scale & .013 & .032 & .013 & .032 \\
\hline Birth Control Is Not Too Difficult to Use & $.618^{* * *}$ & .751 & $.617^{* * *}$ & .753 \\
\hline Able to Refuse Sex if No Birth Control & $.539 * * *$ & .478 & $.541^{* * *}$ & .480 \\
\hline \multicolumn{5}{|l|}{ Cues to Action } \\
\hline Good Communication with Parent & 096 & 071 & .096 & .074 \\
\hline Parent Disapproves of Sex & $-.203^{*}$ & -.097 & $-.207^{*}$ & -.095 \\
\hline Learned about Pregnancy in School & $.422 *$ & .219 & $.413^{*}$ & .221 \\
\hline Learned about AIDS in School & -.178 & .125 & -.176 & 123 \\
\hline Hours of TV per Week & $-.007 *$ & -.004 & $-.007 *$ & -.004 \\
\hline Talked to Female Friend about Problems & -.123 & 108 & -.124 & 109 \\
\hline Talked to Male Friend about Problems & -.100 & $.189+$ & -.099 & $.190+$ \\
\hline Attended Youth Group & -.070 & -.148 & -.069 & -.152 \\
\hline \multicolumn{5}{|l|}{ Gender Ideals } \\
\hline More Respected if Sexually Active (disagree) & & & -.083 & .023 \\
\hline More Attractive is Sexually Active (disagree) & & & .064 & -.056 \\
\hline Initial -2 Log Likelihood & \multicolumn{2}{|c|}{5106.74} & \multicolumn{2}{|c|}{5106.74} \\
\hline -2 Log Likelihood (sig. of model improvement) & \multicolumn{2}{|c|}{$4832.01 *$} & \multicolumn{2}{|c|}{4830.96} \\
\hline McFadden's Pseudo R-square & \multicolumn{2}{|c|}{.054} & \multicolumn{2}{|c|}{.054} \\
\hline Observations & \multicolumn{2}{|c|}{4031} & \multicolumn{2}{|c|}{4031} \\
\hline
\end{tabular}


Table 9.4 presents the initial results using the Health Belief Model to predict the probability of having used birth control during the most recent instance of sexual intercourse. Model 1 again reveals that the variables concerning AIDS are not significantly associated with the use of birth control at most recent intercourse. The results related to pregnancy here are of somewhat different magnitude compared with those for the use of birth control at first intercourse, suggesting that the relationship between health beliefs and use of birth control may change as sexual experience increases. In Model 2 the risk of pregnancy and the benefits of avoiding pregnancy become non-significant compared to the findings on use at first intercourse, as does the coefficient for Hispanics. The use of birth conzrol at first intercourse is a highly significant predictor of use at most recent intercourse, however, and this effect is the largest in the model. Not surprisingly, the pseudo $\mathrm{R}^{2}$ jumps to .142 for this model, over .055 in Model 1.

Models 3 through 6 (see table 9.5) reveal that cues to action have little association with the probability of having used birth control during the most recent sexual intercourse. Only parental disapproval of adolescent sex has any effect, and unfortunately this factor reduces the probability of birth control use. The pseudo $\mathrm{R}^{2}$ values are relatively high in these models, though this is most likely attributable to the inclusion of use of birth control at first intercourse in these models (though the results are not reported in the tables).

Table 9.6 includes the full model predicting the probability of having used birth control during the most recent sexual encounter. The addition of gender ideals has no 
Table 9.4 Logistic Regression Analysis Predicting Use of Birth Control at Most Recent Intercourse: Health Belief Model with Gender Interactions

\begin{tabular}{|c|c|c|c|}
\hline & Model 1 & Model & \\
\hline & All & Male & Female \\
\hline \multicolumn{4}{|l|}{ Health Belief Model } \\
\hline Risk of Pregnancy & $.170^{*}$ & 134 & 159 \\
\hline Risk of AIDS & .079 & 217 & .020 \\
\hline Now Worst Time for Pregnancy & $.565^{* * *}$ & $.306^{*}$ & .592 \\
\hline AIDS Causes Suffering & -.104 & -.163 & -.068 \\
\hline Benefits of Avoiding Pregnancy Scale & $.018^{*}$ & .018 & .018 \\
\hline Birth Control Is Not Too Difficult to Use & $.823^{* * *}$ & $.676^{* * *}$ & .591 \\
\hline Able to Refuse Sex if No Birth Control & $.551^{* * *}$ & $.553^{* * *}$ & 499 \\
\hline \multicolumn{4}{|l|}{ Gender } \\
\hline Male & & \multicolumn{2}{|l|}{ ref. } \\
\hline Female & & \multicolumn{2}{|l|}{-.582} \\
\hline \multicolumn{4}{|l|}{ Mother's Education } \\
\hline High School or Less & & \multicolumn{2}{|l|}{ ref. } \\
\hline More than High School & & \multicolumn{2}{|l|}{.129} \\
\hline \multicolumn{4}{|l|}{ Race/Ethnicity } \\
\hline European American & & \multicolumn{2}{|l|}{ ref. } \\
\hline African American & & \multicolumn{2}{|l|}{.062} \\
\hline Asian & & \multicolumn{2}{|l|}{$-.477^{* *}$} \\
\hline Hispanic & & -.239 & \\
\hline Other Race/Ethnicity & & \multicolumn{2}{|l|}{-.015} \\
\hline \multicolumn{4}{|l|}{ Age } \\
\hline 15 years & & \multicolumn{2}{|l|}{ ref. } \\
\hline 16 years & & \multicolumn{2}{|l|}{.009} \\
\hline 17 years & & \multicolumn{2}{|l|}{.125} \\
\hline 18 years & & \multicolumn{2}{|l|}{.083} \\
\hline $19+$ years & & \multicolumn{2}{|l|}{-.019} \\
\hline \multicolumn{2}{|l|}{ Used Birth Control at First Intercourse } & \multicolumn{2}{|c|}{$1.423^{* * *}$} \\
\hline Initial -2 Log Likelihood & 4990.21 & \multicolumn{2}{|c|}{4990.21} \\
\hline -2 Log Likelihood (sig. of model improvement) & 4713.85 & \multicolumn{2}{|c|}{$4281.63^{* * *}$} \\
\hline McFadden's Pseudo R-square & .055 & \multicolumn{2}{|l|}{.142} \\
\hline Observations & 4031 & \multicolumn{2}{|l|}{4031} \\
\hline
\end{tabular}

${ }^{*} \mathrm{p}<.05 \quad{ }^{* *} \mathrm{p}<.01 \quad{ }^{* * *} \mathrm{p}<.001$ 
Table 9.5 Logistic Regression Analysis Predicting Use of Birth Control at Most Recent Intercourse: Cues to Action

\begin{tabular}{|c|c|c|c|c|c|c|c|c|c|}
\hline & \multicolumn{3}{|c|}{ Model 3} & \multicolumn{2}{|c|}{ Model 4} & \multicolumn{2}{|c|}{ Model 5} & \multicolumn{2}{|c|}{ Model 6} \\
\hline & Male & & Female & Male & Female & Male & Female & Male & Female \\
\hline \multicolumn{10}{|l|}{ Health Beliefs } \\
\hline Risk of Pregnancy & .148 & & .159 & .135 & .116 & .133 & .159 & .129 & .178 \\
\hline Risk of AIDS & .215 & & .014 & .210 & .024 & .219 & .020 & .211 & .026 \\
\hline Now Worst Time for Pregnancy & .315 & & .589 & $.310^{*}$ & .583 & $.304^{*}$ & .592 & $.303^{*}$ & .601 \\
\hline AIDS Causes Suffering & -.155 & & -.061 & -.148 & -.063 & -.162 & -.069 & -.169 & -.076 \\
\hline Benefits of Avoiding Pregnancy Scale & .025 & & .024 & .018 & .018 & .018 & .018 & .019 & .019 \\
\hline Birth Control Is Not Too Difficult to Use & .679 & $* * *$ & .587. & $.677^{* * *}$ & .592 & $.675^{* * *}$ & .591 & $.679^{* * *}$ & .581 \\
\hline Able to Refuse Sex if No Birth Control & .574 & $* * *$ & .479 & $.556 * * *$ & .499 & $.554^{* * *}$ & .500 & $.560 * * *$ & .495 \\
\hline \multicolumn{10}{|l|}{ Cues to Action } \\
\hline Good Communication with Parent & .039 & & .194 & & & & & & \\
\hline Parent Disapproves of Sex & -.305 & ** & -.148 & & & & & & \\
\hline Learned about Pregnancy in School & & & & .306 & .186 & & & & \\
\hline Learned about AIDS in School & & & & -.479 & .093 & & & & \\
\hline Hours of TV per Week & & & & & & -.001 & -.001 & & \\
\hline Talked to Female Friend about Problems & & & & & & & & -.044 & -.207 \\
\hline Talked to Male Friend about Problems & & & & & & & & -.097 & .380 \\
\hline Attended Youth Group & & & & & & & & -.123 & -.168 \\
\hline Initial -2 Log Likelihood & \multicolumn{3}{|c|}{4990.21} & \multicolumn{2}{|c|}{4990.21} & \multicolumn{2}{|c|}{4990.21} & \multicolumn{2}{|c|}{4990.21} \\
\hline \multicolumn{2}{|l|}{$\begin{array}{l}\text {-2 Log Likelihood (sig. of model improvement) } \\
\text { McFadden's Pseudo R-square }\end{array}$} & \multicolumn{2}{|c|}{4270.98} & \multicolumn{2}{|c|}{$\begin{array}{l}4276.24 \\
143\end{array}$} & \multicolumn{2}{|c|}{$\begin{array}{l}4281.53 \\
142\end{array}$} & \multicolumn{2}{|c|}{4274.27} \\
\hline McFadden's Pseudo R-square & & \multicolumn{2}{|c|}{.144} & \multirow{2}{*}{\multicolumn{2}{|c|}{.143}} & \multirow{2}{*}{\multicolumn{2}{|c|}{.142}} & \multirow{2}{*}{\multicolumn{2}{|c|}{$\begin{array}{l}.143 \\
4031\end{array}$}} \\
\hline Observations & & 4031 & & & & & & & \\
\hline
\end{tabular}


Table 9.6 Logistic Regression Analysis Predicting Use of Birth Control at Most Recent Intercourse: Cues to Action and Gender Ideals

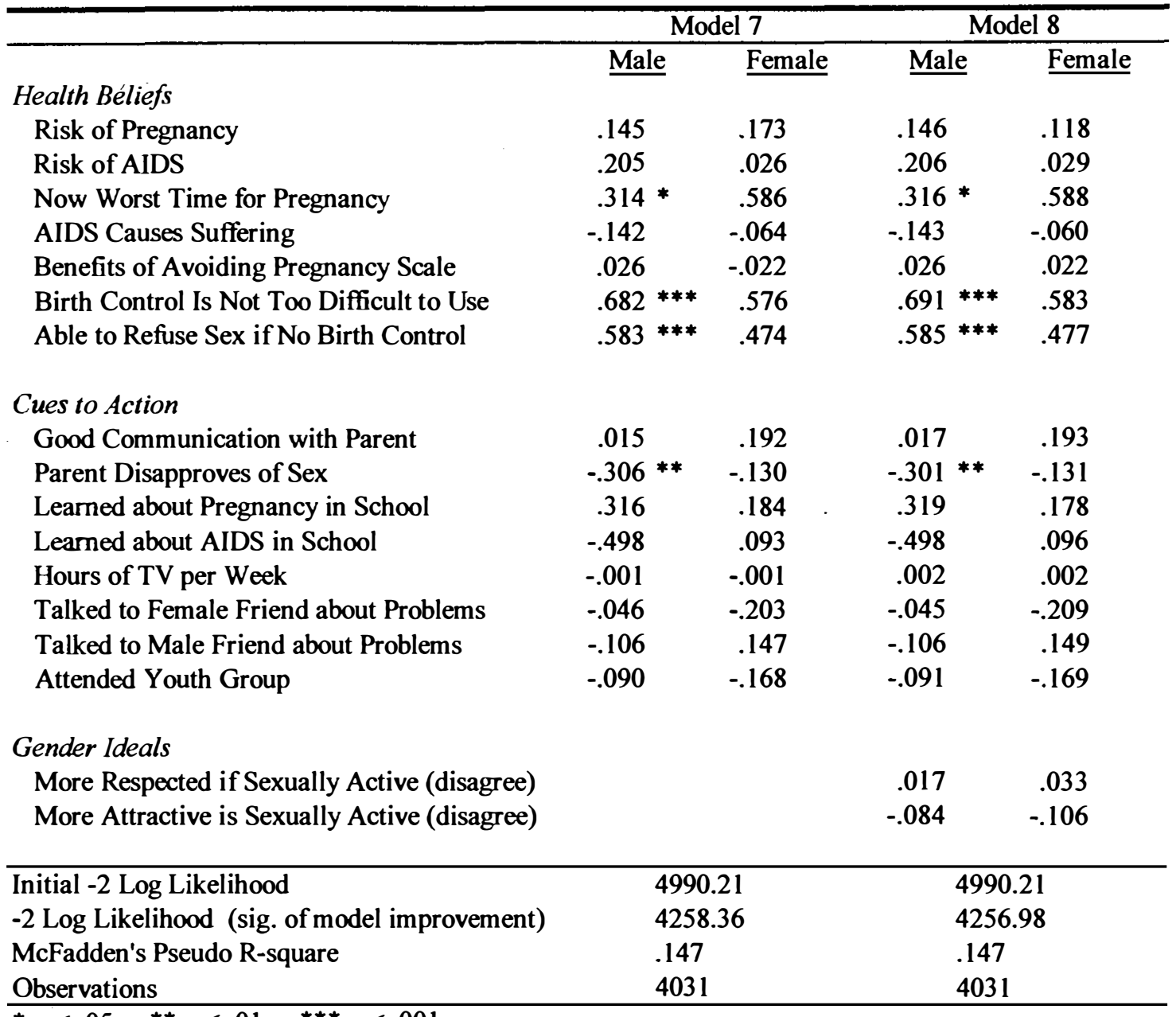

${ }^{*} \mathrm{p}<.05 \quad{ }^{* *} \mathrm{p}<.01 \quad{ }^{* * *} \mathrm{p}<.001$ 
significant effect, though the four variables that were significant in the previous models remain so in the full model.

\section{DISCUSSION}

Compared with my findings in previous chapters, the limited utility of the Health Belief Model in predicting the use of birth control is somewhat surprising. The decision to use birth control to protect against pregnancy and STD transmission would appear to be a clear-cut case in which health beliefs should translate directly into health behaviors, and yet only a select few of the predictors in the model are significant and the reduction in prediction error quite low. The pattern of significant and non-significant factors makes sense, however, in light of my adolescent respondents' reported concerns regarding the potential risks of sexual behavior.

There are several consistent findings that emerge in the two models predicting use of birth control at first and most recent intercourse. Believing now to be a bad time for pregnancy, my measure of severity, is significantly associated with the use of birth control at most recent intercourse for both females and males in the full model, though it has no effect in the model predicting the use of birth control at first intercourse. This contradicts my hypothesis that the severity of pregnancy would only be a factor for young women. I had also hypothesized that susceptibility would be a significant factor for females and males, and though this appears to be a significant factor in the use of birth control at first intercourse it is not associated with use at most recent intercourse. These findings seem to suggest that while a sense of susceptibility to pregnancy may be a factor 
early in an adolescent's sexual career, this fear may fade as they become more sexually experienced.

Based on my interviews with adolescents, I had hypothesized that numerous barriers to birth control use would exist. My results do bear this hypothesis out, as both of my measures of barriers are highly significant in each of the models (though my variables represent a lack of barriers, it stands to reason that those adolescents who do perceive barriers would be less likely to have used birth control). I had also predicted that the norms of gendered sexuality would interact with barriers to reduce young women's use of birth control; this does not appear to be the case, however, as none of the gender interactions or gender ideals are significant.

Though the lack of significant findings in this chapter is disappointing, I believe there are a number of plausible explanations. First and most alarming is the apparent lack of concern among adolescents about the risk of STDs, including HIV. My interviews with adolescents revealed a paradoxical, if understandable, estimation of the risk of STDs. Adolescents knew they should be concerned about STDs, and yet I found little evidence to suggest that adolescents had truly embraced this concern and incorporated it into their decision making. Adolescents themselves saw this lack of concern as problematic, and yet attributed it to the general adolescent sense of invulnerability. This lack of concern is a common theme in the literature on adolescent responses to the HIV epidemic as well. Many researchers have suggested that while knowledge of HIV risk is a necessary precursor behavior change, it is not sufficient to reduce risk behavior (Fisher, Misovich, and Fisher, 1992). Crosby (1996) further argues that the passive learning engendered by school-based sex education programs is insufficient to overcome 
adolescents' perceived invulnerability to HIV infection. Perhaps it is not surprising, then, that my measures of perceived susceptibility do not translate into preventive health behaviors: adolescents simply have not had the direct experience with HIV/AIDS necessary to accurately assess their potential vulnerability and sufficient to change their risk behavior.

Another potential reason for the limited utility of the Health Belief Model in predicting use of birth control arises from a lack of a concrete understanding of "safe sex." Though the discourse of safe sex is prominent in the media, little explanation is offered as to what safe sex actually entails. In addition, all but the most comprehensive school-based sex education programs speak in general terms about protecting one's self, but are usually prohibited from providing detailed information on the correct use of condoms or how to obtain hormonal contraceptives. Hillier and colleagues' (1998) indepth interviews with British adolescents revealed that although most spoke of the importance of practicing "safe sex," when pushed many could not explain precisely what actions constituted safe sex practices. This lack of deep understanding was mirrored in my interviewees' discussion of being tested for STDs - though many described this as a requirement for sexually active individuals, not a single adolescent could explain how or where one would get tested. It may be that adolescents' knowledge of the importance of safe sex practices operates at the surface level only, failing to become so deeply embedded in adolescents as to be considered health beliefs in the traditional sense. If this is the case, it should perhaps be no surprise that health beliefs are of limited utility as predictors of health behaviors in the case of birth control use. 


\section{CONCLUSION}

The consistent use of birth control (and protection more broadly defined, for prevention of STDs) is the key means of preventing the potential risks associated with sexual intercourse. If adolescents choose to become sexually active, they must be convinced that birth control is not simply an option but a necessity. While it may be possible in the future to portray the use of effective birth control as a moral imperative (similar to efforts to encourage condom use among the gay population in light of the AIDS epidemic), the current approach to birth control focuses solely on an individual's desire to avoid negative health outcomes. I would argue that school-based sex education, predicated as it is upon maintaining health, offers the best potential site for improving adolescents' use of birth control.

What seems clear, however, both from my results and other literature in the field, is that school-based sex education must change dramatically in order to become effective at promoting the consistent use of birth control. The question is thus how best to address the importance of consistent use-by altering adolescents' perceptions of their vulnerability to pregnancy and STDs, or by directly addressing the actual process of choosing and using effective methods of protection. My results illustrate that adolescents who believe they have the skills necessary to use protection are much more likely to do so; this variable has the largest coefficient of all significant predictors. This suggests altering school-based sex education curricula to directly address the use of birth control, moving beyond a mere discussion of failure rates to discuss both how to use specific methods and where to obtain them. Such changes would require a rejection of the traditional rhetoric that giving adolescents explicit information about sex encourages 
them to experiment. If this logic holds (which research indicates it likely does not, contrary to public opinion), then sex education in its current incarnation actually encourages unprotected sex by refusing to give adolescents the skills necessary to effectively use birth control. This blurs the line between morality and health in sex education, as adolescents are effectively punished with ignorance and its consequences if they choose to become sexually active. 
CHAPTER TEN: A Brief Exploration of Race/Ethnicity in Adolescent Sexual Decision Making

Though the central focus of this dissertation is the influence of gender on the sexual health behaviors of adolescents, the meaning and consequences of gender are culturally specific. My results in previous chapters indicate that gender and race/ethnicity interact to shape individual experiences, necessitating an examination of the unique social locations created by these intersections. In this chapter I apply an intersection approach to my analysis, widening my focus to examine the interactive nature of gender and race/ethnicity in the decisions adolescents make about their sexual health.

The intersection approach (characterized by the simultaneous consideration of the systems of patriarchy, racism, and capitalist exploitation) developed in response to concerns that mainstream feminist scholarship failed to consider the experiences of women outside of the European American middle class. The emphasis on women's shared experiences under patriarchy, articulated most clearly by radical feminists (see, for example, Firestone's The Dialectic of Sex) suggested an essential, universal experience of gender, an experience that many women (especially minorities, the economically disadvantaged, and lesbians) did not share. As a result, many theoretical approaches arose in the late 1970 s and 1980 s which sought to address the multiple ideological forces that work together to shape women's lives; for example, socialist-feminists critiqued the mutually reinforcing systems of capitalism and patriarchy (Eisenstein, 1979; Hartmann, 
1981), while many African-American feminists emphasized their unique oppression under white supremacy and patriarchy (Giddings, 1984; hooks, 1984).

Although attempts to consider the theoretical interaction of patriarchy with racism and capitalist exploitation helped to move feminist theorizing forward, these developments suffered from a tendency to emphasize a single system of oppression over others. Socialist-feminism, for example, was harshly critiqued for allowing class analysis to subsume gender, viewing women's exploitation solely as a function of their relation to the market (Young, 1981). Critiques were also leveled against theorists who suggested that African-American women's experiences could be seen as a result of their "double jeopardy" under white supremacy and patriarchy, which implied that experiences of oppression could simply be "added up" to determine an individual's degree of subjugation (Spelman, 1988).

Intersection analysis, emerging in reaction to these critiques, starts from the perspective that no system of oppression can be considered in isolation from others; moreover, as systems of power, specific forms of oppression (i.e sexism, racism, class exploitation) cannot be ranked as more or less destructive, though their salience may be situationally dependent (Brewer, 1993). Through interaction at the macrolevel, these systems of oppression create unique social locations which individuals experience at the microlevel of lived experience (Zinn and Dill, 1996). This perspective therefore points to what has been called the "simultaneity of oppression," recognizing the theoretical impossibility of isolating the unique effects of any one form of oppression in shaping an individuals' attitudes and experiences. By focusing on the unique experiences of individuals at specific sites of intersection, this perspective seeks to move beyond the 
traditional dominant/subordinate bifurcation, allowing a more fluid, nuanced understanding of individuals' situation-specific experiences with power.

While the preliminary theoretical development of intersection analysis has focused on intersections of gender, race, and class, it is clear that intersectionality by definition includes any system of oppression which proves to be salient in individuals' lives. In the case of sexual health, therefore, the interaction of sexuality as a system of oppression must be considered. Following Patricia Hill Collins (2000), I conceptualize sexuality as a "site where heterosexualism, class, race, nation, and gender as systems of oppression converge." While women's experiences with sexuality (constrained by compulsory heterosexuality and the powerlessness resulting from traditional femininity) have been extensively considered, the implications of the additional layers of race/ethnicity and class are yet to be investigated systematically in the context of women's sexual health practices.

Though much of the analysis conducted in the intersection tradition has focused on women's experiences, a critical analysis of patriarchal relations requires that men's experiences with masculinity also be considered and deconstructed. In recent years several scholars have examined the unique ways that gender shapes men's lives and interacts with other systems of privilege and oppression (Kimmel and Messner, 2001). In addition, attention has also turned to the experience of whiteness and the implications of majority racial status in a racially stratified society. Overall, the move toward intersection analysis represents a continuation of the effort to understand race/ethnicity, gender, and class as purely social rather than physical attributes, which has special salience in the study of sexuality and health. 
Adolescence represents a crucial time in the development of sexual identity, but it also marks the point at which other categories of identity become particularly salient. As adolescents' social worlds broaden during the high school years, the need to claim racial/ethnic identities (and thus to more fully experience their consequences) increases dramatically (Taylor, Gilligan, and Sullivan, 1995). In addition, while time spent in mixed-sex groups increases during adolescence, the boundaries governing the appropriate performance of femininity and masculinity are also enforced more rigorously at this time (Martin, 1996). The macrolevel forces of privilege and oppression are thus evident in the lives of adolescents, and there is reason to believe that these factors impact the sexual decision making of adolescents.

\section{Gender, Race/Ethnicity, and All Predictor Variables}

I first present bivariate tables reporting the gender distribution on all predictors separately by four key racial/ethnic categories: African Americans, Asians, European Americans, and Hispanics. Within each table I report the percentage of adolescents reporting the "positive" response. For the health beliefs and gender ideals, positive responses are associated with those health beliefs predicted to reduce sexual risk behavior. The direction of the relationship between the cues to action and preventive health behaviors is more complex; therefore, the table simply represents an answer of "yes" on each of the cues to action questions. The chi-square statistic is used to determine the statistical significance of the difference between female's and male's responses. 
Table 10.1 Predictor Variables by Gender, African American Adoles cents

\begin{tabular}{|c|c|c|c|}
\hline & Females & Males & Sig. \\
\hline & $(N=1410)$ & $(N=1422)$ & \\
\hline Health Beliefs & $\%$ & $\%$ & \\
\hline Risk of Pregnancy & 82.4 & 76.2 & $* * *$ \\
\hline Risk of AIDS & 82.5 & 78.4 & * \\
\hline Now Worst Time for Pregnancy & 75.2 & 75.5 & \\
\hline AIDS Causes Suffering & 83.1 & 86.5 & * \\
\hline Benefits of Avoiding Pregnancy (scale) & 14.2 & 13.8 & \\
\hline Birth Control Is Not Too Difficult to Use & 69.5 & 65.9 & \\
\hline Able to Refuse Sex if No Birth Control & 79.7 & 63.5 & $* * *$ \\
\hline \multicolumn{4}{|l|}{ Cues to Action } \\
\hline Leamed about Pregnancy in School & 89.9 & 85.1 & $* * *$ \\
\hline Leamed about AIDS in School & 91.5 & 90.7 & \\
\hline Hours of TV Watched per Week & 29.4 & 26.3 & \\
\hline Discussed Problems with Female Friend & 59.9 & 32.2 & $* * *$ \\
\hline Discussed Problems with Male Friend & 46.9 & 34.1 & $* * *$ \\
\hline Good Communication with Parent & 80.0 & 85.9 & $* * *$ \\
\hline Parent Disapproves of Adolescent Sex & 78.4 & 55.6 & $* * *$ \\
\hline \multicolumn{4}{|l|}{ Gender Ideals } \\
\hline \multicolumn{4}{|l|}{ More Attractive to Opposite Sex if } \\
\hline Known to be Sexually Active (disagree) & 67.5 & 37.5 & $* * *$ \\
\hline \multicolumn{4}{|l|}{ More Respected by Peers if } \\
\hline Known to be Sexually Active (disagree) & 61.8 & 32.8 & $* * *$ \\
\hline$p<.05^{*} \quad p<.01^{* *} \quad p<.001^{* * *}$ & & & \\
\hline
\end{tabular}

Table 10.1 reveals a number of significant differences between the attitudes of African American females and males. African American females report higher perceptions of susceptibility to the possibility of negative outcomes resulting from sexual intercourse, while males are more likely to view the suffering from AIDS as severe. African American females are significantly more likely than males to report that they could resist sexual intercourse if birth control was not available. Females are more likely to report that they tum to friends (both female and male) to discuss problems, though more males report having good communication with a parent. 
Table 10.2 Predictor Variables by Gender, Asian Adolescents

\begin{tabular}{|c|c|c|c|}
\hline & Females & Males & Sig. \\
\hline & $(\mathrm{N}=297)$ & $(\mathrm{N}=332)$ & \\
\hline Health Beliefs & $\%$ & $\%$ & \\
\hline Risk of Pregnancy & 84.4 & 78.5 & \\
\hline Risk of AIDS & 88.9 & 84.4 & \\
\hline Now Worst Time for Pregnancy & 86.0 & 82.4 & \\
\hline AIDS Causes Suffering & 81.3 & 82.4 & \\
\hline Benefits of Avoiding Pregnancy (scale) & 19.1 & 18.3 & \\
\hline Birth Control Is Not Too Difficult to Use & 45.7 & 58.6 & ** \\
\hline Able to Refuse Sex if No Birth Control & 69.2 & 60.3 & * \\
\hline \multicolumn{4}{|l|}{ Cues to Action } \\
\hline Learned about Pregnancy in School & 86.0 & 85.8 & \\
\hline Learned about AIDS in School & 91.5 & 95.3 & \\
\hline Hours of TV Watched per Week & 13.8 & 18.7 & * \\
\hline Discussed Problems with Female Friend & 66.6 & 33.1 & $* * *$ \\
\hline Discussed Problems with Male Friend & 42.6 & 33.5 & $* * *$ \\
\hline Good Communication with Parent & 80.2 & 85.3 & \\
\hline Parent Disapproves of Adolescent Sex & 89.4 & 81.6 & ** \\
\hline \multicolumn{4}{|l|}{ Gender Ideals } \\
\hline \multicolumn{3}{|l|}{ More Attractive to Opposite Sex if } & $* * *$ \\
\hline \multicolumn{4}{|l|}{ More Respected by Peers if } \\
\hline Known to be Sexually Active (disagree) & 62.5 & 44.3 & $* * *$ \\
\hline $\mathrm{p}<.05^{*} \quad \mathrm{p}<.01^{* *} \quad \mathrm{p}<.001^{* * *}$ & & & \\
\hline
\end{tabular}

Interestingly, African American females are 23 percent more likely than their male counterparts to report that their parent(s) would disapprove of their being sexually active. As predicted, males are much more likely than females to agree with the idealized gendered sexuality statements: over 60 percent of African American males believe they would be more respected and attractive if known to be sexually active.

The attitudes reported by Asian adolescents do not vary a great deal by gender. ${ }^{29}$ Alarmingly, over half of the Asian females agree that birth control is too difficult to use,

\footnotetext{
${ }^{29}$ It is possible that the lack of significant differences among Asian adolescents may stem from the small sample size. For example, the percent difference on the "risk of pregnancy" variable is $6.2 \%$ for African Americans, while the difference is $5.9 \%$ for Asian adolescents.
} 
though 70 percent claim they would be able to resist sex if no birth control were available. Again, females were more likely than males to report discussing problems with friends. Asian adolescents also feel that their parents would be opposed to their being sexually active, with 89.4 percent of females and 81.6 percent of males reporting parental disapproval. Asian males are more likely than Asian females to ascribe to ideals of gendered sexuality, though the percent differences by gender are the smallest of any racial/ethnic group.

Table 10.3 Predictor Variables by Gender, European American Adolescents

\begin{tabular}{|c|c|c|c|}
\hline & Females & Males & Sig. \\
\hline & $(\mathrm{N}=6004)$ & $(\mathrm{N}=6217)$ & \\
\hline Health Beliefs & $\%$ & $\%$ & \\
\hline Risk of Pregnancy & 87.8 & 78.6 & *** \\
\hline Risk of AIDS & 85.7 & 74.9 & $* * *$ \\
\hline Now Worst Time for Pregnancy & 84.1 & 88.1 & *** \\
\hline AIDS Causes Suffering & 87.9 & 87.8 & \\
\hline Benefits of Avoiding Pregnancy (scale) & 16.8 & 16.9 & \\
\hline Birth Control Is Not Too Difficult to Use & 69.3 & 69.8 & \\
\hline Able to Refuse Sex if No Birth Control & 84.5 & 67.6 & *** \\
\hline \multicolumn{4}{|l|}{ Cues to Action } \\
\hline Leamed about Pregnancy in School & 87.6 & 83.5 & *** \\
\hline Learned about AIDS in School & 91.1 & 92.8 & ** \\
\hline Hours of TV Watched per Week & 16.5 & 18.3 & \\
\hline Discussed Problems with Female Friend & 74.4 & 36.5 & *** \\
\hline Discussed Problems with Male Friend & 55.6 & 39.9 & *** \\
\hline Good Communication with Parent & 82.4 & 87.7 & *** \\
\hline Parent Disapproves of Adolescent Sex & 83.8 & 75.5 & *** \\
\hline \multicolumn{4}{|l|}{ Gender Ideals } \\
\hline \multicolumn{4}{|l|}{ More Attractive to Opposite Sex if } \\
\hline Known to be Sexually Active (disagree) & 64.3 & 40.1 & *** \\
\hline \multicolumn{4}{|l|}{ More Respected by Peers if } \\
\hline Known to be Sexually Active (disagree) & 73.1 & 41.4 & *** \\
\hline$p<.05^{*} \quad p<.01^{* *} \quad p<.001^{* * *}$ & & & \\
\hline
\end{tabular}


There are significant $(\mathrm{p}<.001)$ gender differences on all but four indicator variables among European American adolescents. Females again exhibit a higher degree of agreement with the susceptibility variables, while males view the potential of pregnancy more severely than females. Almost a third of European American males report that they would probably not be able to resist having sex in the absence of birth control. European American females report a great deal of reliance on friends, with 74.4 percent discussing problems with a female friend and over half speaking with male friends. A small but significant (8.3 percent) difference exists in European American adolescents views on how their parents feel about their sexual activity. Finally, European

Table 10.4 Predictor Variables by Gender, Hispanic Adolescents

\section{Health Beliefs}

Risk of Pregnancy

Risk of AIDS

Now Worst Time for Pregnancy

AIDS Causes Suffering

Benefits of Avoiding Pregnancy (scale)

Birth Control Is Not Too Difficult to Use

Able to Refuse Sex if No Birth Control

Cues to Action

Learned about Pregnancy in School

Learned about AIDS in School

Hours of TV Watched per Week

Discussed Problems with Female Friend

Discussed Problems with Male Friend

Good Communication with Parent

Parent Disapproves of Adolescent Sex

\section{Gender Ideals}

More Attractive to Opposite Sex if

Known to be Sexually Active (disagree)

More Respected by Peers if

Known to be Sexually Active (disagree)

$p<.05^{*} p<.01^{* *} \quad p<.001^{* * *}$

$\begin{array}{lcc}\text { Females } & \text { Males } & \text { Sig. } \\ (\mathrm{N}=499) & (\mathrm{N}=518) & \end{array}$

$\begin{array}{lll}79.0 & 74.5 & \\ 83.4 & 75.6 & * * \\ 74.8 & 82.2 & * \\ 81.3 & 88.3 & * * \\ 16.2 & 15.9 & \\ 53.3 & 63.6 & * * \\ 71.2 & 61.7 & * *\end{array}$

84.6

83.3

88.0

93.4

18.9

22.8

59.0

38.4

42.4

36.1

78.2

86.1

84.1

62.7

68.9

36.8

69.1

$43.2 \quad * * *$

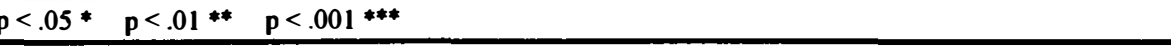


American adolescents are the most likely to reject traditional ideals of gendered sexuality, though females are still much more likely to do so compared with males.

Finally, Table 10.4 presents the differences in all predictors by gender for Hispanic adolescents. While Hispanic females are more likely than males to feel susceptible to AIDS, they view the severity of AIDS less harshly than males. As in the case of Asian adolescents, there is a large gender gap in views on the ability to use birth control, with Hispanic males exhibiting a greater sense of efficacy than Hispanic females. Hispanic males report better communication with parents than Hispanic females, while Hispanic females rate their parents' disapproval of sex much higher than do Hispanic males. Approximately 70 percent of Hispanic females reject the gendered sexuality ideals, while a similar proportion of Hispanic males embrace these norms.

In sum, it appears that there are significant gender differences in the majority of the predictor variables within each racial/ethnic group; this confirms my hypothesis that health beliefs, cues to action, and gender ideals are likely to vary by social location. A few key race-based differences stand out as well. While Hispanic and European American adolescents have similar views on the benefits of avoiding pregnancy, African American adolescents report relatively low scores on this scale while Asian adolescents score higher relative to Hispanic and European Americans. A smaller proportion of African American adolescents also reject the statement that being sexually active increases the respect given by peers. Both of these results suggest that the beliefs of African American adolescents may place them at increased risk for sexual risk behavior, relative to their Hispanic, Asian, and European American peers. 


\section{Gender, Race/Ethnicity, and the Transition to Sexual Intercourse}

Previous research indicates that racial/ethnic differences in the age at transition to sexual intercourse may be the primary reason for ongoing sexual health disparities in the United States. Indeed, there are significant racial/ethnic differences in rates of STD infection as well as in unplanned pregnancies (CDC, 2001). Much research fails to consider race/ethnicity and gender simultaneously, however, missing crucial social location distinctions in sexual health behavior. In this section I examine the distribution of age at first intercourse by race/ethnicity and gender to determine the extent to which demographic differences exist within the AddHealth sample.

Table 10.5 The Transition to First Sexual Intercourse, African American Adolescents

\begin{tabular}{lcc}
\hline & \multicolumn{1}{c}{ Females } & Males \\
\cline { 2 - 3 } Mean Age at Transition & 16 years, 8 months & 15 years, 6 months \\
25th Percentile & 15 years, 0 months & 13 years, 7 months \\
50th Percentile (median) & 16 years, 5 months & 15 years, 8 months \\
75th Percentile & 18 years, 4 months & 18 years, 0 months \\
Percent Censored (No Transition) & $53.36 \%$ & $44.33 \%$ \\
\hline Observations & 2155 & 1782 \\
\hline
\end{tabular}

Table 10.5 reveals several notable differences in the age at transition to first sexual intercourse for female and male African American adolescents. African American males experience a much younger average age at transition compared to African American females. A quarter of the sexually active African American males had made the transition to intercourse before their $14^{\text {th }}$ birthday, which is considerably younger than any other group in the sample. African American males are also much more likely to be 
sexually active; this is the only group in which over half of the adolescents had made the transition to intercourse by the time of the AddHealth interview.

Table 10.6 The Transition to First Sexual Intercourse, Asian Adolescents

\begin{tabular}{lcc}
\hline & \multicolumn{1}{c}{ Females } & Males \\
\cline { 2 - 3 } Mean Age at Transition & 19 years, 2 months & 19 years, 1 month \\
25th Percentile & 16 years, 10 months & 16 years, 11 months \\
50th Percentile (median) & NA & 19 years, 6 months \\
75th Percentile & NA & NA \\
Percent Censored (No Transition) & $76.21 \%$ & $76.27 \%$ \\
\hline Observations & 601 & 670 \\
\hline
\end{tabular}

Table 10.6 illustrates how dramatically the sexual behavior of Asian adolescents differs from the rest of the sample. The average age at transition for both female and males is fully two years later than for non-Asians. Given the high number of censored cases, the median and $75^{\text {th }}$ percentile cannot be calculated as too few adolescents have experienced the transition to sexual intercourse. Most striking is the fact that only a quarter of Asian females and males report sexual intercourse, the smallest proportion in the sample.

Table 10.7 The Transition to First Sexual Intercourse, European American Adolescents

\begin{tabular}{lcc}
\hline & \multicolumn{1}{c}{ Females } & Males \\
\cline { 2 - 3 } Mean Age at Transition & 17 years, 3 months & 17 years, 7 months \\
25th Percentile & 15 years, 7 months & 15 years, 11 months \\
50th Percentile (median) & 17 years, 0 months & 17 years, 7 months \\
75th Percentile & 19 years, 0 months & NA \\
Percent Censored (No Transition) & $64.44 \%$ & $67.13 \%$ \\
\hline Observations & 5110 & 4923 \\
\hline
\end{tabular}


The results in Table 10.7 point to substantial gender differences among European American adolescents. Young women experience the transition to sexual intercourse approximately four months earlier on average compared to young men. In addition, the age at transition is lower at each quartile for young women, suggesting that the gender differences in age at debut continue throughout adolescence for European Americans. Finally, a greater proportion of European American females than males in the sample had experienced sexual intercourse.

Table 10.8 The Transition to First Sexual Intercourse, Hispanic Adolescents

\begin{tabular}{|c|c|c|}
\hline & Females & Males \\
\hline Mean Age at Transition & 17 years, 8 months & 17 year, 1 month \\
\hline 25th Percentile & 16 years, 0 months & 15 years, 2 months \\
\hline 50th Percentile (median) & 18 years, 2 months & 17 years, 5 months \\
\hline 75th Percentile & NA & 19 years, 8 months \\
\hline Percent Censored (No Transition) & $68.05 \%$ & $58.13 \%$ \\
\hline Observations & 795 & 781 \\
\hline
\end{tabular}

Lastly, Table 10.8 reveals the gender differences in the age at transition for Hispanic adolescents. Here we see that Hispanic males experience sexual debut at an earlier average age than Hispanic females. In addition, there is a 10 percent gender difference in the proportion of Hispanic adolescents who are sexually active.

The results in these four tables demonstrate that the unique social locations created by the intersection of race/ethnicity and gender result in substantial differences in a key sexual health behavior, the age at transition to sexual intercourse. In addition, these results reveal that no single pattern applies across gender or racial/ethnic group-in the case of African Americans and Hispanics young men experience an earlier transition, 
European American females transition to intercourse earlier than European American males, and no gender difference in age at debut exits among those of Asian descent.

This intersection analysis of the predictor variables and the age at transition to sexual intercourse reveals that the specific social locations created by the interaction of gender and race/ethnicity are likely to contribute to differences in sexual decision making among adolescents. Unfortunately, this is exceedingly difficult to model statistically, as multiplicative interaction terms are nearly impossible to interpret. While separate models can be estimated by race/ethnicity or gender, this makes the direct comparison of the magnitude and significance of effects impossible. Moreover, the reduction in sample size that results from subgroup analysis results in low levels of significance. Currently this statistical difficulty represents a major problem in intersection analysis and is the focus of much debate, as researchers attempt to create methods able to accommodate the challenges of interaction terms. I believe it is clear, however, both from the exploratory analysis presented in this chapter and the force of the theoretical arguments in their favor, that a consideration of the intersection of race/ethnicity, gender, and other dimensions of inequality has the potential to offer much-needed insight into the social determinants of health disparities. 


\section{CHAPTER ELEVEN: Conclusions and Future Directions}

In this work I have considered when, with whom, and how (protected or not) adolescents decide to engage in heterosexual intercourse; these are the three questions adolescents themselves identify as being at the heart of their sexual decision making. My primary contention has been that although the Health Belief Model may serve as a useful tool for predicting adolescent sexual decision making, the embeddedness of sexual behavior within the cultural discourse of gendered sexuality suggests that gender should modify the Health Belief Model in meaningful ways. In short, I have argued that a sociological understanding of the construction and performance of gender can improve our understanding of a crucial public health issue, adolescent sexual health. The findings from both my qualitative interviews with adolescents and my analysis of the National Longitudinal Study of Adolescent Health provide evidence for this claim, and though the majority of my findings are in line with traditional thinking about adolescent sexual behavior there are a number of findings that require additional attention.

In this final chapter I will first review how and why I have hypothesized that gendered sexuality should influence the decisions adolescents make about their sexual behavior. I then review the role of health beliefs, cues to actions, and gender ideals in adolescent sexual decision making. After discussing the potential policy implications of my research, I conclude with a brief consideration of the limitations of this study and an exploration of future directions for my research. 


\section{Summary of Findings}

Gendered Sexuality in Adolescent Health. I have argued that the decisions adolescents make about their sexual behaviors are motivated by both health and social concerns. The first step in my research was thus to establish whether adolescents themselves acknowledge the health risks and social implications of adolescent sexuality. My interviews with adolescents established that health concerns do enter into adolescent sexual decision making, though such concerns are moderated by the typical adolescent sense of invincibility. The adolescents noted, however, that the health concerns associated with sexual activity applied primarily to young women, who are expected to take steps to protect themselves from unintended pregnancies and STDs.

My interviews also revealed the central role that expectations about gender play in adoelscent sexual decision making. Interestingly, young men felt themselves to be much more constrained by gender than their female peers. My male respondents consistently noted how their male peers and the media encourage sexual behavior; indeed, many males suggested that the immense emphasis placed (often by parents and sex education) on the risks women face from sex actually serves to underscore how consequence-free sex is for young men. Both females and males extensively discussed the connection between sexual behavior and social reputation, noting that while young men's reputations are enhanced by sexual behavior, young women's reputations can be devastated by even the implication of sexual desire.

Having ascertained a link between adolescent sexual decision making, health, and gendered sexuality, I then turned to my statistical analysis of the AddHealth data. I selected several sexual behaviors to which I applied my modified Health Belief Model. 
From a statistical standpoint, the model I developed actually works best to predict the decision to remain sexually abstinent, as the pseudo $\mathrm{R}^{2}$ for the full model reaches .21 (this is roughly analogous to saying that a fifth of the variance in the decision to remain sexually abstinent can be explained by the predictors I selected for the model). The pseudo $\mathrm{R}^{2}$ is considerably lower for the decision to avoid non-romantic sexual encounters and the decision to use birth control, both of which represent decisions made subsequent to the original decision to become sexually active.

To summarize the findings from Chapters Six through Nine, I have created a summary measure which considers the relative influence of each of the health beliefs, cues to action, and gender ideals. Following Janz and Becker (1984), I constructed a "significance ratio" by counting the number and direction of all significant results from each of the models estimated. In order to account for gender differences, I calculated this measure separately for young women and men. ${ }^{30}$

\footnotetext{
${ }^{30}$ There were 34 possible occurrences of each health belief, 25 occurrences of each cue to action, and 5 possible occurrences of each gender ideal. I summed the nurnber of times each coefficient reached significance (considering positive and negative results separately) and divided by the total number of occurrences for that variable.
} 
Table 11.1 Significance Ratios for All Health Beliefs, Cues to Action, and Gender Ideals

\begin{tabular}{lcccc}
\hline & \multicolumn{2}{c}{ Males } & \multicolumn{2}{c}{ Females } \\
\cline { 2 - 6 } & Protective & Risk & Protective & Risk \\
\hline Health Belief Model & & & & \\
Risk of Pregnancy & 0.29 & - & 0.32 & -- \\
Risk of AIDS & 0.20 & -- & 0.20 & -- \\
Now Worst Time for Pregnancy & 0.32 & & 0.50 & -- \\
AIDS Causes Suffering & -- & 0.29 & -- & 0.23 \\
Benefits of Avoiding Pregnancy Scale & 0.38 & -- & 0.38 & -- \\
Birth Control Is Not Too Difficult to Use & 0.50 & 0.03 & 0.29 & 0.29 \\
Able to Refuse Sex if No Birth Control & 1.00 & -- & 1.00 & -- \\
Cues to Action & & & & \\
Good Communication with Parent & 0.20 & -- & 0.24 & -- \\
Parent Disapproves of Sex & 0.16 & 0.24 & 0.16 & 0.24 \\
Learned about Pregnancy in School & 0.12 & 0.04 & 0.24 & 0.04 \\
Learned about AIDS in School & 0.04 & -- & 0.04 & -- \\
Hours of TV per Week & -- & 0.32 & 0.24 & 0.12 \\
Talked to Female Friend about Problems & -- & 0.16 & -- & 0.12 \\
Talked to Male Friend about Problems & -- & 0.16 & -- & 0.16 \\
Attended Youth Group & 0.28 & -- & 0.28 & -- \\
Gender Ideals & & & & \\
More Respected if Sexually Active (disagree) & 0.60 & -- & 0.60 & -- \\
More Attractive is Sexually Active (disagree) & -- & -- & -- & -- \\
\hline Note: Table reports relative influence of all variables over all models. & & \\
\hline
\end{tabular}

Health Beliefs. Table 11.1 reports the significance ratios for each predictor variable, which reveal the relative influence of the health beliefs, cues to action, and gender ideals. These significant ratios can be interpreted as the number of times that each variable was found to be a significant predictor in my models, and also whether the variable operates as a risk or protective factor in adolescent sexual decision making. For example, the significance ratio of .29 for males on the "risk of pregnancy" variable indicates that this was a significant predictor of males' sexual health behaviors in 29 percent of my models. Moreover, the "risk of pregnancy" variable operates as a protective factor for males, meaning that those males who report feeling at risk for impregnating someone are more likely to protect themselves against sexual health risks. A significance ratio of .23 for 
females on the "AIDS causes suffering" variable indicates that this was a significant risk factor for females in 23 percent of my models, increasing their risk of engaging in risky sexual behavior. The significance ratio of 1.00 for the "able to refuse sex if no birth control" variable indicates that this variable was significant for both females and males in all of my models.

My results generally conform to Janz and Becker's (1984) meta-analysis of 29 studies using the Health Belief Model, which found barriers and benefits to be the most consistent predictors across studies. For both females and males, one of my measures of barriers is the most consistent predictor of preventive health behaviors. Those adolescents who exhibit high levels of birth control efficacy (i.e.,, those who do not perceive barriers to birth control use) were consistently more likely to avoid sexual risk behavior. My measures of susceptibility were significant in the fewest number of cases for both females and males; this may result from high overall levels of sexual health knowledge among the respondents

Cues to Action. The findings in Table 11.1 regarding the role of cues to action in adolescent sexual decision making reveal a number of mixed results. Some of these findings are predicted by previous research, and my findings further underscore the influence of gender. The fact that parents operate as both a protective and risk factor is consistent with existing literature on family communication about adolescent sexual behavior. Many studies have found positive, honest communication between parents and children to be highly effective in reducing adolescent sexual risk behavior; indeed, adolescents often express a desire for more openness with parents (Moore, Peterson, and 
Furstenberg, 1986). Studies have also found, however, that adolescents whose parents use coercive means (such as grounding or shaming) in an attempt to control sexual behavior often react with increased participation in sexual risk behavior (Miller et al., 1986).

The results for school-based sex education are similarly mixed and differ by gender as well. Sex education about HIV/AIDS had little effect for either females or males, which is disturbing given the rapidly increasing rate of HIV infection among young adults. Interestingly, sex education about pregnancy acts as both a protective and risk factor. It is impossible from these results to conclude why leaming about pregnancy increases sexual risk behavior, though many of my adolescent interviewees suggested that leaming the facts about pregnancy allowed them to put those risks aside. That is to say, adolescents who understand how pregnancy occurs may not feel themselves to be at as a great a risk as those for whom pregnancy remains a mystery. It is important to remember, however, that sex education operates primarily as a protective factor, and should certainly not be discounted.

Exposure to media exhibits further differences by gender. For young men, media exposure increases sexual risk behavior. Indeed, this variable has the single largest significance ratio for young men, suggesting it plays a crucial role in shaping male adolescent sexual behavior. Previous research suggests that this finding makes good sense, given how media are used by adolescents. Research conducted for the Kaiser Family Foundation reports that adolescents seek out sexual content in the media as an easy, unembarrassing means of leaming about sex (Huston, Wartella, and Donnerstein, 1998). Given that young men are less likely to discuss factual information about sex with 
their parents and peers, coupled with the fact that many adolescents feel that sex education is primarily aimed at young women, it is little surprise that the media hold such sway over adolescent males. Moreover, the depiction of sex as consequence-free and imperative for gaining social status helps to explain why media should act as a risk factor for young men. This reasoning also explains why the influence of media is smaller for young women. In addition to receiving information about sex from a variety of other sources, the media often show young women suffering negative consequences from sexual activity.

Finally, it appears that peers play a comparable role in the sexual behavior of females and males. Talking with same-sex and opposite-sex peers operates as a risk factor, though the significance ratios are among the smallest, suggesting the influence of one-on-one interactions with peers to be limited. The effect of attending youth groups is unambiguous, however, as this cue to action is the strongest protective factor for females and is second largest for males. In their study of adolescents who pledged to remain virgins, Bearman and Brückner (2001) found that associating with like-minded peers in a youth group raised the social cost of sexual risk behavior, indicating that the real power of peers may be in their development and enforcement of subcultural group norms. This is in keeping with my interviews with adolescents, who described peer pressure as a rather amorphous group phenomenon for which no one individual was primarily responsible.

Gender Interactions and Gender Ideals. Given the central role of gender in my dissertation, I have operationalized the influence of gender in adolescent sexual decision 
making in two distinct ways in my statistical models-by interacting gender with all predictors and through the inclusion of variables representing gender ideals. Both of these strategies produced a number of significant results, confirming that differences exist in females' and males' sexual decision making processes.

In many cases, the inclusion of gender interaction terms alters the magnitude or significance of the health belief variables. Though the majority of health beliefs are significant in each of the initial models, the variables representing the risk of pregnancy (a measure of perceived susceptibility) and the benefits of avoiding pregnancy both become non-significant when gender is introduced into the model. One of the measures of benefits-disagreeing that birth control is too difficult to use-switches direction when gender is included. Young women who agree that birth control is too difficult to use are more likely to have become sexually active, possibly pointing to the important role of self-efficacy in avoiding sexual health risks; the variable operates in the predicted direction in the case of both avoidance of non-romantic sex and the use of birth control, however. In addition, the inclusion of cues to action also alters the health beliefs in at least one case-when peers are added into the model, susceptibility to AIDS loses significance. As the cues to action are hypothesized to act as a pathway for gender socialization, this result further confirms that gender plays a role in sexual decision making.

In addition to the gender interactions, one of the measures I have used to represent how the discourse of gendered sexuality enters into adolescent sexual decision making is highly significant in a number of the models. The significance ratio for the "more respected if sexually active" variable is the second highest of all predictors; only ability 
to refuse sex if no birth control is available (a measure of barriers) is stronger. This is clear evidence that gender ideals and health beliefs both matter significantly in adolescent sexual decision making, supporting the overarching hypothesis guiding my research.

\section{Policy Implications}

Adolescent sexuality has been the focus of intense public debate, pitting what many would view as an ideal-adolescent sexual abstinence-against the more practical desire to ensure that adolescents who do engage in sex do so in as safe a manner as possible. The results of my analysis indicate that the protective factors I have identified - health beliefs and a rejection of traditional gender ideals-work best to predict sexual abstinence, while the predictors of other sexual health practices are left largely unexplained. This finding has direct implications for the timing and curriculum content of school-based sex education.

School-based sex education must seriously address the potential health risks associated with sexual intercourse as early as possible, in middle school if local public opinion allows. Many of my adolescent respondents reported not having been exposed to the graphic realities of STDs until their senior year of high school; indeed, several noted that the pictures of syphilis chancres and genital warts truly made them think twice about unprotected sexual intercourse. Moreover, my analysis of the age at transition to sexual intercourse reveals that a substantial proportion of certain groups (most notably African American males) become sexually active during the middle school years. Given that adolescents who delay sexual intercourse consequently have fewer sexual partners during 
adolescence and are more likely to use birth control consistently, efforts to delay sexual intercourse result in a reduction of sexual risk behavior.

School-based sex education should also continue to be sex-segregated throughout the high school years, as the pressure adolescents feel to perform gender appropriately undoubtedly influences their experiences in sex education classes. This is especially true for young men, who may be harassed by their peers if they display a lack of sexual knowledge or experience. Young women may also feel unable to openly discuss their sexual needs and desires, a crucial aspect of sexual development, in front of their male peers. Continuing sex-segregation might allow sex education courses to more fully recognize their potential as a site where open discussions about sexuality can begin, ideally under the guidance of a qualified instructor who can respond to adolescents' concerns with accurate information and insight.

\section{Study Limitations and Future Directions}

Most sociological studies suffer from some type of design flaw, due to limited resources such as time or money. This study is no exception, though I have attempted to minimize the impact of these limitations to the greatest extent possible by employing a mixed method design. It is important, however, to review the limitations of this study and to consider their implications for the results I have presented.

My goal in conducting qualitative interviews with a sample of adolescents was to gain insight into adolescent culture by listening to the voices of adolescents themselves as they described their sexual decision making processes. The sample that I interviewed was extremely homogeneous, however, raising questions about the range of adolescent 
culture that I have been able to describe. First, the constraints imposed by the Institutional Review Board required that I interview adolescents who were at least 18 years of age. While I interviewed only adolescents who were still living at home (and presumably still acting as their parents' children rather than independent adults), there is little doubt that these adolescents' experiences with sexuality differ significantly from those of their younger peers. It is likely that these adolescents viewed themselves as less constrained by bonds with parents and peers than younger adolescents might, and though this may be a result of faulty retrospective recall it is impossible to determine within this study.

In addition to the limited age range of my respondents, my respondents also shared many demographic similarities. All were from upper-middle class families and all were college-bound. With the exception of the two Asian American adolescents all were of European descent, suggesting that the view of adolescent culture I developed was in fact a picture of privileged white adolescent culture. Several of the adolescent respondents also came from the same social clique (a consequence of snowball sampling no doubt), further increasing the likelihood that they shared similar views on sexuality.

To address the limited generalizability of my qualitative work, I conducted statistical analyses of one of the largest, most comprehensive studies of adolescent health currently available. The National Longitudinal Study of Adolescent Health (AddHealth) presented a number of difficulties for my research as well, however. The most significant problem for my research posed by the AddHealth data set is the lack of measures of gender ideals. I have chosen two variables which capture adolescents' opinions on the consequences of sexual activity, but these variables do not directly address the cultural 
discourse of gendered sexuality which is the central focus of my study. Though significant gender differences in these sexuality variables suggest that they do approximate views on gendered sexuality, that such an important aspect of my research cannot be directly assessed is regrettable. Ideally, measures which directly assess the connection between normative heterosexuality and the performance of gender would be preferable, including agreement or disagreement with statements such as whether women should be passive and males dominant in sexual encounters. Such measures have been included in other major health studies and would have expanded the sociological analyses which could be undertaken with the AddHealth data.

Another major shortcoming of this study is the assumption of heterosexuality; this arises from my inability to determine my adolescent respondents' sexual orientations (I was forbidden from asking intimate questions by the Institutional Review Board) coupled with inadequate measures of orientation in the AddHealth data. Given that the cultural discourse of gendered sexuality relates exclusively to heterosexual orientation, there is little doubt that the role of gender ideals in sexual decision making would differ significantly for adolescents who identify as lesbian, gay, or bisexual. Evidence from previous studies support this assumption, finding that adolescents who later came to identify as lesbian, gay, and bisexual were more likely to "overperform" their traditional gender role within heterosexual relationships during their youth in order to reduce the risk of being "outed" as homosexual. For example, a retrospective study of women who came to identify as lesbian or bisexual as adults found that during adolescence they were significantly more likely than heterosexual adolescents to engage in sexual risk behavior, 
including greater frequency of intercourse and use of less effective methods of birth control, resulting in higher levels of unplanned pregnancy (Saewyc et al., 1999).

The limitations of both the qualitative and quantitative portions of my research point to the need for additional interviews with a more diverse group of adolescents. As I continue this research my primary goal will be to interview sufficient numbers of African American, Asian, and Hispanic adolescents (as well as additional European American adolescents) of all economic backgrounds and sexual orientations, to be able to connect my qualitative findings to the quantitative analysis of racial/ethnic differences in sexual decision making. Conducting additional interviews will enable me to develop a richer understanding of how gendered sexuality operates in conjunction with race/ethnicity, social class, and sexual orientation, providing a deeper analysis that recognizes the unique voices of individuals at various social locations.

\section{Conclusions}

The goal of this work has been to more fully understand adolescent sexual decision making from the perspective of adolescents themselves. I have chosen to focus on the health risk perspective on adolescent sexual behavior, given its prevalence in public discussions of adolescent sexuality. I have also considered the role of traditional gender ideals in adolescent sexual decision making, believing sexuality and gender to be inextricably linked. Both of these discourses - health risk and gendered sexuality-are based on normative assumptions which I have left largely unexamined until this point in the interest of maintaining neutrality. It must be noted, however, that I do not believe that adolescent sexuality is risky in and of itself. Society has chosen to paint adolescent 
sexuality in negative terms for a number of reasons, including America's sexual prudishness. Adolescent sexuality only represents a health risk in American society because we have constructed it to be so, by withholding factual information about obtaining and using effective contraception and disease prevention and by eschewing open discussions about negotiating sexual relationships. The health risks adolescents face are thus specific to the way a society chooses to deal with adolescent sexuality, and health risks can be largely eliminated (as many European countries have demonstrated) if a society so chooses.

The real "risks" arising from adolescent sexuality may in fact be much more intimately tied to the ideology of gendered sexuality, and this is equally true for young women and young men. In short, the sexual scripts available to females and males may not square with their own desires for their sexual lives. Males may wish not to pursue numerous sexual relationships with little emotional attachment, and yet they may be judged harshly by their peers (and even by themselves) if they reject this dominant sexual script. Likewise, most females certainly would not choose to experience the social stigma of being known as a "slut," and yet most any sexual behavior outside the context of a single, committed relationship will likely result in such a label being assigned. If anything, this work demonstrates that the primary risk adolescents face, in their eyes at least, is the social risk of venturing beyond the boundaries of prescribed sexual scripts. It may be that what is seen as adolescents' lack of regard for the protection of their health actually derives from a more general sense of constraint; adolescents feel powerless to change the dominant norms of gendered sexuality, and this lack of efficacy may translate into an inability to make sexual decisions which protect their health. In this way, health 
beliefs and gender ideals may operate in a reciprocal fashion, suggesting that both must be addressed in an effort to ensure that adolescent sexual decision making allows adolescents to experience sexuality in a manner that is truly healthy in the broadest possible sense. 


\section{REFERENCES}

Abel, Elizabeth, Lucy Marion, and Anne Seraphine. 1998. "The Evaluation of Motivation for Sexual Health Among Women." Western Journal of Nursing Research 20:166-180.

Abma, Joyce, Anne Driscoll, and Kristin Moore. 1998. "Young Women's Degree of Control over First Intercourse: An Exploratory Analysis." Family Planning Perspectives 30:12-18.

Agha, Sohail. 2002. "A Quasi-Experimental Study to Assess the Impact of Four Adolescent Sexual Health Interventions in Sub-Saharan Africa." International Family Planning Perspectives 28:67-77.

AGI. 1999. "Facts in Brief: Teen Sex and Pregnancy." New York: The Allen Guttmacher Institute.

- 2002. "In Their Own Right: Addressing the Sexual and Reproductive Health Needs of American Men." New York: The Allen Guttmacher Institute.

Amaro, Hortensia, and Anita Raj. 2000. "On the Margin: Power and Women's HIV Risk Reduction Strategies." Sex Roles April:723-749.

Austin, Erika Laine. 2003. "Women's STD Prevention and Detection Practices: The Specificity of Social Location." Race, Class, Gender forthcoming.

Bartky, Sandra. 1990. Femininity and Domination. London: Routledge.

Bearman, Peter, and Hannah Brückner. 2001. "Promising the Future: Virginity Pledges and First Intercourse." American Journal of Sociology 106:859-912.

Bearman, Peter, Jo Jones, and Richard Udry. 1997. "The National Longitudinal Study of Adolescent Health: Research Design." Chapel Hill, NC: Carolina Population Center.

Blinn-Pike, Lynn. 1999. "Why Abstinent Adolescents Report They Have Not Had Sex: Understanding Sexually Resilient Youth." Family Relations 48:295-301.

Brewer, Rose M. 1993. "Theorizing Race, Class, and Gender: The New Scholarship of Black Feminist Intellectuals and Black Women's Labor." Pp. 13-30 in Theorizing Black Feminisms: The Visionary Pragmatism of Black Women, edited by Stalie James and Abena Busia. London: Routledge.

Brown, Jane, and Sarah Keller. 2000. "Can the Mass Media Be Healthy Sex Educators?" Family Planning Perspectives 32:255-256. 
CDC. 2001. "Special Focus Profiles: STDs in Racial and Ethnic Minorities." Atlanta, GA: Centers for Disease Control and Prevention.

—. 2002. "Young People at Risk: HIV/AIDS Among America's Youth." Atlanta, GA: Centers for Disease Control and Prevention.

Chilman, Catherine. 1990. "Promoting Healthy Adolescent Sexuality." Family Relations 39:123-131.

Christopher, F. Scott. 2001. To Dance the Dance: A Symbolic Interactionist Exploration of Premarital Sexuality. Mahwah, NJ: Lawrence Erlbaum Associates.

Clark, Liana, Alwyn Cohall, Alain Joffe, and Cynthia Starr. 1997. "Beyond the Birds and the Bees: Talking to Teens About Sex." Patient Care 31:102-117.

Clarke, Valerie, Hildegarde Lovegrove, Amanda Williams, and Michelle Macpherson. 2000. "Unrealistic Optimism and the Health Belief Model." Journal of Behavioral Medicine 23:367-376.

Collins, Patricia Hill. 2000. Black Feminist Thought: Knowledge, Consciousness and the Politics of Empowerment. New York: Routledge.

Condelli, Larry. 1986. "Social and Attitudinal Determinants of Contraceptive Choice: Using the Health Belief Model." Journal of Sex Research 22:478-491.

Connell, R. W. 1987. Gender and Power: Society, the Person, and Sexual Politics. Cambridge, UK: Polity Press.

Crockett, Lisa, C. Raymond Bingham, Joanne Chopak, and Judith Vicary. 1996. "Timing of First Sexual Intercourse: The Role of Social Control, Social Learning, and Problem Behavior." Journal of Youth and Adolescence 25:89-111.

Crosby, Richard. 1996. "Combating the Illusion of Adolescent Invincibility to HIV/AIDS." Journal of School Health 66:186-191.

Dailard, Cynthia. 2001. "Sex Education: Politicians, Parents, Teachers, and Teens." The Guttmacher Report on Public Policy 4:9-12.

DeGaston, Jacqueline, Stan Weed, and Larry Jensen. 1996. "Understanding Gender Differences in Adolescent Sexuality." Adolescence 31:217-231.

D'Emilio, John, and Estelle Freedman. 1988. Intimate Matters: A History of Sexuality in America. New York: Harper and Row. 
DiFranceiso, Wayne, Jeffrey Kelly, Kathleen Sikkema, Anton Somlai, Debra Murphy, and L. Yvonne Stevenson. 1998. "Differences Between Completers and Early Dropouts from 2 HIV Intervention Trials: A Health Belief Approach to Understanding Prevention Program Attrition." American Journal of Public Health 88:1068-1073.

Eisen, Marvin, Gail Zellman, and Alfred McAlister. 1992. "A Health Belief ModelSocial Learning Theory Approach to Adolescents' Fertility Control: Findings from a Controlled Field Trial." Health Education Quarterly 19:249-262.

Eisenstein, Zillah. 1979. "Developing a Theory of Capitalist Patriarchy and Socialist Feminism." Pp. 5-40 in Capitalist Patriarchy and the Case for Socialist Feminism, edited by Zillah Eisenstein. New York: Monthly Review Press.

Fausto-Sterling, Anne. 2000. Sexing the Body: Gender Politics and the Construction of Sexuality. New York: Basic Books.

Fine, Michelle. 1988. "Sexuality, Schooling, and Adolescent Females: The Missing Discourse of Desire." Harvard Educational Review 58:29-53.

Firestone, Shulamith. 1970. The Dialectic of Sex: The Case for Feminist Revolution. New York: Bantam.

Fisher, Jeffrey, Stephen Misovich, and William Fisher. 1992. "Impact of Perceived Social Norms on Adolescents' AIDS-Risk Behavior and Prevention." Pp. 117-136 in Adolescents and AIDS: A Generation in Jeopardy, edited by Ralph DiClemente. Newbury Park, CA: Sage.

Fisher, Terri. 1989. "An Extension of the Findings of Moore, Peterson, and Furstenberg (1986) Regarding Family Sexual Communication and Adolescent Sexual Behavior." Journal of Marriage and the Family 51:637-639.

Ford, Kathleen, Woosung Sohn, and James Lepkowski. 2001. "Characteristics of Adolescents' Sexual Partners and Their Association with Use of Condoms and Other Contraceptive Methods." Family Planning Perspectives 33:100-105, 132.

Forste, Renata, and David Haas. 2002. "The Transition of Adolescent Males to First Sexual Intercourse: Anticipated or Delayed." Perspectives on Sexual and Reproductive Health 34:184-190.

Fu, Haishan, Jacqueline Darroch, Taylor Haas, and Nalini Ranjit. 1999. "Contraceptive Failure Rates: New Estimates from the 1995 National Survey of Family Growth." Family Planning Perspectives 31:56-63.

Gage, Anastasia. 1998. "Sexual Activity and Contraceptive Use: The Components of the Decisionmaking Process." Studies in Family Planning 29:154-167. 
Gagnon, John, and William Simon. 1973. Sexual Conduct: The Social Sources of Human Sexuality. Chicago: Aldine.

Genuis, Stephen, and Shelagh Genuis. 1995. "Adolescent Sexual Involvement: Time for Primary Prevention." The Lancet 345:240-241.

Giddings, Paula. 1984. When and Where I Enter...The Impact of Black Women on Race and Sex in America. New York: William Morrow.

Gilligan, Carol. 1982. In a Different Voice: Psychological Theory and Women's Development. Cambridge, MA: Harvard University Press.

Goffman, Erving. 1963. "Stigma and Social Identity." Pp. 1-40 in Stigma: Notes on the Management of Spoiled Identity. New York: Simon \& Schuster.

Gutierrez, Lorraine, Hyun Joo Oh, and Mary Rogers Gilmore. 2000. "Toward an Understanding of (Em)Power(Ment) for HIV/AIDS Prevention with Adolescent Women." Sex Roles April:851-611.

Hartmann, Heidi. 1981. "The Unhappy Marriage of Marxism and Feminism: Towards a More Progressive Union." Pp. 1-41 in Women and Revolution: A Discussion of the Unhappy Marriage of Feminism and Marxism, edited by Lydia Sargent. Boston: South End Press.

Heins, Marjorie. 2001. "Sex, Lies, and Politics: Congress is Poised to Reauthorize Fearmongering 'Abstinence-Only' Sex Ed." The Nation 272:20-26.

Herold, Edward. 1983. "The Health Belief Model: Can it Help Us to Understand Contraceptive Use Among Adolescents?" Journal of School Health 53:19-21.

Hillier, Lynne, Lyn Harrison, and Deborah Warr. 1998. "'When You Carry Condoms All the Boys Think You Want It': Negotiating Competing Discourses About Safer Sex." Journal of Adolescence 21:15-29.

Hiltabiddle, Susan J. 1996. "Adolescent Condom Use, the Health Belief Model, and the Prevention of Sexually Transmitted Disease." JOGNN 25:61-66.

Hine, Thomas. 1999. The Rise and Fall of the American Teenager. New York: Harper Collins.

Holland, Janet, Caroline Ramazanoglu, Sue Sharpe, and Rachel Thomson. 1996.

"Reputations: Journeying into Gendered Power Relations." in Sexual Cultures:

Communities, Values, and Intimacy, edited by Jeffery Weeks and Janet Holland. London: Macmillan Press.

hooks, bell. 1984. Feminist Theory: From Margin to Center. Boston: South End Press. 
Huston, Aletha, Ellen Wartella, and Edward Donnerstein. 1998. "Measuring the Effects of Sexual Content in the Media: A Report to the Kaiser Family Foundation." Menlo Park, CA: The Kaiser Family Foundation.

Irvine, Janice. 1994. "Cultural Differences and Adolescent Sexualities." in Sexual Cultures and the Construction of Adolescent Identities. Philadelphia: Temple University Press.

Janz, Nancy, and Marshall Becker. 1984. "The Health Belief Model: A Decade Later." Health Education Quarterly 11:1-47.

Kaestle, Christine, David Morisky, and Dorothy Wiley. 2002. "Sexual Intercourse and Age Difference Between Adolescent Females and Their Romantic Partners." Perspectives on Sexual and Reproductive Health 34:304-305.

Kane, Emily, and Mimi Schippers. 1996. "Men's and Women's. Beliefs about Gender and Sexuality." Gender \& Society 10:650-665.

Kessler, Suzanne, and Wendy McKenna. 1985. Gender: An Ethnomethodological Approach. Chicago: University of Chicago Press.

Kimmel, Michael, and Michael Messner (Eds.). 2001. Men's Lives. Boston, MA: Allyn \& Bacon.

Kirby, Douglas. 1992. "School-Based Programs to Reduce Sexual Risk-Taking Behavior." Journal of School Health 62:280-287.

Kirby, Douglas, Lynn Short, Janet Collins, Deborah Rugg, Lloyd Kolbe, Marion Howard, Brent Miller, Freya Sonenstein, and Laurie Zabin. 1994. "School-Based Programs to Reduce Sexual Risk Behaviors: A Review of Effectiveness." Public Health Reports 109:339-360.

Landry, David, Lisa Kaeser, and Cory L. Richards. 1999. "Abstinence Promotion and the Provision of Information about Contraception in Public School District Sexuality Education Policies." Family Planning Perspectives 31:280-286.

Lansky, Amy, James Thomas, and Jo Anne Earp. 1998. "Partner-Specific Sexual Behaviors Among Persons with Both Main and Other Partners." Family Planning Perspectives 30:93-96.

Laraque, Danielle, Diane McLean, Pamela Brown-Peterside, Diane Ashton, and Beverly Diamond. 1997. "Predictors of Reported Condom Use in Central Harlem Youth as Conceptualized by the Health Belief Model." Journal of Adolescent Health 21:318-327. 
Laws, Judith Long, and Pepper Schwartz. 1977. Sexual Scripts: The Social Construction of Female Sexuality. Hinsdale, IL: Dryden Press.

Lear, Dana. 1997. Sex and Sexuality: Risk and Relationships in the Age of AIDS. Thousand Oaks, CA: Sage.

Levine, Judith. 2002. Harmful to Minors: The Perils of Protecting Children from Sex. Minneapolis, MN: University of Minnesota Press.

Levinson, Ruth Andrea, James Jaccard, and LuAnn Beamer. 1995. "Older Adolescents' Engagement in Casual Sex: Impact of Risk Perception and Psychosocial Motivations." Journal of Youth and Adolescence 24:349-365.

Lindberg, Laura Duberstein, Leighton Ku, and Freya Sonenstein. 2000. "Adolescents' Reports of Reproductive Health Education, 1988 and 1995." Family Planning Perspectives 32:220-226.

Lorber, Judith. 1994. Paradoxes of Gender. New Haven, CT: Yale University Press.

Luker, Kristen. 1996. Dubious Conceptions: The Politics of Teenage Pregnancy. Cambridge, MA: Harvard University Press.

Maccoby, Eleanor. 1998. The Two Sexes: Growing Up Apart, Coming Together. Cambridge: Harvard University Press.

MacCorquodale, Patricia. 1984. "Gender Roles and Premarital Contraception." Journal of Marriage and the Family 46:57-63.

Manning, Wendy, Monica Longmore, and Peggy Giordano. 2000. "The Relationship Context of Contraceptive Use at First Intercourse." Family Planning Perspectives 32:104-110.

Martin, Karin A. 1996. Puberty, Sexuality, and the Self: Girls and Boys at Adolescence. New York: Routledge.

McKay, Alexander. 1998. Sexual Ideology and Schooling: Towards Democratic Sexuality Education. Toronto, Canada: University of Toronto Press.

Mechanic, David. 1994. "Conceptions of Health." in Inescapable Decisions: The Imperatives of Health Care Reform. New Brunswick, NJ: Transaction.

Miller, Brent, J. Kelly McCoy, Terrance Olson, and Christopher Wallace. 1986. "Parental Discipline and Control Attempts in Relation to Adolescent Sexual Attitudes and Behavior." Journal of Marriage and the Family 48:503-512. 
Miller, Kim, Beth Kotchick, Shannon Dorsey, Rex Forehand, and Anissa Ham. 1998. "Family Communication About Sex: What Are Parents Saying and Are Their Adolescents Listening?" Family Planning Perspectives 30:218-222, 235.

Miller, Patricia, and William Simon. 1980. "The Development of Sexuality in Adolescence." in Handbook of Adolescent Psychology, edited by Joseph Adelson. New York: Wiley.

Montgomery, Susanne, Jill Joseph, Marshall Becker, David Ostrow, Ronald Kessler, and John Kirscht. 1989. "The Health Belief Model in Understanding Compliance with Preventive Recommendations for AIDS: How Useful?" AIDS Education and Prevention 1:303-23.

Moore, Kristin, James Peterson, and Frank Furstenberg. 1986. "Parental Attitudes and the Occurrence of Early Sexual Activity." Journal of Marriage and the Family 48:777-782.

Murphy, Debra, Mary Jane Rotheram-Borus, and Helen Reid. 1998. "Adolescent Gender Differences in HIV-Related Sexual Risk Acts, Social-Cognitive Factors, and Behavioral Skills." Journal of Adolescence 21:197-208.

Newcomer, Susan, and J. Richard Udry. 1985. "Parent-Child Communication and Adolescent Sexual Behavior." Family Planning Perspectives 17:169-174.

O'Donnell, Lydia, Carl O'Donnell, and Ann Stueve. 2001. "Early Sexual Initiation and Subsequent Sex-Related Risks Among Urban Minority Youth: The Reach for Health Study." Perspectives on Sexual and Reproductive Health 33:268-275.

Pampel, Fred. 2000. Logistic Regression: A Primer. Thousand Oaks, CA: Sage.

Panchaud, Christine, Susheela Singh, Dina Feivelson, and Jacqueline Darroch. 2000. "Sexually Transmitted Diseases Among Adolescents in Developed Countries." Family Planning Perspectives 32:24-32, 45.

Pleck, Joseph, Freya Sonenstein, and Leighton Ku. 1993. "Masculinity Ideology: Its Impact on Adolescent Males' Heterosexual Relationships." Journal of Social Issues 49:11-31.

Reed, David, and Martin Weinberg. 1984. "Premarital Coitus: Developing and Established Sexual Scripts." Social Psychology Quarterly 47:129-138.

Rhode, Deborah L. 1993. "Adolescent Pregnancy and Public Policy." Political Science Quarterly 108:635-671.

Roberts, Dorothy. 1997. Killing the Black Body: Race, Reproduction, and the Meaning of Liberty. New York: Pantheon. 
Rodgers, Kathleen Boyce. 1999. "Parenting Processes Related to Sexual Risk-Taking Behaviors of Adolescent Males and Females." Journal of Marriage and the Family 61:99-109.

Rose, Suzanna, and Irene Hanson Frieze. 1989. "Young Singles' Scripts for a First Date." Gender \& Society 3:258-268.

Rosenstock, Irwin. 1974. "Historical Origins of the Health Belief Model." Health Education Monographs 2:329-335.

Rosenstock, Irwin, Victor Strecher, and Marshall Becker. 1988. "Social Leaming Theory and the Health Belief Model." Health Education Quarterly 15:175-184.

Saewyc, Elizabeth, Linda Bearinger, Robert Blum, and Michael Resnick. 1999. "Sexual Intercourse, Abuse, and Pregnancy Among Adolescent Women: Does Sexual Orientation Make a Difference." Family Planning Perspectives 31:127-131.

Santelli, John, Charles Warren, Richard Lowry, Ellen Sogolow, Janet Collins, Laura Kann, Rachel Kaufmann, and David Celentano. 1997. "The Use of Condoms with Other Contraceptive Methods Among Young Men and Women." Family Planning Perspectives 29:261-267.

Schwartz, Pepper, and Virginia Rutter. 1998. The Gender of Sexuality. Thousand Oaks, CA: Pine Forge Press.

Signorielli, Nancy. 1993. Mass Media Images and Impact on Health: A Sourcebook. Westoport, CT: Greenwood Press.

Simon, Robin, Donna Eder, and Cathy Evans. 1992. "The Development of Feeling Norms Underlying Romantic Love Among Adolescent Females." Social Psychology Quarterly 55:26-49.

Simon, William, and John Gagnon. 1986. "Sexual Scripts: Permanence and Change." Archives of Sexual Behavior 15:97-120.

Singh, Susheela, and Jacqueline Darroch. 2000. "Adolescent Pregnancy and Childbearing: Levels and Trends in Developed Countries." Family Planning Perspectives 32:14-23.

Solinger, Rickie. 2000. Wake Up Little Susie. New York: Routledge.

Spelman, Elizabeth V. 1988. Inessential Woman: Problems of Exclusion in Feminist Thought. Boston: Beacon.

Steele, Jeanne Rogge. 1999. "Teenage Sexuality and Media Practice: Factoring in the Influences of Family, Friends, and School." The Journal of Sex Research 36:331341 . 
Steers, W. Neil, Eryn Elliott, Jill Nemiro, David Ditman, and Stuart Oskamp. 1996. "Health Beliefs as Predictors of HIV-Preventive Behavior and Ethnic Differences in Prediction." The Journal of Social Psychology 136:99-110.

Sutton, Michael, Jane Brown, Karen Wilson, and Jonathan Klein. 2002. "Shaking the Tree of Knowledge for Forbidden Fruit: Where Adolescents Learn About Sexuality and Contraception." in Sexual Teens, Sexual Media: Investigating Media' Influence on Adolescent Sexuality, edited by Jane Brown, Jeanne Steele, and Kim Walsh-Childers. Mahwah, NJ: Lawrence Erlbaum Associates.

Szirom, Tricia. 1988. Teaching Gender? Sex Education and Sexual Stereotypes. Sydney, Australia: Allen \& Unwin.

Tanenbaum, Leora. 2000. Slut! Growing Up Female with a Bad Reputation. New York: Harper Collins.

Taylor, Jill McLean, Carol Gilligan, and Amy M. Sullivan. 1995. Between Voice and Silence: Women and Girls, Race and Relationship. Cambrigde, MA: Harvard University Press.

Thompson, Sharon. 1995. Going All the Way: Teenage Girls' Tales of Sex, Romance, and Pregnancy. New York: Hill and Wang.

Thorne, Barrie, and Zella Luria. 1986. "Sexuality and Gender in Children's Daily Worlds." Social Problems 33:176-190.

Tolman, Deborah. 1994. "Doing Desire: Adolescent Girls' Struggles for/with Sexuality." Gender \& Society 8:324-342.

Tourangeau, Roger, and Tom Smith. 1996. "Asking Sensitive Questions: The Impact of Data Collection Mode, Question Format, and Question Context." Public Opinion Quarterly 60:275-304.

Upchurch, Dawn, Lene Levy-Storms, Clea Sucoff, and Carol Aneshensel. 1988. "Gender and Ethnic Differences in the Timing of First Sexual Intercourse." Family Planning Perspectives 30:121-127.

Van Roosmalen, Erica. 2000. "Forces of Patriarchy: Adolescent Experiences of Sexuality and Conceptions of Relationships." Youth \& Society 32:202-227.

Verbrugge, Lois. 1985. "Gender and Health: An Update on Hypotheses and Evidence." Journal of Health and Social Behavior 26:156-182.

Weissfeld, Joel, Bruce Brock, John Kirscht, and Victor Hawthorne. 1987. "Reliability of Health Belief Indexes: Confirmatory Factor Analysis in Sex, Race, and Age Subgroups." Health Services Research 21:777-793. 
West, Candace, and Don Zimmerman. 1987. "Doing Gender." Gender \& Society 1:125151.

Young, Iris. 1981. "Beyond the Unhappy Marriage: A Critique of the Dual Systems Theory." Pp. 43-69 in Women and Revolution: A Discussion of the Unhappy Marriage of Marxism and Feminism, edited by Lydia Sargent. Boston: South End Press.

Zinn, Maxine Baca, and Bonnie Thornton Dill. 1996. "Theorizing Difference from Multiracial Feminism." Feminist Studies 22:321-331. 
Appendix 1:

Human Subjects Research Protocol Submitted for Review to the Institutional Review Board for the Social and Behavioral Sciences University of Virginia

\section{GENERAL INFORMATION}

1. Project Title: Adolescent Sexual Decision Making: At the Intersection of Health Beliefs and Gender Ideals

2. Type of submission (check one):

New Protocol

Resubmission of previously rejected protocol

Continuation of approved protocol due to expire

$\underline{\mathrm{X}}$ _Modification of approved protocol not due to expire

Reopening expired protocol

If you checked Resubmission, Continuation, Modification or Reopening, provide the IRB-SBS protocol number:

\#2002-0147-00

3. Principal Investigator and Sub-Investigator(s):

Name: Erika Laine Austin

Title: Graduate Student

School, Department or Center: Department of Sociology

Division (if applicable):

Messenger Mail Address: 539 Cabell Hall

Mailing Address (only if messenger mail address is not available):

Telephone: (434) 245-7083

UVA e-mail address (no aliases, please): ela4r@virginia.edu

Your computing ID is used for tracking on-line human subjects training.

Preferred e-mail address for correspondence (if applicable): ela4r@virginia.edu Are you (Please underline or circle all that apply.):

Faculty Graduate Student Undergraduate Student

This research is for (Please underline or circle all that apply.):

Class project Master's thesis Doctoral dissertation Faculty research

Signature of Principal Investigator: 
4. Please list all other researchers associated with this project.

Name: none

UVA e-mail address (no aliases, please):

5. Faculty Advisor (Must be completed for all student and staff research proposals.):

Name: Steven Nock

School, Department or Center: Department of Sociology

Division (if applicable):

Messenger mail address: 539 Cabell Hall

Telephone: (434) 924-6519

UVA e-mail address (no aliases, please): sln@virginia.edu

Your computing ID is used for tracking on-line training

Signature of Faculty Advisor:

\section{DESCRIPTION OF THE RESEARCH STUDY}

6. Brief Description of the Research. Write an original, brief, non-technical description of the project addressed to lay members of the SBS Review Board. Do not copy the abstract from your grant proposal. Include in your description:

a) Your research hypothesis or question

How do adolescents make decisions about sexual behavior? What sources of information do they draw on and how do they interpret the health- and gender-related messages in those sources?

b) A narrative that explains the major constructs of your study

I am investigating the way that adolescents balance the various messages they receive about sexual decision-making. I am especially interested in the health-related information they receive and how this presents decisions about sex in terms of risk and responsibility. I am also interested in the cultural messages adolescents receive about sex (primarily through the media) about appropriate sexual behavior for females and males. My research focuses on how adolescents make sense of the conflicting messages they receive in an attempt to develop a more comprehensive model of adolescent sexual decision-making than has been previously offered. 
c) The methodology

I will conduct approximately 30 in-depth, face-to-face, structured interviews (see attached interview schedule). The respondents will be audiotaped to ensure accuracy; I will personally transcribe and then destroy the audiotapes.

d) From where/whom the data will be collected;

The data will be collected from individuals who are of the age to have recently have completed high school. This will include both individuals who actually did complete high school, as well as those who dropped out before completion of their degree. I will not interview any minors for this study.

e) How the data will advance your research hypothesis or question

The data will allow me to examine how adolescents themselves analyze the information they are provided on sexual decision-making. This will aid me in the creation of statistical models that better reflect adolescents' decision-making processes.

7. What will the participants do in the study? Describe all steps the participants will follow. What do the data consist of? (Please submit 4 copies of all instruments, surveys, interview questions or outlines).

The purpose of the research will be conveyed to the participants during the initial contact. Once we meet at a neutral, private location, they will be asked to carefully review the informed consent form. I will also secure the respondents permission to audiotape the interview. I will use a structured interview schedule to guide the interview, using followup probes when necessary. I will also provide several scenarios to which the respondents will react and ask them to brainstorm on several topics. All of these questions, scenarios, and brainstorms are included in the attached interview schedule. Once the interview is completed, I will ask the respondent if they want to elaborate any of their statements or if they want to withdraw their consent and destroy the audiotape.

8. Location where study will be conducted (Please be specific.):

The in-depth interviews will be conducted in a location selected by each individual respondent. I will advise the respondent of the importance of selecting a location that is neutral and private; in short, a place where they will feel comfortable discussing sexual decision-making. 
9. Anticipated start and completion dates for collecting and analyzing data:

I will conduct the interviews in July and Augist, 2002. I will complete the preliminary analysis of these data by September, 2002.

10. Funding source:

I do not anticipate receiving any funding for this research.

11. Describe what will be done with the data and resulting analysis and who will have access to this information.

The data I collect will be analyzed in my doctoral dissertation. The data will not be available to anyone other than me, though the analysis will be available in my dissertation.

12. What benefits can reasonably be expected from the study? (Benefits may be either to the participants or to the knowledge base of the area.)

This research will contribute to the understanding of how adolescents make decisions about sexual health issues by collecting information directly from adolescents, rather than inferring why they make the decisions they do.

\section{RECRUITMENT AND SELECTION OF PARTICIPANTS}

13. Participants (If working with different groups, please list for each category.):

Number to be studied in upcoming protocol year: approximately 30

Ages: 18-19; no one under age 18 will be included in the study

Gender: females and males

13. a) What are the criteria you will use for selecting participants?

All hearing, English-speaking adolescents ages 18 and 19 will be eligible for participation in this study. 
b) How will the participants be contacted?

I will contact several adolescents (ages 18-19) I know and explain the purpose of my study to them. I will ask them to inform friends of theirs that I am interested in interviewing them, and provide them with a flyer listing my contact information and a brief description of the study (see attached flyer). Once the adolescents contact me, I will mail them the letter explaining their participation in greater detail, with a confirmation of the time and location of our scheduled interview.

c) State the relationship between Principal Investigator, Faculty Advisor (if applicable) and Participants.

I will not personally know any of the interview respondents; they will be nominated by individuals I know in a limited capacity (through family friends).

15. Describe in detail how you will obtain consent from participants and/or parents. Attach a copy of all Informed Consent/Assent Agreement(s). Please include all the headings included on the sample agreement.

During my initial contact with the respondents I will introduce myself and explain the purpose of the study. If they express willingness to act as respondents, I will send a follow-up letter to their street or e-mail address (based on their preference) that further clarifies my research and provides my credentials and contact information. During my initial contact I will also schedule an interview and arrange an appropriate location at which to meet.

At our arranged meeting, I will provide the respondents with the informed consent form. I will ask them to carefully review the form and ask any questions needed for clarification. If they choose to participate, they will sign the informed consent form. Following the interview the respondent will be asked if they still consent to participating in the study; if they withdraw their consent at this time I will destroy the audiotape in their presence.

As all of my respondents will be ages $18-19$, I will not need to secure parental consent.

16. How will you protect the confidentiality of your participants? (Check one.)

X_ Identifying names or numbers will not be collected. (Data are anonymous.) Codes will be used on data; the list linking codes to personal identifiers will be kept secure. (Data are confidential.) Other: (Describe.) 


\section{RISKS, HAZARDS AND DECEPTION}

17. Are any aspects of the study kept secret from the participants? $\underline{X}_{\text {_ No }}$ _ Y Yes (Describe.)

18. Is any deception used in the study? X No _ Yes (If yes, describe the deception involved and the debrief procedures. Attach a post-experiment debriefing statement and consent form offering participants the option of having data destroyed.)

19. Will participants be debriefed? _ $\underline{X}$ No __ Yes (Attach a copy of your Debriefing Statement. If the answer to protocol question \# 18 is yes, then the investigator must debrief the participant.)

20. Will participants be recorded on audiotape? __ No _

Will participants be photographed or recorded on videotape? _ $\underline{X} \_$No __ Yes

If yes in either case, will participants be recorded or photographed without their knowledge?

_ participants the option of having their tape erased.)

21. What are the possible physical, psychological, professional or personal risks and/or hazards for the participants?

Participants will not face any physical risks in this research. The consent form signed by participants explains that they may feel uncomfortable, embarrassed, or confused during the interview. The form further requests that participants not share any personal information about their sexual behavior, limiting the risks listed above. They will also be advised of their right to refuse to answer any questions they choose.

22. What will you do to protect participants from these risks or hazards?

I have prepared a list of resources that will be available to the respondents at their request. 


\section{Appendix 2: \\ In-Depth Interview Schedule}

\section{Pre-Interview Brainstorming Questions}

Make a list of all of the places that you get information about sex, including what's considered appropriate sexual behavior, the possible risks and outcomes of sex, and how women and men think about sex.

(What are some of the sources you mentioned? Which of these do you rely on for factual information? How would you rank these sources of information?)

Based on what you see in society (in the media, discussed amongst your friends), describe how women are "expected" to act in sexual situations... how men are "supposed" to act in sexual situations. Think about stereotypes and what's considered normal and appropriate.

(What are some of the stereotypes about women's and men's sexuality that you listed? Do you think these stereotypes are changing over time?)

\section{General Questions}

What came to mind when I told you I wanted to talk about "sexuality?"

What does the term "sexual health" mean to you?

My research is on adolescent sexual decision-making. What are the decisions that adolescents face?

How comfortable do you feel discussing issues related to sex in an interview like this?

\section{Health}

Tell me about the sex education you've had in school.

Do you talk about the risks of sex in your sex education classes?

Do you talk about any positive aspects of sexuality in your sex education classes? 
Is the decision to have sex presented primarily as a health decision or a moral decision in your sex education classes?

Do you talk specifically about how to make decisions about sex in your sex education classes?

Do you talk about how to buy condoms or where to get birth control?

Where do adolescents find out about how to buy these things?

How susceptible or "at-risk" do you think most adolescents feel to the risks of sex, like STDs and pregnancy?

Do you think most adolescents feel that they can take steps to prevent the risks of sex? Like what?

Do you think that girls and boys got the same messages about sex in your sex education classes?

Do you feel that the sex education you get in school is useful and realistic, based on what you know about how adolescents think about sex?

How could your sex education classes be more useful to you-what information do you wish was included?

\section{Parents}

How comfortable do you feel discussing sex with your mom and/or dad?

Do you wish you could talk to them more about issues related to sex?

Do your parents emphasize the risks of sex? The moral risks or the health risks, or something else?

Do they talk about how to make healthy decisions and how to resist peer pressure?

Do you think that your parents talk to your brother(s)/sister(s) differently about sex than they do with you? 


\section{The Media}

Let's talk about the lists you made describing women's and men's sexuality. How much do you think your ideas about sexuality are shaped by what you see in the media?

How realistic do you think the media's portrayal of teenage sexuality is?

Do you ever look to magazines like YM, Cosmo, Maxim, or Playboy for information about sex?

Have you ever used the Internet to try to get information about sex?

\section{Peers}

How much do you and your friends talk about sexual decision-making? Is this usually gossip or talking about factual information?

People talk a lot about "peer pressure" to have sex. Do you see that happening among your friends?

How do you see concerns about reputation and gossip shaping people's decisions about sex?

What are some words that you and your friends use to describe women that are sexually active? What about men?

\section{Gender and Sexuality}

Do you think that young women and men think about sex differently? Do they make decisions differently?

What do you think are women's biggest concerns related to sex? What are men's biggest concerns?

Why do we think so differently about men and women who have lots of sexual partners?

Do you think that most people think it's important to be in love when they have sex? Do women and men differ on this?

How do you think being a (woman/man) has shaped the decisions you've made about sex? 
Do you think that women and men feel the same about practicing safer sex? Do they both think about the health risks of sex? What about risks to reputation?

Do you think that women are sometimes afraid to ask guys to wait to have sex or to practice safer sex? Do you think that guys are afraid of the same things?

Sometimes it seems that people have sex or practice unsafe sex for what we might consider to be the "wrong" reasons. What do you think some of these reasons might be?

What if there were no health risks associated with sex--how would people's decisions be different?

What if society didn't treat women and men differently--how would this change people's decisions?

\section{Scenario 1}

You ask to borrow your friend Sarah's calculator for a math quiz. She says, "Sure-just get it out of my bag." As you're searching through her bag for the calculator, you see that she has several condoms tucked in a side pocket.

What is your reaction to the fact that Sarah is carrying condoms?

(Follow up question: Would your reaction be different if it was a male friend carrying condoms?)

\section{Scenario 2}

Your best friend comes to you and says they are thinking of having sex with their girl/boyfriend, who they have been dating for five months. Your friend wants advice on how to figure out whether they should have sex.

What do you tell your friend?

(Follow up questions: If you had to make a list of the most important things your friend should think about, what would be on the list? What sources would you point your friend to for more information on making this decision? What would you say are the benefits of becoming sexually active? What are the benefits of waiting?) 
Table A3.1 Logistic Regression Analysis Predicting Probability of Being a Virgin: Health Belief Model with Gender Interactions (with Standard Errors)

\begin{tabular}{|c|c|c|c|}
\hline & Model I & Mo & \\
\hline & All & Male & Fem \\
\hline \multicolumn{4}{|l|}{ Health Belief Model } \\
\hline Risk of Pregnancy & $.076(.06)$ & $.097(.08)$ & -.046 \\
\hline Risk of AIDS & $.245(.06)$ & $.174(.08)$ & .165 \\
\hline Now Worst Time for Pregnancy & $.502(.07)$ & $.223(.11)$ & .541 \\
\hline AIDS Causes Suffering & $-.384(.07)$ & $-.469(.11)$ & .266 \\
\hline Benefits of Avoiding Pregnancy Scale & $.138(.01)$ & $.111(.01)$ & .003 \\
\hline Birth Control Is Not Too Difficult to Use & $-.322(.05)$ & $-.057(.08)$ & -.422 \\
\hline Able to Refuse Sex if No Birth Control & $.344(.05)$ & $.505(.07)$ & -.315 \\
\hline Gender & & \multicolumn{2}{|l|}{ ref. } \\
\hline Male & & \multicolumn{2}{|c|}{$-.390(.30)$} \\
\hline \multicolumn{4}{|l|}{ Female } \\
\hline \multicolumn{4}{|l|}{ Mother's Education } \\
\hline High School or Less & & \multicolumn{2}{|l|}{ ref. } \\
\hline More than High School & & \multicolumn{2}{|c|}{$.323(.05)$} \\
\hline \multicolumn{4}{|l|}{ Race/Ethnicity } \\
\hline European American & & \multicolumn{2}{|l|}{ ref. } \\
\hline African American & & \multicolumn{2}{|c|}{$-.726(.07)$} \\
\hline Asian & & \multicolumn{2}{|c|}{$.644(.15)$} \\
\hline Hispanic & & \multicolumn{2}{|c|}{$.132(.12)$} \\
\hline Other Race/Ethnicity & & \multicolumn{2}{|c|}{$-.469(.13)$} \\
\hline \multicolumn{4}{|l|}{ Age } \\
\hline 15 years & & \multicolumn{2}{|l|}{ ref. } \\
\hline 16 years & & \multicolumn{2}{|c|}{$-.484(.07)$} \\
\hline 17 years & & \multicolumn{2}{|c|}{$-1.086(.07)$} \\
\hline 18 years & & \multicolumn{2}{|c|}{$-1.341(.07)$} \\
\hline $19+$ years & & \multicolumn{2}{|c|}{$-1.481(.17)$} \\
\hline Observations & 8785 & 8785 & \\
\hline
\end{tabular}


Table A3.2 Logistic Regression Analysis Predicting Probability of Being a Virgin: Cues to Action (with Standard Errors)

\begin{tabular}{|c|c|c|c|c|c|c|c|c|}
\hline & \multicolumn{2}{|c|}{ Model 3} & \multicolumn{2}{|c|}{ Model 4} & \multicolumn{2}{|c|}{ Model 5} & \multicolumn{2}{|c|}{ Model 6} \\
\hline & Female & Male & Female & Male & Female & Male & Female & Male \\
\hline \multicolumn{9}{|l|}{ Health Beliefs } \\
\hline Risk of Pregnancy & $.003(.14)$ & $.073(.09)$ & $-.061(.14)$ & $.101(.08)$ & $-.048(.14)$ & $.096(.08)$ & $-.042(.14)$ & $.100(.09)$ \\
\hline Risk of AIDS & $.101(.13)$ & $.205(.08)$ & $.168(.13)$ & $.172(.08)$ & $.146(.13)$ & $.190(.08)$ & $.102(.13)$ & $.107(.08)$ \\
\hline Now Worst Time for Pregnancy & $.530(.16)$ & $.131(.12)$ & $.537(.16)$ & $.221(.11)$ & $.564(.16)$ & $.205(.11)$ & $.552(.16)$ & $.180(.11)$ \\
\hline AIDS Causes Suffering & $.293(.16)$ & $-.481(.11)$ & $.267(.15)$ & $-.469(.11)$ & $.256(.15)$ & $-.456(.11)$ & $.286(.16)$ & $-.454(.11)$ \\
\hline Benefits of Avoiding Pregnancy Scale & $.005(.01)$ & $.090(.01)$ & $.002(.01)$ & $.111(.01)$ & $.006(.01)$ & $.109(.01)$ & $.001(.01)$ & $.106(.01)$ \\
\hline Birth Control Is Not Too Difficult to Use & $-.443(.11)$ & $-.062(.08)$ & $-.422(.11)$ & $-.059(.08)$ & $-.408(.11)$ & $-.067(.08)$ & $-.387(.11)$ & $-.019(.08)$ \\
\hline Able to Refuse Sex if No Birth Control & $-.310(.12)$ & $.447(.07)$ & $-.324(.12)$ & $.512(.07)$ & $-.309(.12)$ & $.500(.07)$ & $-.243(.12)$ & $.500(.07)$ \\
\hline \multicolumn{9}{|l|}{ Cues to Action } \\
\hline Good Communication with Parent & $.367(.15)$ & $.376(.11)$ & & & & & & \\
\hline Parent Disapproves of Sex & $.311(.15)$ & $1.024(.09)$ & & & & & & \\
\hline Learned about Pregnancy in School & & & $.304(.18)$ & $-.217(.12)$ & & & & \\
\hline Learned about AIDS in School & & & $-.155(.22)$ & $.269(.16)$ & & & & \\
\hline Hours of TV per Week & & & & & $.012(.01)$ & $-.007(.01)$ & & \\
\hline Talked to Female Friend about Problems & & & & & & & $.424(.12)$ & $-.523(.07)$ \\
\hline Talked to Male Friend about Problems & & & & & & & $-.825(.11)$ & $-.206(.07)$ \\
\hline Attended Youth Group & & & & & & & $.370(.10)$ & $.298(.07)$ \\
\hline$\overline{\text { Observations }}$ & 8785 & & $\overline{8785}$ & & 8785 & & $\overline{8785}$ & \\
\hline
\end{tabular}


Table A3.3 Logistic Regression Analysis Predicting Probability of Being a Virgin: Cues to Action and Gender Ideals (with Standard Errors)

\begin{tabular}{|c|c|c|c|c|}
\hline & \multicolumn{2}{|c|}{ Model 7} & \multicolumn{2}{|c|}{ Model 8} \\
\hline & Female & Male & Female & Male \\
\hline \multicolumn{5}{|l|}{ Health Beliefs } \\
\hline Risk of Pregnancy & $.006(.15)$ & $.077(.09)$ & $.009(.15)$ & $.064(.09)$ \\
\hline Risk of AIDS & $.018(.14)$ & $.161(.08)$ & $.024(.14)$ & $.135(.08)$ \\
\hline Now Worst Time for Pregnancy & $.577(.17)$ & $.075(.12)$ & $.594(.17)$ & $.039(.12)$ \\
\hline AIDS Causes Suffering & $.262(.16)$ & $-.449(.11)$ & $.270(.16)$ & $-.466(.11)$ \\
\hline Benefits of Avoiding Pregnancy Scale & $.006(.01)$ & $.086(.01)$ & $.001(.01)$ & $.091(.01)$ \\
\hline Birth Control Is Not Too Difficult to Use & $-.397(.11)$ & $-.041(.08)$ & $-.373(.12)$ & $-.094(.08)$ \\
\hline Able to Refuse Sex if No Birth Control & $-.239(.13)$ & $.453(.08)$ & $-.208(.13)$ & $.402(.08)$ \\
\hline \multicolumn{5}{|l|}{ Cues to Action } \\
\hline Good Communication with Parent & $.305(.15)$ & $.325(.11)$ & $.304(.15)$ & $.299(.11)$ \\
\hline Parent Disapproves of Sex & $.267(.15)$ & $1.101(.09)$ & $.254(.15)$ & $.981(.09)$ \\
\hline Learned about Pregnancy in School & $.256(.19)$ & $-.246(.12)$ & $.188(.19)$ & $-.182(.12)$ \\
\hline Learned about AIDS in School & $-.226(.23)$ & $.346(.17)$ & $-.194(.24)$ & $.304(.17)$ \\
\hline Hours of TV per Week & $.009(.01)$ & $-.008(.01)$ & $.009(.01)$ & $-.008(.01)$ \\
\hline Talked to Female Friend about Problems & $.453(.12)$ & $-.547(.07)$ & $.448(.12)$ & $-.561(.08)$ \\
\hline Talked to Male Friend about Problems & $-.784(.11)$ & $-.212(.07)$ & $-.777(.11)$ & $-.219(.07)$ \\
\hline Attended Youth Group & $.330(.11)$ & $.240(.07)$ & $.373(.11)$ & $.201(.08)$ \\
\hline \multicolumn{5}{|l|}{ Gender Ideals } \\
\hline More Respected if Sexually Active (disagree) & & & $-.273(.11)$ & $.686(.08)$ \\
\hline More Attractive is Sexually Active (disagree) & & & $.038(.11)$ & $.009(.08)$ \\
\hline Observations & 8785 & & 8785 & \\
\hline
\end{tabular}


Table A3.4 Cox Proportional Hazards Model Predicting Transition to First Intercourse: Health Belief Model with Gender Interactions (with Standard Errors)

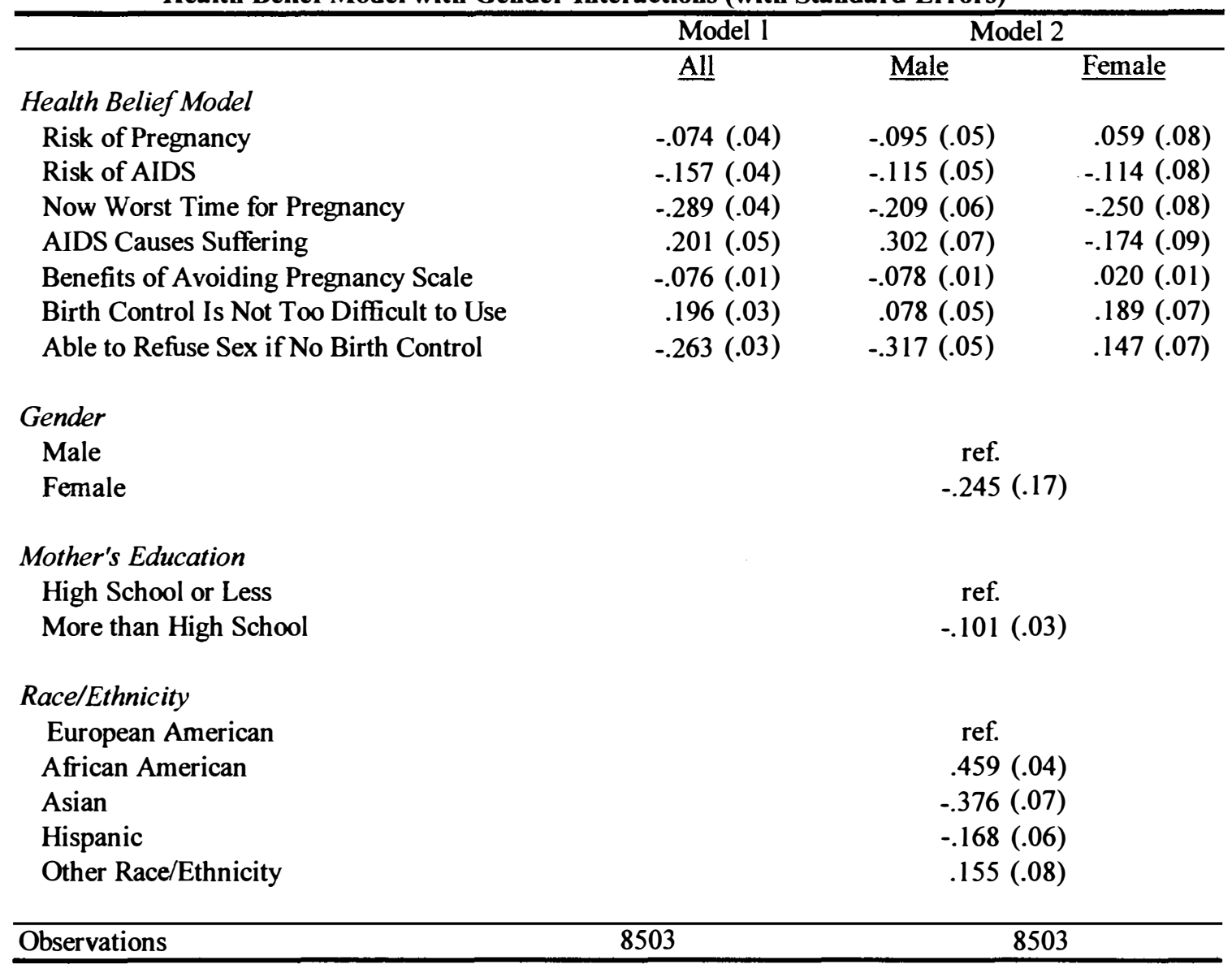


Table A3.5 Cox Proportional Hazards Model Predicting Transition to First Intercourse: Cues to Action (with Standard Errors)

\begin{tabular}{|c|c|c|c|c|c|c|c|c|}
\hline & \multicolumn{2}{|c|}{ Model 3} & \multicolumn{2}{|c|}{ Model 4} & \multicolumn{2}{|c|}{ Model 5} & \multicolumn{2}{|c|}{ Model 6} \\
\hline & Male & Female & Male & Female & Male & Female & Male & Female \\
\hline \multicolumn{9}{|l|}{ Health Beliefs } \\
\hline Risk of Pregnancy & $-.058(.05)$ & $.022(.08)$ & $-.094(.05)$ & $.062(.08)$ & $-.081(.05)$ & $.032(.08)$ & $-.074(.05)$ & $.013(.08)$ \\
\hline Risk of AIDS & $-.148(.05)$ & $-.201(.09)$ & $-.116(.05)$ & $-.112(.08)$ & $-.138(.05)$ & $-.089(.08)$ & $-.093(.05)$ & $-.087(.08)$ \\
\hline Now Worst Time for Pregnancy & $-.156(.06)$ & $-.177(.08)$ & $-.209(.06)$ & $-.246(.08)$ & $-.183(.06)$ & $-.232(.08)$ & $-.190(.06)$ & $-.171(.08)$ \\
\hline AIDS Causes Suffering & $.292(.07)$ & $-.203(.09)$ & $.305(.07)$ & $-.172(.09)$ & $.288(.07)$ & $-.174(.09)$ & $.302(.07)$ & $-.228(.09)$ \\
\hline Benefits of Avoiding Pregnancy Scale & $-.058(.00)$ & $.012(.01)$ & $-.079(.01)$ & $.020(.01)$ & $-.074(.01)$ & $.020(.01)$ & $-.071(.01)$ & $.023(.01)$ \\
\hline Birth Control Is Not Too Difficult to Use & $.050(.05)$ & $.199(.07)$ & $.078(.05)$ & $.192(.07)$ & $.066(.05)$ & $.190(.07)$ & $.013(.05)$ & $.169(.07)$ \\
\hline Able to Refuse Sex if No Birth Control & $-.294(.04)$ & $.131(.07)$ & $-.317(.04)$ & $.145(.07)$ & $-.335(.04)$ & $.154(.07)$ & $-.331(.05)$ & $.148(.07)$ \\
\hline \multicolumn{9}{|l|}{ Cues to Action } \\
\hline Good Communication with Parent & $-.142(.06)$ & $-.223(.08)$ & & & & & & \\
\hline Parent Disapproves of Sex & $-.514(.05)$ & $.023(.07)$ & & & & & & \\
\hline Learned about Pregnancy in School & & & $.116(.08)$ & $-.154(.12)$ & & & & \\
\hline Learned about AIDS in School & & & $-.153(.11)$ & $.037(.15)$ & & & & \\
\hline Hours of TV per Week & & & & & $.005(.00)$ & $-.004(.01)$ & & \\
\hline Talked to Female Friend about Problems & & & & & & & $.245(.05)$ & $.161(.07)$ \\
\hline Talked to Male Friend about Problems & & & & & & & $.149(.05)$ & $.443(.07)$ \\
\hline Attended Youth Group & & & & & & & $-.230(.05)$ & $-.129(.06)$ \\
\hline Observations & \multicolumn{2}{|c|}{8503} & \multicolumn{2}{|c|}{8503} & \multicolumn{2}{|c|}{8503} & \multicolumn{2}{|c|}{8503} \\
\hline
\end{tabular}


Table A3.6 Cox Proportional Hazards Model Predicting Transition to First Intercourse: Cues to Action and Gender Ideals (with Standard Errors)

\begin{tabular}{|c|c|c|c|c|}
\hline & \multicolumn{2}{|c|}{ Model 7} & \multicolumn{2}{|c|}{ Model 8} \\
\hline & Male & Female & Male & Female \\
\hline \multicolumn{5}{|l|}{ Health Beliefs } \\
\hline Risk of Pregnancy & $-.054(.05)$ & $-.037(.08)$ & $-.059(.05)$ & $-.032(.08)$ \\
\hline Risk of AIDS & $-.127(.05)$ & $-.045(.08)$ & $-.109(.05)$ & $-.046(.08)$ \\
\hline Now Worst Time for Pregnancy & $-.154(.06)$ & $-.126(.08)$ & $-.141(.06)$ & $-.138(.08)$ \\
\hline AIDS Causes Suffering & $.298(.07)$ & $-.239(.09)$ & $.299(.07)$ & $-.232(.09)$ \\
\hline Benefits of Avoiding Pregnancy Scale & $-.056(.01)$ & $.013(.01)$ & $-.059(.01)$ & $.017(.00)$ \\
\hline Birth Control Is Not Too Difficult to Use & $.018(.05)$ & $.165(.07)$ & $.026(.05)$ & $.177(.07)$ \\
\hline Able to Refuse Sex if No Birth Control & $-.297(.04)$ & $.127(.07)$ & $-.273(.04)$ & $.115(.07)$ \\
\hline \multicolumn{5}{|l|}{ Cues to Action } \\
\hline Good Communication with Parent & $-.102(.06)$ & $-.210(.08)$ & $-.098(.06)$ & $-.197(.08)$ \\
\hline Parent Disapprove & $-.479(.05)$ & $.032(.07)$ &.$-452(.05)$ & $.016(.07)$ \\
\hline Learned about Pregnancy in School & $.074(.08)$ & $-.140(.13)$ & $.035(.09)$ & $-.088(.12)$ \\
\hline Learned about AIDS in School & $-.208(.11)$ & $.103(.15)$ & $-.178(.11)$ & $.077(.15)$ \\
\hline Hours of TV per Week & $.006(.01)$ & $-.003(.01)$ & $.005(.01)$ & $-.003(.01)$ \\
\hline Talked to Female Friend about Problems & $.242(.05)$ & $-.143(.07)$ & $.244(.05)$ & $-.145(.07)$ \\
\hline Talked to Male Friend about Problems & $.144(.04)$ & $.419(.07)$ & $.150(.04)$ & $.406(.07)$ \\
\hline Attended Youth Group & $-.175(.04)$ & $-.127(.06)$ & $-.155(.04)$ & $-.142(.06)$ \\
\hline \multicolumn{5}{|l|}{ Gender Ideals } \\
\hline More Respected if Sexually Active (disagree) & & & $-.380(.05)$ & $.133(.06)$ \\
\hline More Attractive is Sexually Active (disagree) & & & $.001(.05)$ & $-.046(.06)$ \\
\hline
\end{tabular}


Table A3.7 Logistic Regression Analysis Predicting Avoidance of Casual Sex:

Health Belief Model with Gender Interactions (with Standard Errors)

\begin{tabular}{|c|c|c|c|}
\hline & Model I & $\overline{\text { Model } 2}$ & \\
\hline & All & Male & Female \\
\hline \multicolumn{4}{|l|}{ Health Belief Model } \\
\hline Risk of Pregnancy & $.215(.09)$ & $.082(.13)$ & $.094(.19)$ \\
\hline Risk of AIDS & $-.027(.08)$ & $.016(.12)$ & $-.062(.18)$ \\
\hline Now Worst Time for Pregnancy & $-.075(.09)$ & $-.007(.16)$ & $-.181(.20)$ \\
\hline AIDS Causes Suffering & $-.141(.11)$ & $-.315(.17)$ & $.226(.22)$ \\
\hline Benefits of Avoiding Pregnancy Scale & $.058(.01)$ & $.019(.01)$ & $.031(.01)$ \\
\hline Birth Control Is Not Too Difficult to Use & $.228(.08)$ & $.003(.12)$ & $.381(.17)$ \\
\hline Able to Refuse Sex if No Birth Control & $.427(.08)$ & $.350(.11)$ & $.041(.17)$ \\
\hline \multicolumn{4}{|l|}{ Gender } \\
\hline Male & & ref. & \\
\hline Female & & $-.798(.40)$ & \\
\hline \multicolumn{4}{|l|}{ Mother's Education } \\
\hline High School or Less & & ref. & \\
\hline More than High School & & $(.02)(.07)$ & \\
\hline \multicolumn{4}{|l|}{ Race/Ethnicity } \\
\hline European American & & ref. & \\
\hline African American & & $-.063(.09)$ & \\
\hline Asian & & $(.58)(.26)$ & \\
\hline Hispanic & & $-.058(.17)$ & \\
\hline Other Race/Ethnicity & & $-.294(.18)$ & \\
\hline \multicolumn{4}{|l|}{ Age } \\
\hline 15 years & & ref. & \\
\hline 16 years & & $-.409(.12)$ & \\
\hline 17 years & & $-.794(.12)$ & \\
\hline 18 years & & $-.880(.12)$ & \\
\hline $19+$ years & & $-1.242(.22)$ & \\
\hline Age (in months) at First Intercourse & & $(.03)(.01)$ & \\
\hline Observations & 4031 & 4031 & \\
\hline
\end{tabular}


Table A3.8 Logistic Regression Analysis Predicting Avoidance of Casual Sex: Cues to Action (with Standard Errors)

\begin{tabular}{|c|c|c|c|c|c|c|c|c|}
\hline & \multicolumn{2}{|c|}{ Model 3} & \multicolumn{2}{|c|}{ Model 4} & \multicolumn{2}{|c|}{ Model 5} & \multicolumn{2}{|c|}{ Model 6} \\
\hline & Male & Female & $\underline{\text { Male }}$ & Female & Male & Female & Male & Female \\
\hline \multicolumn{9}{|l|}{ Health Beliefs } \\
\hline Risk of Pregnancy & $.090(.13)$ & $.078(.19)$ & $.087(.13)$ & $.071(.19)$ & $.078(.13)$ & $.098(.19)$ & $.084(.13)$ & $107(.19)$ \\
\hline Risk of AIDS & $-.004(.12)$ & $-.042(.18)$ & $.018(.12)$ & $-.059(.18)$ & $.035(.12)$ & $-.076(.18)$ & $-.004(.12)$ & $-.046(.18)$ \\
\hline Now Worst Time for Pregnancy & $-.036(.15)$ & $-.160(.20)$ & $-.014(.15)$ & $-.194(.20)$ & $-.019(.15)$ & $-.160(.20)$ & $-.009(.15)$ & $-.185(.20)$ \\
\hline AIDS Causes Suffering & $-.334(.17)$ & $.264(.22)$ & $-.313(.17)$ & $.237(.22)$ & $-.311(.17)$ & $.223(.22)$ & $-.327(.17)$ & $.245(.22)$ \\
\hline Benefits of Avoiding Pregnancy Scale & $.016(.01)$ & $.031(.01)$ & $.023(.01)$ & $.027(.01)$ & $.018(.01)$ & $.034(.02)$ & $.018(.01)$ & $.032(.01)$ \\
\hline Birth Control Is Not Too Difficult to Use & $-.002(.12)$ & $.373(.17)$ & $.016(.12)$ & $.376(.17)$ & $-.010(.12)$ & $.395(.17)$ & $.029(.12)$ & $.336(.17)$ \\
\hline Able to Refuse Sex if No Birth Control & $.338(.11)$ & $.045(.17)$ & $.366(.11)$ & $.015(.17)$ & $.357(.11)$ & $.035(.17)$ & $.342(.11)$ & $.051(.17)$ \\
\hline \multicolumn{9}{|l|}{ Cues to Action } \\
\hline Good Communication with Parent & $.283(.15)$ & $-.109(.19)$ & & & & & & \\
\hline Parent Disapproves of Sex & $.145(.11)$ & $-.012(.16)$ & & & & & & \\
\hline Learned about Pregnancy in School & & & $-.173(.19)$ & $.543(.26)$ & & & & \\
\hline Learned about AIDS in School & & & $-.424(.24)$ & $.475(.32)$ & & & & \\
\hline Hours of TV per Week & & & & & $-.006(.01)$ & $.009(.01)$ & & \\
\hline Talked to Female Friend about Problems & & & & & & & $-.040(.11)$ & $-.187(.17)$ \\
\hline Talked to Male Friend about Problems & & & & & & & $-.087(.11)$ & $.196(.16)$ \\
\hline Attended Youth Group & & & & & & & $.256(.11)$ & $-.158(.15)$ \\
\hline Observations & 4031 & & 4031 & & 4031 & & 4031 & \\
\hline
\end{tabular}


Table A3.9 Logistic Regression Analysis Predicting Avoidance of Casual Sex:

Cues to Action and Gender Ideals (with Standard Errors)

\begin{tabular}{|c|c|c|c|c|}
\hline & \multicolumn{2}{|c|}{ Model 7} & \multicolumn{2}{|c|}{ Model 8} \\
\hline & Male & Female & Male & Female \\
\hline \multicolumn{5}{|l|}{ Health Beliefs } \\
\hline Risk of Pregnancy & $.093(.13)$ & $.075(.19)$ & $.089(.13)$ & $.068(.20)$ \\
\hline Risk of AIDS & $-.003(.12)$ & $-.037(.18)$ & $-.018(.12)$ & $-.021(.18)$ \\
\hline Now Worst Time for Pregnancy & $-.062(.16)$ & $-.150(.29)$ & $-.087(.16)$ & $-.123(.20)$ \\
\hline AIDS Causes Suffering & $-.339(.17)$ & $.288(.22)$ & $-.341(.17)$ & $.292(.22)$ \\
\hline Benefits of Avoiding Pregnancy Scale & $.017(.01)$ & $.031(.01)$ & $.021(.01)$ & $.026(.01)$ \\
\hline Birth Control Is Not Too Difficult to Use & $.020(.12)$ & $.341(.17)$ & $-.021(.12)$ & $.363(.17)$ \\
\hline Able to Refuse Sex if No Birth Control & $.354(.11)$ & $.019(.17)$ & $.339(.11)$ & $.027(.17)$ \\
\hline \multicolumn{5}{|l|}{ Cues to Action } \\
\hline Good Communication with Parent & $.303(.15)$ & $-.149(.19)$ & $.292(.15)$ & $-.153(.19)$ \\
\hline Parent Disapproves of Sex & $.135(.11)$ & $.001(.16)$ & $.141(.11)$ & $-.024(.16)$ \\
\hline Learned about Pregnancy in School & $-.204(.19)$ & $.575(.26)$ & $-.174(.19)$ & $.549(.26)$ \\
\hline Learned about AIDS in School & $-.392(.24)$ & $.438(.32)$ & $-.403(.24)$ & $.437(.32)$ \\
\hline Hours of TV per Week & $-.007(.02)$ & $.010(.01)$ & $-.008(.01)$ & $.012(.01)$ \\
\hline Talked to Female Friend about Problems & $-.054(.11)$ & $-.172(.17)$ & $-.058(.11)$ & $-.189(.17)$ \\
\hline Talked to Male Friend about Problems & $-.080(.11)$ & $.208(.16)$ & $-.075(.11)$ & $.188(.16)$ \\
\hline Attended Youth Group & $.254(.11)$ & $-.182(.15)$ & $.254(.11)$ & $-.172(.16)$ \\
\hline \multicolumn{5}{|l|}{ Gender Ideals } \\
\hline More Respected if Sexually Active (disagree) & & & $.292(.11)$ & $-.062(.16)$ \\
\hline More Attractive is Sexually Active (disagree) & & & $.086(.11)$ & $-.035(.15)$ \\
\hline Observations & 4031 & & 4031 & \\
\hline
\end{tabular}


Table A3.10 Logistic Regression Analysis Predicting Use of Birth Control at First Intercourse: Health Belief Model with Gender Interactions (with Standard Errors)

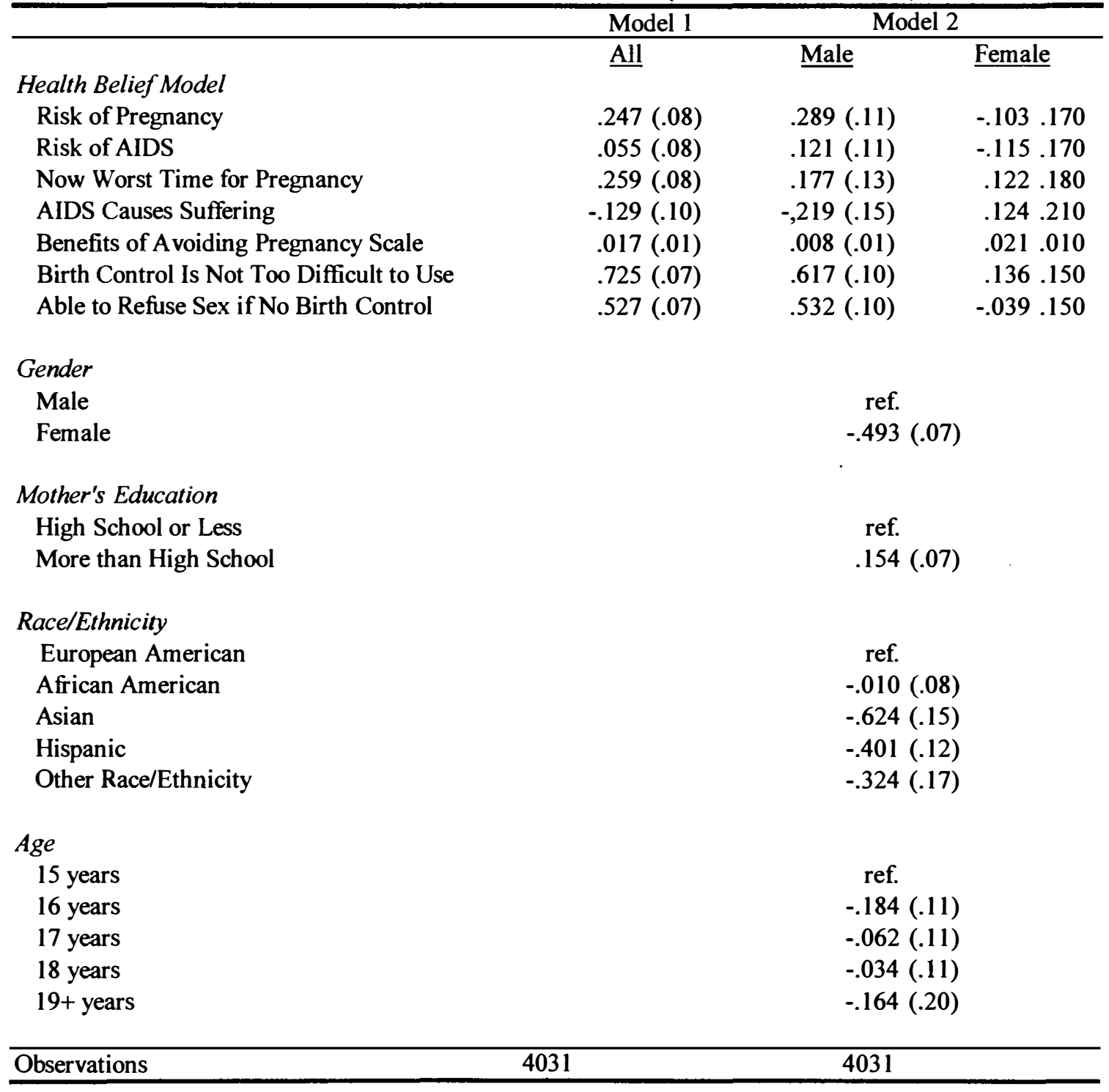


Table A3.11 Logistic Regression Analysis Predicting Use of Birth Control at First Intercourse: Cues to Action (with Standard Errors)

\begin{tabular}{|c|c|c|c|c|c|c|c|c|}
\hline & \multicolumn{2}{|c|}{ Model 3} & \multicolumn{2}{|c|}{ Model 4} & \multicolumn{2}{|c|}{ Model 5} & \multicolumn{2}{|c|}{ Model 6} \\
\hline & Male & Female & Male & Female & Male & Female & Male & Female \\
\hline \multicolumn{9}{|l|}{ Health Beliefs } \\
\hline Risk of Pregnancy & $.304(.11)$ & $-.119(.17)$ & $.284(.11)$ & $-.102(.17)$ & $.289(.11)$ & $-.103(.17)$ & $.287(.11)$ & $-.100(.17)$ \\
\hline Risk of AIDS & $.114(.11)$ & $-.108(.17)$ & $.112(.11)$ & $-.100(.17)$ & $.134(.11)$ & $-.127(.17)$ & $.107(.11)$ & $-.090(.17)$ \\
\hline Now Worst Time for Pregnancy & $.182(.13)$ & $.118(.18)$ & $.182(.13)$ & $.106(.18)$ & $.160(.13)$ & $.128(.18)$ & $.167(.13)$ & $.143(.18)$ \\
\hline AIDS Causes Suffering & $-.218(.15)$ & $.124(.21)$ & $-.208(.15)$ & $.119(.21)$ & $-.211(.15)$ & $.111(.21)$ & $-.223(.15)$ & $.126(.21)$ \\
\hline Benefits of Avoiding Pregnancy Scale & $.012(.01)$ & $.019(.01)$ & $.007(.01)$ & $.022(.01)$ & $.008(.01)$ & $.021(.01)$ & $.009(.01)$ & $.020(.01)$ \\
\hline Birth Control Is Not Too Difficult to Use & $.617(.10)$ & $.136(.15)$ & $.617(.10)$ & $.120(.15)$ & $.610(.10)$ & $.142(.15)$ & $.625(.10)$ & $.126(.15)$ \\
\hline Able to Refuse Sex if No Birth Control & $.541(.10)$ & $-.058(.15)$ & $.521(.10)$ & $-.029(.15)$ & $.536(.10)$ & $-.042(.15)$ & $.538(.10)$ & $-.047(.15)$ \\
\hline \multicolumn{9}{|l|}{ Cues to Action } \\
\hline Good Communication with Parent & $.113(.13)$ & $-.057(.17)$ & & & & & & \\
\hline Parent Disapproves of Sex & $-.208(.10)$ & $.095(.15)$ & & & & & & \\
\hline Learned about Pregnancy in School & & & $.413(.18)$ & $-.212(.26)$ & & & & \\
\hline Learned about AIDS in School & & & $-.181(.24)$ & $.314(.31)$ & & & & \\
\hline Hours of TV per Week & & & & & $-.006(.01)$ & $.002(.01)$ & & \\
\hline Talked to Female Friend about Problems & & & & & & &. $.119(.10)$ & $.224(.16)$ \\
\hline Talked to Male Friend about Problems & & & & & & & $-.088(.10)$ & $.275(.15)$ \\
\hline Attended Youth Group & & & & & & & $.090(.10)$ & $-.050(.14)$ \\
\hline Observations & 4031 & & $\overline{4031}$ & & 4031 & & 4031 & \\
\hline
\end{tabular}


Table A3.12 Logistic Regression Analysis Predicting Use of Birth Control at First Intercourse: Cues to Action and Gender Ideals (with Standard Errors)

\begin{tabular}{|c|c|c|c|c|}
\hline & \multicolumn{2}{|c|}{ Model 7} & \multicolumn{2}{|c|}{ Model 8} \\
\hline & Male & Female & Male & Female \\
\hline \multicolumn{5}{|l|}{ Health Beliefs } \\
\hline Risk of Pregnancy & $.297(.11)$ & $-.117(.17)$ & $.296(.11)$ & $-.113(.17)$ \\
\hline Risk of AIDS & $.104(.11)$ & $-.081(.17)$ & $.104(.11)$ & $-.080(.17)$ \\
\hline Now Worst Time for Pregnancy & $.157(.13)$ & $.129(.18)$ & $.156(.14)$ & $.120(.18)$ \\
\hline AIDS Causes Suffering & $-.200(.16)$ & $.107(.21)$ & $-.200(.16)$ & $.108(.21)$ \\
\hline Benefits of Avoiding Pregnancy Scale & $.012(.01)$ & $.018(.01)$ & $.012(.01)$ & $.019(.01)$ \\
\hline Birth Control Is Not Too Difficult to Use & $.618(.10)$ & $.132(.15)$ & $.617(.10)$ & $.135(.15)$ \\
\hline Able to Refuse Sex if No Birth Control & $.539(.10)$ & $-.060(.15)$ & $.540(.10)$ & $-.060(.15)$ \\
\hline \multicolumn{5}{|l|}{ Cues to Action } \\
\hline Good Communication with Parent & $.095(.13)$ & $-.025(.17)$ & $.096(.13)$ & $-.021(.17)$ \\
\hline Parent Disapproves of Sex & $-.203(.10)$ & $.106(.15)$ & $-.207(.10)$ & $.112(.15)$ \\
\hline Learned about Pregnancy in School & $.421(.18)$ & $-.203(.26)$ & $.412(.18)$ & $-.192(.26)$ \\
\hline Learned about AIDS in School & $-.178(.24)$ & $.302(.31)$ & $-.175(.24)$ & $.299(.31)$ \\
\hline Hours of TV per Week & $-.007(.01)$ & $.003(.01)$ & $-.007(.01)$ & $.003(.01)$ \\
\hline Talked to Female Friend about Problems & $-.123(.10)$ & $.231(.16)$ & $-.123(.10)$ & $.233(.16)$ \\
\hline Talked to Male Friend about Problems & $-.100(.10)$ & $.288(.15)$ & $-.099(.10)$ & $.289(.15)$ \\
\hline Attended Youth Group & $-.070(.10)$ & $-.078(.15)$ & $-.068(.10)$ & $-.081(.15)$ \\
\hline \multicolumn{5}{|l|}{ Gender Ideals } \\
\hline More Respected if Sexually Active (disagree) & & & $-.083(.11)$ & $.022(.15)$ \\
\hline More Attractive is Sexually Active (disagree) & & & $.064(.10)$ & $-.057(.15)$ \\
\hline Observations & 4031 & & 4031 & \\
\hline
\end{tabular}


Table A3.13 Logistic Regression Analysis Predicting Use of Birth Control at Most Recent Intercourse: Health Belief Model with Gender Interactions (with Standard Errors)

\begin{tabular}{|c|c|c|c|}
\hline & Model 1 & & \\
\hline & $\underline{\text { All }}$ & Male & Female \\
\hline \multicolumn{4}{|l|}{ Health Belief Model } \\
\hline Risk of Pregnancy & $.170(.08)$ & $.113(.12)$ & $.025(.19)$ \\
\hline Risk of AIDS & $.079(.08)$ & $.217(.12)$ & $-.197(.18)$ \\
\hline Now Worst Time for Pregnancy & $.563(.09)$ & $.306(.15)$ & $.286(.19)$ \\
\hline AIDS Causes Suffering & $-.104(.10)$ & $-.163(.17)$ & $.094(.23)$ \\
\hline Benefits of Avoiding Pregnancy Scale & $.017(.01)$ & $.018(.01)$ & $-.001(.01)$ \\
\hline Birth Control Is Not Too Difficult to Use & $.822(.07)$ & $.676(.11)$ & $-.085(.16)$ \\
\hline Able to Refuse Sex if No Birth Control & $.550(.07)$ & $.553(.11)$ & $-.053(.17)$ \\
\hline \multicolumn{4}{|l|}{ Gender } \\
\hline Male & \multicolumn{3}{|c|}{ ref. } \\
\hline Female & & \multicolumn{2}{|c|}{$-.582(.39)$} \\
\hline \multicolumn{4}{|l|}{ Mother's Education } \\
\hline High School or Less & \multicolumn{3}{|c|}{ ref. } \\
\hline More than High School & \multicolumn{3}{|c|}{$.129(.07)$} \\
\hline \multicolumn{4}{|l|}{ Race/Ethnicity } \\
\hline European American & \multicolumn{3}{|c|}{ ref. } \\
\hline African American & \multicolumn{3}{|c|}{$.061(.09)$} \\
\hline Asian & \multicolumn{3}{|c|}{$-.477(.16)$} \\
\hline Hispanic & \multicolumn{3}{|c|}{$-.238(.13)$} \\
\hline Other Race/Ethnicity & \multicolumn{3}{|c|}{$-.015(.19)$} \\
\hline \multicolumn{4}{|l|}{ Age } \\
\hline 15 years & \multicolumn{3}{|c|}{ ref. } \\
\hline 16 years & \multicolumn{3}{|c|}{$.009(.12)$} \\
\hline 17 years & \multicolumn{3}{|c|}{$.125(.11)$} \\
\hline 18 years & \multicolumn{3}{|c|}{$.082(.12)$} \\
\hline $19+$ years & \multicolumn{3}{|c|}{$-.019(.22)$} \\
\hline Used Birth Control at First Intercourse & \multicolumn{3}{|c|}{$1.423(.07)$} \\
\hline Observations & \multicolumn{3}{|c|}{4031} \\
\hline
\end{tabular}


Table A3.14 Logistic Regression Analysis Predicting Use of Birth Control at Most Recent Intercourse: Cues to Action (with Standard Errors')

\begin{tabular}{|c|c|c|c|c|c|c|c|c|}
\hline & \multicolumn{2}{|c|}{ Model 3} & \multicolumn{2}{|c|}{ Model 4} & \multicolumn{2}{|c|}{ Model 5} & \multicolumn{2}{|c|}{ Model 6} \\
\hline & Male & Female & Male & Female & Male & Female & Male & Female \\
\hline \multicolumn{9}{|l|}{ Health Beliefs } \\
\hline Risk of Pregnancy & $.148(.13)$ & $.011(.19)$ & $.134(.13)$ & $.019(.19)$ & $.133(.13)$ & $.025(.19)$ & $.129(.13)$ & $.049(.19)$ \\
\hline Risk of AIDS & $.215(.12)$ & $-.200(.18)$ & $.210(.12)$ & $-.186(.18)$ & $.219(.12)$ & $-.199(.18)$ & $.211(.12)$ & $-.185(.18)$ \\
\hline Now Worst Time for Pregnancy & $.315(.15)$ & $.274(.19)$ & $.310(.15)$ & $.272(.19)$ & $.303(.15)$ & $.288(.19)$ & $.303(.15)$ & $.297(.19)$ \\
\hline AIDS Causes Suffering & $-.155(.17)$ & $.093(.23)$ & $-.148(.17)$ & $.085(.23)$ & $-.161(.17)$ & $.092(.23)$ & $-.169(.17)$ & $.093(.23)$ \\
\hline Benefits of Avoiding Pregnancy Scale & $.025(.01)$ & $-.003(.01)$ & $.018(.01)$ & $-.001(.01)$ & $.017(.01)$ & $-.001(.01)$ & $.019(.01)$ & $.001(.01)$ \\
\hline Birth Control Is Not Too Difficult to Use & $.679(.11)$ & $-.092(.16)$ & $.676(.11)$ & $-.085(.16)$ & $.675(.11)$ & $-.084(.16)$ & $.679(.11)$ & $-.098(.16)$ \\
\hline Able to Refuse Sex if No Birth Control & $.573(.11)$ & $-.095(.17)$ & $.555(.11)$ & $-.057(.17)$ & $.554(.11)$ & $-.054(.17)$ & $.560(.11)$ & $-.065(.17)$ \\
\hline \multirow{2}{*}{\multicolumn{9}{|c|}{ Cues to Action }} \\
\hline & & & & & & & & \\
\hline $\begin{array}{l}\text { Good Communication with Parent } \\
\text { Parent Disapproves of Sex }\end{array}$ & $.039(.15)$ & $.152(.19)$ & & & & & & \\
\hline Parent Disapproves of Sex & $-.305(.11)$ & $.156(.17)$ & & & & & & \\
\hline Learned about Pregnancy in School & & & $.306(.20)$ & $-.120(.28)$ & & & & \\
\hline Learned about AIDS in School & & & $-.479(.27)$ & $.575(.34)$ & & & & \\
\hline Hours of TV per Week & & & & & $-.001(.01)$ & $.001(.01)$ & & \\
\hline Talked to Female Friend about Problems & & & & & & & $-.044(.12)$ & $-.163(.18)$ \\
\hline Talked to Male Friend about Problems & & & & & & & $-.097(.11)$ & $.234(.17)$ \\
\hline Attended Youth Group & & & & & & & $-.122(.12)$ & $-.045(.16)$ \\
\hline Observations & 4031 & & 4031 & & 4031 & & 4031 & \\
\hline
\end{tabular}


Table A3.15 Logistic Regression Analysis Predicting Use of Birth Control at Most Recent Intercourse: Cues to Action and Gender Ideals (with Standard Errors)

\begin{tabular}{|c|c|c|c|c|}
\hline & \multicolumn{2}{|c|}{ Model 7} & \multicolumn{2}{|c|}{ Model 8} \\
\hline & Male & Female & Male & Female \\
\hline \multicolumn{5}{|l|}{ Health Beliefs } \\
\hline Risk of Pregnancy & $.145(.12)$ & $.028(.19)$ & $.146(.13)$ & $.028(.19)$ \\
\hline Risk of AIDS & $.201(.12)$ & $-.179(.19)$ & $.205(.13)$ & $-.177(.19)$ \\
\hline Now Worst Time for Pregnancy & $.314(.15)$ & $.272(.19)$ & $.315(.15)$ & $.272(.19)$ \\
\hline AIDS Causes Suffering & $-.142(.17)$ & $.078(.23)$ & $-.142(.17)$ & $.083(.23)$ \\
\hline Benefits of Avoiding Pregnancy Scale & $.026(.01)$ & $-.004(.01)$ & $.025(.01)$ & $-.004(.02)$ \\
\hline Birth Control Is Not Too Difficult to Use & $.682(.11)$ & $-.105(.16)$ & $.691(.12)$ & $-.108(.16)$ \\
\hline Able to Refuse Sex if No Birth Control & $.583(.11)$ & $-.108(.17)$ & $.585(.11)$ & $-.107(.17)$ \\
\hline \multicolumn{5}{|l|}{ Cues to Action } \\
\hline Good Communication with Parent & $.015(.15)$ & $.177(.19)$ & $.017(.15)$ & $.176(.19)$ \\
\hline Parent Disapproves of Sex & $-.306(.12)$ & $.176(.17)$ & $-.300(.12)$ & $.171(.17)$ \\
\hline Leamed about Pregnancy in School & $.316(.20)$ & $-.132(.28)$ & $.319(.20)$ & $-.141(.28)$ \\
\hline Learned about AIDS in School & $-.497(.28)$ & $.590(.34)$ & $-.498(.28)$ & $.594(.34)$ \\
\hline Hours of TV per Week & $-.001(.01)$ & $.001(.01)$ & $-.001(.01)$ & $.001(.01)$ \\
\hline Talked to Female Friend about Problems & $-.045(.12)$ & $-.157(.18)$ & $-.045(.12)$ & $-.163(.18)$ \\
\hline Talked to Male Friend about Problems & $-.106(.11)$ & $.253(.17)$ & $-.106(.11)$ & $.255(.17)$ \\
\hline Attended Youth Group & $-.090(.12)$ & $-.078(.16)$ & $-.090(.12)$ & $-.078(.16)$ \\
\hline \multicolumn{5}{|l|}{ Gender Ideals } \\
\hline More Respected if Sexually Active (disagree) & & & $.017(.12)$ & $.016(.16)$ \\
\hline More Attractive is Sexually Active (disagree) & & & $-.084(.12)$ & $-.022(.16)$ \\
\hline Observations & 4031 & & 4031 & \\
\hline
\end{tabular}

